\title{
Taurine and preimplantation embryonic development in vitro
}

Citation for published version (APA):

Dumoulin, J. C. M. (1997). Taurine and preimplantation embryonic development in vitro. [Doctoral Thesis, Maastricht University]. Datawyse / Universitaire Pers Maastricht. https://doi.org/10.26481/dis.19971030jd

Document status and date:

Published: 01/01/1997

DOI:

10.26481/dis.19971030jd

Document Version:

Publisher's PDF, also known as Version of record

\section{Please check the document version of this publication:}

- A submitted manuscript is the version of the article upon submission and before peer-review. There can be important differences between the submitted version and the official published version of record.

People interested in the research are advised to contact the author for the final version of the publication, or visit the DOI to the publisher's website.

- The final author version and the galley proof are versions of the publication after peer review.

- The final published version features the final layout of the paper including the volume, issue and page numbers.

Link to publication

\footnotetext{
General rights rights.

- You may freely distribute the URL identifying the publication in the public portal. please follow below link for the End User Agreement:

www.umlib.nl/taverne-license

Take down policy

If you believe that this document breaches copyright please contact us at:

repository@maastrichtuniversity.nl

providing details and we will investigate your claim.
}

Copyright and moral rights for the publications made accessible in the public portal are retained by the authors and/or other copyright owners and it is a condition of accessing publications that users recognise and abide by the legal requirements associated with these

- Users may download and print one copy of any publication from the public portal for the purpose of private study or research.

- You may not further distribute the material or use it for any profit-making activity or commercial gain

If the publication is distributed under the terms of Article $25 \mathrm{fa}$ of the Dutch Copyright Act, indicated by the "Taverne" license above, 
Taurine and preimplantation embryonic development in vitro 
(c) Dumoulin, Johannes Christianus Marie

ISBN 90-9010896-3

Produktie en druk: Datawyse / Universitaire Pers Maastricht. 


\section{Taurine and preimplantation embryonic development in vitro}

\section{PROEFSCHRIFT}

ter verkrijging van de graad van doctor aan

de Universiteit Maastricht,

op gezag van de Rector Magnificus, Prof. mr. M.J. Cohen, volgens het besluit van het College van Decanen,

in het openbaar te verdedigen

op donderdag 30 oktober 1997 om 16.00 uur

door

Johannes Christianus Marie Dumoulin 


\section{Promotores:}

Prof. Dr. J.L.H. Evers

Prof. Dr. J.P.M. Geraedts

\section{Beoordelingscommissie:}

Prof. Dr. P. B. Soeters (voorzitter)

Prof. Dr. A.C. Van Steirteghem (Vrije Universiteit Brussel, België)

Dr. H.W.M. van Straaten

Prof. Dr. H.A.J. Struijker Boudier

Prof. Dr. G. H. Zeilmaker (Erasmus Universiteit Rotterdam) 




\section{Contents}

Page

Chapter 1 General introduction

1.1. Embryonic development in vivo and in vitro

1.2. Preimplantation embryonic development

1.3. In vivo and in vitro environments of embryos

1.4. Recent improvements in culture systems

1.5. Taurine

1.6. Aims of the study

Chapter 2 Positive effect of taurine on preimplantation development of mouse embryos in vitro

Chapter 3 Temporal effects of taurine on mouse preimplantation devellopment in vitro

Chapter 4 Modulation of embryonic $\mathrm{Na}^{+}-\mathrm{K}^{+}-\mathrm{ATP}$ ase activity and mouse preimplantation development in vitro in media containing high concentrations of potassium

Chapter 5 Temporal effects of ouabain on in-vitro development of mouse zygotes

Chapter 6 Taurine acts as an osmolyte in human and mouse oocytes and embryos

Chapter 7 General discussion

7.1. Effect of taurine on embryonic development in vitro

7.2. Effect of taurine on cells and tissues in general

7.3. Possible functions of taurine in cells

7.4. Possible functions of taurine in embryos

7.5. Future aspects 
References

Summary

123

Samenvatting

125

Curriculum vitae

List of publications

Bedankt!!

141 
Chapter 1

General introduction 


\subsection{Embryonic development in vivo and in vitro}

\section{Differences in assisted and natural conception in the human}

Oocytes of many mammalian species can be successfully fertilized in vitro and the resulting embryos can be cultured in vitro through part, or all, of their preimplantation developmental period. In the human, techniques of fertilization and embryo culture in vitro are used as part of assisted conception treatments. Since the birth of the first "test tube baby" Louise Brown in 1978 [357], In Vitro Fertilization (IVF) and transfer of the resulting embryos (ET) has become an established method in the treatment of infertile couples. Today, IVF is performed routinely in hundreds of centres around the world. More than 140,000 treatment cycles were performed worldwide in 1993 according to a World Collaborative Report on Assisted Reproduction Techniques published in 1995 [259]. Succes rates of IVF as an infertility treatment in terms of clinically recognized pregnancies and live birth deliveries. per oocyte retrieval have slowly risen from $16.4 \%$ and $12.0 \%$ in 1989 to $19.9 \%$ and $14.8 \%$ in 1993 according to the World Reports $[259,423]$. National registries in France (FIVNAT) $[111,258]$, USA [238, 239, 373], UK [288, 369], and individual IVF-centres reporting on large series [ 8,367$]$, show comparable success rates during the years. The most recent reports from the USA and Canada national registry show a further increase of the success rate (deliveries per oocyte retrieval) to $20.7 \%[349,350]$.

Possible causes of this relatively low "take a baby home"- rate of IVF are: 1) the human is a relatively 'subfertile' species, and 2) the techniques used in this treatment, be it ovarian stimulation, fertilization and embryo culture in vitro are suboptimal.

\section{The human species is a relatively 'subfertille' species}

Indeed, natural human fecundity is low in comparison with many animal species. The chances of spontaneous pregnancy (detected by sensitive hCG testing) in presumably fertile couples are found to be at most $25-30 \%$ in the first few cycles $[92,414,432]$. A number of factors may contribute to this low pregnancy rate, including anovulation, infrequent sexual intercourse, reduced semen quality, failure of oocyte or sperm transport, fertilization failure, and lack of uterine receptivity [422]. The main reason however for this low chance of achieving a spontaneous pregnancy is probably the high degree of early preimplantation embryonic wastage. It has been estimated that, in vivo, about $25 \%$ of all fertilized oocytes are lost prior to implantation, a further $30 \%$ in the peri-implantation period, about $15 \%$ are spontaneously aborted between the 6th and 28 th weeks of pregnancy, and $1 \%$ are stillborn in the later stages of pregnancy [168]. From in vitro studies it is known that only about $20-50 \%$ of fertilized human oocytes reach the blastocyst stage [110,144,219,382], although it must be taken into consideration that most studies on human blastocyst formation use the embryos remaining after two or three of the best had been transferred. In vivo, it has been reported that only about $20-25 \%$ of human embryos obtained after uterine lavage from women of proven fertility were blastocysts, while the majority of recovered embryos were either uncleaved or retarded in development, indicating that also development in vivo to the blastocyst stage is low [57, 333]. 
Besides the relatively low chance of a fertilized oocyte to survive through the preimplantation period, in vivo as well as in vitro, high rates of pregnancy loss after implantation (including occult as well as clinically recognized spontaneous abortions) of approximately $30 \%$ have been reported (ranging from $15 \%$ to $62 \%$ ) [91, 150, 250, 412, 414, 432].

The largest part of this embryonic and fetal wastage is thought to be dule to chromosomal abinormalities in the embryo, which can originate either from abnormal gametes, failures occurring during fertilization, or arise during the early cleavage stages of development. In a review article, summarizing data from 11 studies from a total of 1120 oocytes remaining unfertilized after IVF, the overall proportion of chromosomal abnomality (including aneuploid, polypiaid, and structural alterations) was estimated to be $35 \%$, while a conservative estimation of aneuploidy ( 2 times the hyperhaploidy rate) was $13 \%$ [429]. A second study summarizing data from 9 studies on a total of 772 oocytes estimated the aneuploidy rate to be $19 \%$, whille structural abnormalities were found in $1.2 \%$ of oocytes [230]. Comparable data were obtained in our own laboratory $[295,296]$. In human spermatozoa, the incidence of disomy for individual chromosomes in studies utilizing the fluorescence in situ hybridization (FISH) technique were found to vary between $0.03 \%$ and $0.67 \%[41,71,231,418]$, while the incidence of sperm karyotypes showing any form of aneuploidy (visualized after cross-species fertilization with hamster or mouse oocytes) was found to be 1.3-4\% [168, 197, 230]. Structural aberrations of different types were found in about $5-11 \%$ of human sperm [168, 197, 230 ]. Errors of fertilization are also a common cause of a genetically defect zygote. After IVF about $6 \%$ of zygotes have more than two pronuclei, which in most cases is caused by fertilization of more than one sperm [297], whille in about $2 \%$ of zygotes, only one pronucleus is detected (parthenogenesis) [297]. Also in vivo, polyploidy is a common cause of a genetically defect fetus, as in about $8 \%$ of spontaneous abortions triploidy has been found [168]. In embryos developed from zygotes showing two pronuclei, high rates of chromosomal aberrations were found ranging in several studies from $23 \%$ to $40 \%$ [429], with aneuploidy rates ranging from $19 \%$ [169] to $28 \%$ [430], mosaicism ranging from $2 \%$ [169] to $36 \%$ [430], and normal karyotypes ranging from only $13 \%$ [430] to $77 \%$ [169]. Cytogenetic studies on this subject have to be viewed with caution for several reasons: (i) the number of analysed embryos is usually small due to the unavailability of human embryos; (ii) the source of embryos differs in different studies, some embryos originating from donated oocytes which were fertilized specifically for research, while most embryos are spare embryos which are not used for embryo transfer or cryopreservation; and (iii) in most cases, only a few cells of an embryo give analysable metafase chromosomes, resulting in a probable underestimation of mosaicism. Using the FISH technique, with wich virtually all cells from an embryo can be analysed, extremely high levels of mosaicism of individual chromosomes have been reported, ranging from $20 \%$ to $70 \%[76,147,263]$. That many concepti are genetically abnormal has also clearly been shown by the identification of many chromosomally imbalanced fetuses, which are found in more than $50 \%$ of spontaneous abortions $[48,149$. $150,168,223$ ]. This would mean that at least $8 \%$ of all conceptuses which survive long enough to give rise to a clinically recognized pregnancy have an abnormality of chiromosome number or structure [168].

Thus, we can conclude that the human may indeed be considered a relatively subfertile species, that a large part of this subfertility can be attributed to chromosomal abnormalities, and that this fact may, at least partly, explain the low success rates of IVF. 


\section{The IVF-ET techniques are suboptimal}

Although the introduction of IVF has led to an enormous increase of research in the field of early embryology. MF-ET techniques are still far from optimal. The overall pregnancy rate after IVF and ET approximately equals that of the spontaneous pregnancy rate, however, it must be taken into account that in most cases of IVF, more than one embryo is replaced. The implantation rate per transferred embryo in most large series of IVF cycles is only about $11 \%-17 \%[12,93,94,160,298,355]$; although some clinics report up to $22 \%$ [144].

Many factors, besides the intrinsic abnormalities of human embryos already discussed, influence the implantation rate after IVF-ET: (i) the high average female age $[160,326$, 369]; (ii) the ovarian stimulation regimen [129]; (iii) etiology of infertility $[225,326]^{*}$ (iv) technical difficulties of the embryo transfer (either patient-related [97, 420], transfer catheter dependent [131], or simply because embryos are being expelled into the vagina after transfer, which is reported to occur in as many as $15 \%$ of transfers $[185,299,339]$; $(v)$ the number and morphological aspect of transferred embryos [68, 72, 176, 308, 326, 355]; (vi) the uterine receptivity [289,325]; and (vii) impaired developmental capacity of embryos due to sub-optimal culture conditions.

Sub-optimal culture conditions resulting in impaired embryo development are considered to be among the most important factors for the low implantation rate after IVF [122]. However, little scientific evidence can be found to substantiate the latter. As described above, data of pregnancy or implantation rates after IVF give only very indirect information on embryo developmental potentiall. There are very few "hard" data on the requirements of human embryos for normal growth in vitro. The reasons for this paucity of data are obvious: it would be unethical, as well as practicably impossible to commit human embryos to large-scale culture experiments, or to compare directly embryo development in vitro with that in wivo.

\section{Differences between preimplantation embryonic development in vivo and in vitro in mammalian species other than the human}

More information about the effect of in vitro culture on embryonic development is provided by research on animals. When comparing embryos cultured during the complete, or during part of the preimplantation period in vitro with embryos that developed in vivo, it has been demonstrated in many species that in vitro culture will result in impaired embryo development. Embryos cultured in vitro, as compared to those developing in vivo, are characterized by:

a) a slower development, as reflected by:

- prolonged G2 phases in the early cleavage stages (4-cell stage in the pig [302], 2-cell stage in the mouse [348]);

- lower uptake and incorporation rates of thymidine and uridine indicating reduced DNA and RNA synthesis (in the mouse [145, 331], rabbit [68]);

- reduced incorporation of methionine into protein, indicating reduced protein synthesis. (in the pig [421], rabbit [177]);

- reduced cell numbers at the blastocyst stage (in the mouse [49, 146, 182, 282, 416] rat [387], goat [330]); affecting the numbers of both inner cell mass cells and trophoblast cells (in the mouse $[99,182]$ ); 
b) biochemical differences, e.g.:

- an increased production of hydrogen peroxide (in mouse 2-cell embryos [265]);

- different amino acid contents (in the mouse [399]):

- a high rate of lactate production (in mouse blastocysts [121]);

- a significantly higher glycogen content (in mouse blastocysts [90, 280]):

c) developmental blocks at certain stages during the preimplantation development, see page 16.

\section{Effect of in vitro culture during the preimplantation period on postimplantation development}

Besides these differences between in vitro and in vivo developed embryos already noticeable during the preimplantation period, evidence exists that in vitro culture of preimplantation embryos can affect postimplantation development. Compared to embryos developed in vivo, embryos cultured in vitro have a reduced potential to implant and develop into a foetus once transferred to the uterus of foster mothers (in the mouse $[50,126,143,190,192$, 240], sheep [405], cow [100], pig [32]). Furthermore, evidence exists that exposure of preimplantation mouse embryos to certain chemicals results in a higher incidence of malformations of fetuses, a decrease in the live birth rate, and a higher mortality rate of the offspring $[163,186]$. Although of course in the culture medium used for human IVF, no obvious toxic substances are used, it is important to realise that, contrary to a general belief that prior to implantation the embryo is either untharmed, or dies before implantation after exposure to an embryotoxic agent, damage can be inflicted to embryos during the first few days of preimplantation development of which the consequences manifest only after implantation [186]. Lower implantation rates and fetal weights in the mouse [123, $126,143,192]$, and rat [431]; and higher rates of fetal malformation in the mouse [191] have been observed when suboptimal media and culture conditions are used. In sheep, in vitro culture of embryos has been shown to lead to an increased gestation period, abnormal high birth weight and an increased stillbirth rate $[156,377,405]$. The birth weight of the lambs was shown to be affected by the culture medium in which the embryos were cultured for five days [377]. The same, as yet unexplained, phenomenon was reported in the cow: fetuses at seven month of gestation resulting from in vitro fertilization and seven days of in vitro culture were heavier than fetuses from embryos produced in vivo and had skeletal abnormalities [105].

In the human, pregnancies resulting from IVF have been shown to result in premature delivery and lower birthweight as compared to pregnancies in the general population, even when only singleton pregnancies are taken into consideration $[35,112,290,328,366$. 367 ]. Also the rate of perinatal, neonatal, and infant mortality have been reported to be slightly higher than the national average $[112,328]$. The congenital malformation rate at birth of 6,879 children resulting from IVF $(2.8 \%)$ was shown to be comparable with the general population $(2.1 \%)$ [112]. When considering the outcome of pregnancies resulting from assisted conception, it must be born in mind that, beside the fact that about $25 \%$ of these pregnancies are multiple (compared to only about $1 \%$ with natural conception), the average age of these women is about 5 years older than that of other women, and that many have a history of previous adverse pregnancy outcomes or tubal damage [35]. These factors increase the risk of obstetric complications and of adverse outcomes of subsequent pregnancies [35]. 


\subsection{Preimplantation embryonic development}

\section{Morphological aspects of preimplantation embryonic development}

In this paragraph, a brief outline will be given of mouse embryonic preimplantation development as an illustration of the embryonic development during the preimplantation period in mammals.

Cleavage during the first three days after fertilization, i.e. from the zygote stage to the late 8-cell/early 16-cell (morula) stage, occurs in the oviduct [305]. The first cleavage division will take place at approximately $18-23 \mathrm{~h}$ after fertilization [159, 305]. The second cell cycle, like the first, is relatively long $( \pm 20 \mathrm{~h})$ whereas the subsequent cycles are shorter $( \pm 12$ h) [305, 348]. The $\mathrm{G} 1$ phase during the 2 -cell stage takes place from $0-1 \mathrm{~h}$ post-cleavage (hpc), the S-phase from 1-6 hpc, and the G2-phase from 6-18 hpc [305].

On the third day after fertilization, the embryo reaches the morula stage. The term 'morula' is a purely morphological description that refers to a compact aggregate of blastomeres, and which can include all stages of development from compacted 8-cells to the 32-stage, prior to blastocoel formation [305]. At the late morula stage (16-to 32-cell embryos) the embryos pass through the uterotubal junction from the aviduct into the uterus [305]. The blastomeres of late 8-cell embryos flatten upon one another (compact), decompact during mitosis to the 16-cell stage and then subsequently recompact again [305]. During the process of compaction, membranes of the outermost cells become closely connected and develop intercellular tight junctions and gap junctions [113]. This sealing off of the external environment has two effects that are important for further development [417]. First, some blastomeres are completely enclosed so that there are "outer" and "inner" blastomeres. Second, outer blastomeres will have two types of cell surfaces: free (facing the ZP) and apposed (flattened against adjacent blastomeres) making them polar. On the other hand, inner blastomeres will have only one type of cell surface making them "apolar". The polarity of the outer cells involves many characteristics, e.g. apical surfaces (facing the ZP) become covered with microvilli, membrane ion pumps segregate into apical and basolateral (facing the blastocoel) domains, nuclei migrate basally, mitochondria and lipid droplets become localized to apposed cell borders (see [39] and [415] for references)

Soon after the permeability seal is created by tight junctions between the outer cells, fluid begins to accumulate in the intercellular spaces and results in the formation of the blastocoelic cavity [39]. For the first time in the developing embryo, which is now called a blastocyst, two distinct types of cells may be discerned. On the surface of the embryo, polar blastomeres become epithelial cells and form the trophectoderm, which will give rise to extraembryonic tissues. A small group of inner apolar cells ( $\pm 30 \%$ of total) become inner cell mass (ICM), which will eventually give rise to the embryo proper [182, 248]. The expansion of the blastocoelic cavity involves an active transport of $\mathrm{Na}^{+}, \mathrm{Cl}^{-}$, and $\mathrm{HCO}_{3}^{-}$from the medium into the blastocoel, creating an osmotic gradient that drives water across the trophectoderm $[39,228]$. In the mouse, extracellular $\mathrm{Na}^{+}$is taken up by the trophectoderm cells by a $\mathrm{Na}^{+} / \mathrm{H}^{+}$exchanger and a Na -channel [228], and extruded into the blastocoel by the $\mathrm{Na}^{+} / \mathrm{K}^{+}$-ATPase $[39,407,415] . \mathrm{Cl}^{-}$entry seems not to be carrier-mediated, but probably enters the blastocoel through a paracellular route, between the trophectoderm cells [228]. 


\section{Aspects of gene regulation during early embryonic development}

At the time the oocyte resumes meiosis I (at germinal vesicle breakdown), just before ovulation, RNA synthesis declines to almost non-detectable levels, and early cleavage stages in a variety of mammalian species are characterized by the absence of RNA synthesis $[302,305,368]$. This transcriptional shut-down is not complete, as small amounts of RNA synthesis have been demonstrated in zygotes (mouse [69,314], human [372]), and in the bovine 2-and 4-cell stages [402]. Oocytes have sufficient amounts of rRNA, IRNA, mRNA and ribosomes to be able to synthesize proteins from the time of fertilization to the stage. at which time the embryonic genome will be activated (see Table 1) [89, 305, 368]. Thus. the early events that take place before the activation of the embryonic genome are largely, if not exclusively, under maternal control [159,368]. The changes found in polypeptide synthesis during this early period are mainly due to either a sequential activation and translation of maternally-derived mRNA, or to post-translational modifications of existing proteins $[159,368]$.

Synthesis of significant amounts of RNA from the embryonic genome starts at a speciesspecific cell stage (for review, see [368], and Table 1). In the mouse, the first transcription of significant amounts of embryonic RNA occurs in the G1 phase at the very early 2-cell stage [306]. At this time heat shock proteins [34], as well as a developmentally regulated transcription-requiring complex [302], are transcribed and subsequently translated. The second and major transcription of embryonic genes takes place at the mid 2-cell stage causing a major qualitative change in polypeptide profile [306], including the first paternally derived products [334]. In the human, activation of the embryonic genome occurs at the 4- to 8-cell stage and development based on utilization of maternally inherited information alone is not possible beyond this point $[52,368]$. Synthesis of mRNA and rRNA is first detectable at the 4-cell and 6-to 8-cell stage, respectively $[368,371]$; and there seems to be a remarkable heterogeneity among blastomeres suggesting that gene activation may not take place at the same time in all of the blastomeres within an embryo [371]. Paternally derived gene products have already been described in human 8-cell embryos [95].

Concomitant with the switch-on of the embryonic genes, a switch-off or destruction of much, if not all, maternally inherited mRNA takes place in the mouse $[44,368]$. Also in other species like the pig, cow, and sheep, there are indications that the degradation of maternally derived mRNA occurs during the stage at which the embryo starts its own RNA production [302]. After the switch-on of embryonic genes, polypeptides coded for by maternal mRNA are no longer synthesized, due to this very loss of maternal mRNA. However, the majority of the polypeptides synthesized from maternal mRNA before the embryonic gene switch-on, persist undegraded at least to the morula stage [306]. 


\section{Developmental blocks in embryos cullured in vitro}

When cultured in vitro in most conventional media, early stage embryos from most animal species studied cleave to a species-specific developmental stage but in general do not develop further beyond this point (see Table 1). In the mouse, it has been shown that this so-called '2-cell block' is a strain-specific phenomenon, as only embryos obtained from outbred or random bred strains exhibit the block, while embryos of certain inbred strains, and their $F_{1}$ hybrids, develop unimpeded from the 1-cell to the blastocyst stage under the same culture conditions [38, 413]. Cytoplasmic factors have been shown to be involved, as either injection of cytoplasm obtained from blastomeres of 2-cell embryos of non-blocking strains into blastomeres from 2-cell "blacking' embryas [262,307], or fusion of blastomeres from 2-cell embryos of non-blocking and blocking strains [137], permit the embryos to develop to the blastocyst stage.

In all species examined so far, the developmental stage at which embryos tend to arrest, corresponds to the time of the switch from gene control by maternally inherited components stored within the oocyte, to embryonic gene control (see Table 1) [368]. Furthermore, it has been demonstrated in the mouse, human, and sheep, that the appearance of embryonic translation products in the cytoplasm is necessary for normal development beyond the developmental blocks in the different species [368]. Therefore, it has been postulated that either the process of arrest may delay or disturb the onset of gene activation [300], or, conversely, a failure of the onset of transcription of embryonic proteins may be the cause of these developmental blocks [52]. However this concept is probably too simplistic as cleavage arrest is not always accompanied by failure of activation of the genome, e.g. in cleavage-arrested mouse [130] and human embryos [14], evidence was found of embryonic gene expression. An aiternative explanation for the blocks to development could be found in the concept that conventional culture systems do not reflect the dynamic changes accurring in vivo. Embryo morphology, cell metabolism, and other cell functions change profoundly during the preimplantation period (e.g. amino acid transport mechanisms [391, 392], amino acid requirements [192], energetic requirements [56], and changing responsiveness to growth factors [29]). Concomitant with these changes in the embryo, the environment changes as the embryo moves along from the oviduct to the uterus. The fact that the occurrence of developmental blocks coincides with the transition from oviductal to uterine stages in several species (see Table 1), as well as the finding that changes in the energy substrate composition of the culture medium can overcome the block in the mouse [56], are in accordance with this hypothesis of changes both in the needs of the embryo, as well as in their in vivo environment [29].

Whatever the cause of these developmental blocks, they have to be regarded as artificially induced by sub-optimal culture conditions, as they do not occur in vivo. Indeed, many recent improvements to culture media have been found to overcome these blocks in many species (see later) 
Table 1. Stages of in witro blocks to embryo development in relation to preimplantation developmental events in different species.

\begin{tabular}{|c|c|c|c|c|}
\hline Species & $\begin{array}{l}\text { Stage(s) of } \\
\text { culture block }\end{array}$ & $\begin{array}{l}\text { Stage of initiation } \\
\text { of RNA synthesis } \\
\text { from embryonic } \\
\text { genome }\end{array}$ & $\begin{array}{l}\text { Stage of major } \\
\text { change in qualitative } \\
\text { pattern of } \\
\text { protein synthesis }\end{array}$ & $\begin{array}{l}\text { Stage of entry } \\
\text { into the uterus }\end{array}$ \\
\hline Mouse & 2-cell ( $\mathrm{G} 2$ phase) & 2-cell (G1 phase) & 2-cell (G2 phase) & morula \\
\hline Hamster & 2-cell, 4-cell and 8-cell & 2 -cell & & 4- to 8-cell \\
\hline Rat & 2-cell and 4-cell & & & morula \\
\hline Pig & 4-cell (G2 phase) & 4-cell & 4 - to 8-cell & 4 -cell \\
\hline Human & 4- to 8-cell & 4- to 8-cell & 4- to 8-cell & 12-cell - morula \\
\hline Rabbit & 8-cell & 2 -cell & 2- to 16 -cell & morula \\
\hline Monkey & 8- to 16-cell & & & 16 cell \\
\hline Cow & 8- to 16 -cell & 8-cell & 8- to 16 -cell & 8- to $32-\operatorname{cell}$ \\
\hline Sheep & 8 - to $16-$ cell & 8-to 16-cell & 8- to 16-cell & 8- to 32-cell \\
\hline Cat & morula & & & late morula \\
\hline
\end{tabular}

References: General reviews [27, 29, 136, 148, 368], mouse [34, 44, 130], hamster [346], rat [184], pig [101, $171,302]$, human $[52,371]$, cat [175].

\section{Aspects of membrane transport during preimplantation embryo development}

The plasma membrane of each cell, because of its hydrophobic lipid bilayer, acts as a barrier to most polar compounts. This makes it a very important part of the cell, as it not only separates and protects the cytoplasm from its environment, but it gives the cell the possibility to control the rate of influx of the many substrates for cell metabolism, control intracellular $\mathrm{pH}$, cell volume, membrane potential, and to receive intercellular signals. A myriad of specialized transport systems and ion channels has been described in different cell types, each with different, although sometimes overlapping, substrate selectivities [342]. The mammalian embryo is characterized by dynamic changes in the expression of different transport systems during its preimplantation developmental stages. Exarmples of such developmentally regulated systems are the facilitated cliffusion carriers of glucose GLUT1 and GLUT2 [2], and amino acid transporters from which there are at least six systems for different types of amino acids described in mice and pig that change in activity as preimplantation development proceeds $[302,303,304,388,390,391,392,394,397]$. Two of these transport systems, relevant for this study on the role of taurine on embryonic development will be discussed in more detail.

The $\mathrm{Na}^{*} / \mathrm{K}^{\prime \prime}$-ATPase is a membrane-bound enzyme which pumps 3 sodium ions out of the cell and 2 potassium ions into the cell on each cycle, and thus generates and maintains the steep $\mathrm{Na}^{*}$ gradient which provides the driving force for the many different sodium cotransport systems [342]. This enzyme is found in every cell type studied. Until recently. only indirect evidence for the presence of $\mathrm{Na}^{+} / \mathrm{K}^{+}$-ATPase was available for mouse 2-cell embryos [301]. Messenger-RNA for the $\mathrm{Na}^{*} / \mathrm{K}^{*}$-ATPase $\alpha 1$ and $\beta 1$ subunits present in mouse oocytes is decreased to almost undetectable levels at the 2-cell stage, while a steep increase in both mRNA levels is found from the 4-cell stage to the blastocyst stage [119, 408 ]. In the blastocyst stage, high $\mathrm{Na}^{+} / \mathrm{K}^{*}$-ATPase levels are found, localized to a ring encircling the blastocoelic cavity [407]. This is in accordance with the hypothesis that the 
enzyme is involved in the fluid accumulation resulting in the formation of the blastocoelic cavity [39]. Similar findings of a rapidly increasing rate of $\mathrm{Na}^{*} / \mathrm{K}^{*}$-ATPase synthesis during the late stages of preimplantation development were reported for the rabbit [120, 279].

Uptake of taurine in vertebrate cells has been shown to occur mainly through a $\mathrm{Na}^{*}$ and $\mathrm{Cl}^{-}$-dependent amino acid transporter, which transports specifically $\beta$-but not $\alpha$-amino acids $[347,384,398]$. Taurine is taken up by cells against a concentration gradient by this transport system [398]. Also throughout the complete preimplantation period in the mouse, taurine is taken up via this $\beta$ system, although its activity is greatest at the blastocyst stage $[389,398,400]$. The DNA sequence of this taurine transporter has significant similarity with other $\mathrm{Na}^{*}$ - and $\mathrm{Cl}^{-}$-dependent transporters, such as the betaine transporter and several brain neurotransmitter transporters [384]. The mRNA of this taurine transporter has shown to be present in kidney, ileal mucosa, brain, liver, heart cells [384], and also in mouse embryos throughout preimplantation development $[398,400]$.

Release of taurine occurs via a separate transport system, which is independent of the membrane potential and the $\mathrm{Na}^{+}$and $\mathrm{Cl}^{-\prime}$ gradients across the cell membrane $[18,347]$. This taurine efflux mechanism is volume-activated, energy dependent, and is not related to the taurine concentration gradient across the plasma membrane [18]. Such a $\mathrm{Na}^{+}-$ independent taurine channel has been identified in skate hepatocytes [18], Ehrlich ascites cells [155], cultured mouse astrocytes [287], and also in mouse preimplantation embryos [398].

\subsection{In vivo and in vitro environments of embryos}

\section{In vivo milieu: fluids of the oviduct and uterus}

The fluid of the oviduct is the environment in which oocyte and sperm transport, sperm capacitation, fertilization and embryo transport and early development take place [201]. The mammalian oviduct is a muscular tube with a mucous lining connecting the ovarium area with the uterus. It can be divided into four regions: the preampulla close to the ovary, which includes the fimbriae and infundibulum, the ampulla, the isthmus, and the junctura which is connected to the uterus [198]. In each region the epithelium consists of two main types of cells: ciliated and non-ciliated, or secretory [198]. The ciliated cells are thought to play a role in gamete transport, the secretory cells in the formation of oviduct fluid. Oviduct fluid is a complex mixture of constituents derived from the plasma and selectively passed on by the oviduct epithelium, plus some specific proteins formed by the oviduct epithelium [201].

In Tables 2 and 4 an overview is given of the composition of reproductive tract fluids of several mammals and compared with serum values. Data on the composition of body fluids from different studies should be regarded with extreme caution. This composition varies considerably with age, sex, strain or breed, circadian rhythm, and dietary intake $[10,242,327,379]$. Many of these parameters are often not included in articles. Also improper handling of the sample is a major source of error. Fluids should be separated from cellular components as quick as possible and hemolysis must be avoided, as cells contain significant amounts of potassium and phosphate, which, when released into the fluid, alter its composition [242]. Furthermore, values of most components are dependent on the analytical method used [242]. The composition of reproductive tract fluid is further influenced by the stage 
of the menstrual or oestrus cycle, by the location in the reproductive tract [201], and by the technique of fluid collection itself (e.g. vascular perfusion [79], long term cannulation [232], sampling by catheter or micropipette [46, 323]). Some methods (like the collection by catheterization over extended periods [46], or by passing pieces of oviduct through a clothes wringer (1) [275]) may give poor indication of the tubal environment [46, 79]. To make it even more complex, the microenvironment of oocytes and embryos is further influenced by the presence of cumulus cells because of their production of pyruvate (in the mouse [121]), or lactate (in the human [127]). It is not the intention of this thesis to give a complete overview of the composition of sera and reproductive tract fluids from different animal species. However, it is important to have at least some indication of the composition of the natural environments of embryos. Therefore, data of different studies are included in Tables 2 and 4 without comment, and without taking note of their methodological differences

\section{Culture media}

Culture media used for embryos are mostly modifications of media designed for somatic cell culture and are based on the ionic composition of blood sera [26]. Formulas of several media widely used for the culture of mammalian preimplantation embryos can be found in Tables 3 and 5 . They can be divided into two categories: simple salt solutions supplemented with energy substrates, like pyruvate, glucose, and lactate; and so-called 'complex' tissue culture media. The latter have been designed originally to maintain somatic cell viability in vitro and contain many components such as amino acids, vitamins, nucleic acid precursors, growth factors, and trace elements. Several studies, however, indicate that complex media such as Ham's F10 contain components that are detrimental to embryo development. For instance, hypoxanthine at concentrations as low as $30 \mathrm{nM}[24,82,220,274]$ and nicotinamide [383] have been shown to be detrimental to human and mouse embryos, while transition metals like copper and iron have been implicated in the formation of free oxygen radical species in embryos $[132,173]$.

Culture media are usually supplemented with serum, serum albumin, or other maciomolecules, such as polyvinylalcohol (PVA) [29] or polyvinylpyrrolidone (PVP) [353]. Serum is added because it is supposed to provide beneficial factors to the medium, including energy substrates, amino acids, vitamins, hormones, and growth factors [29]. Macromolecules are added to reduce the stickiness of the embryos to culture vessels and pipettes. 


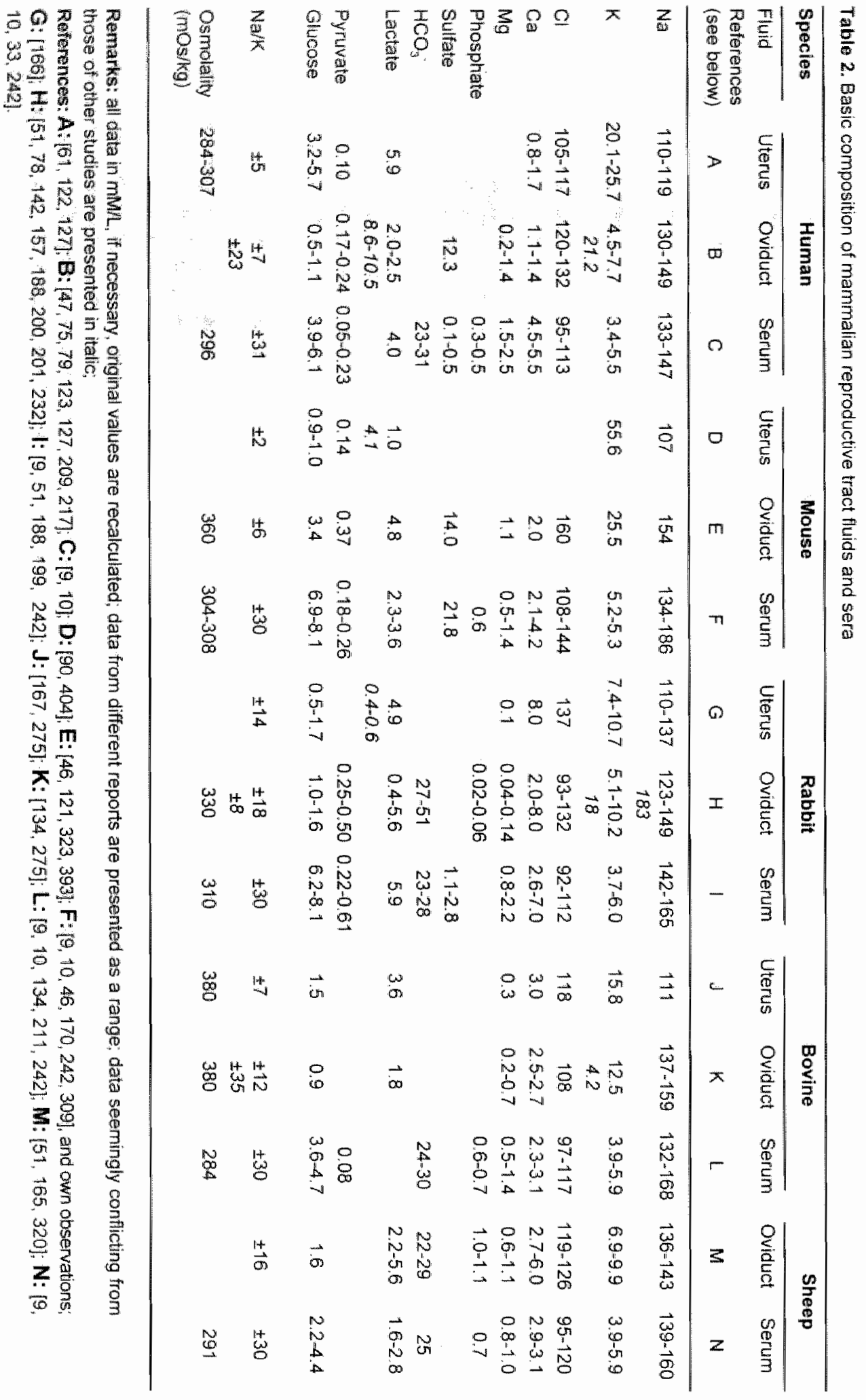




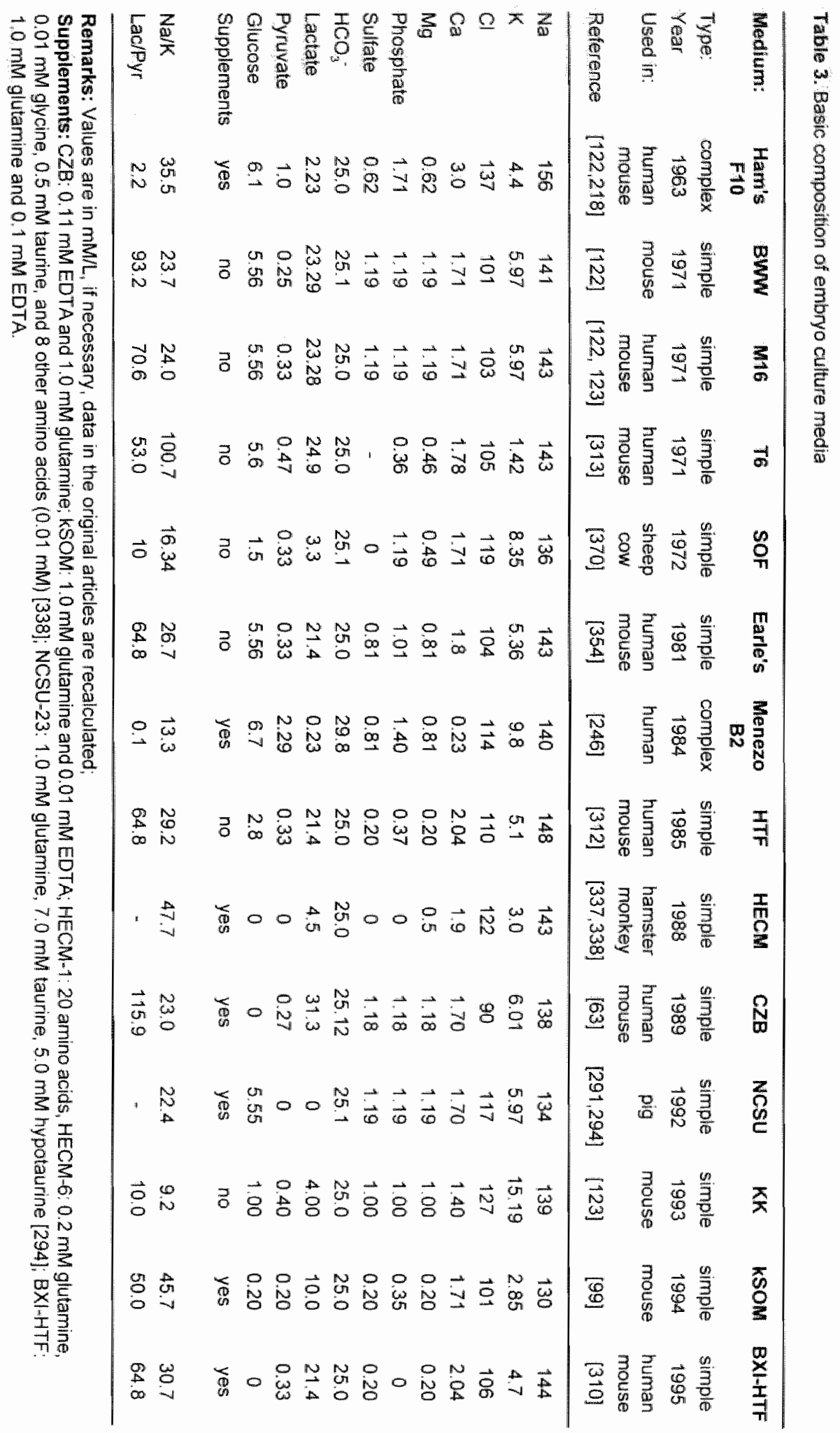




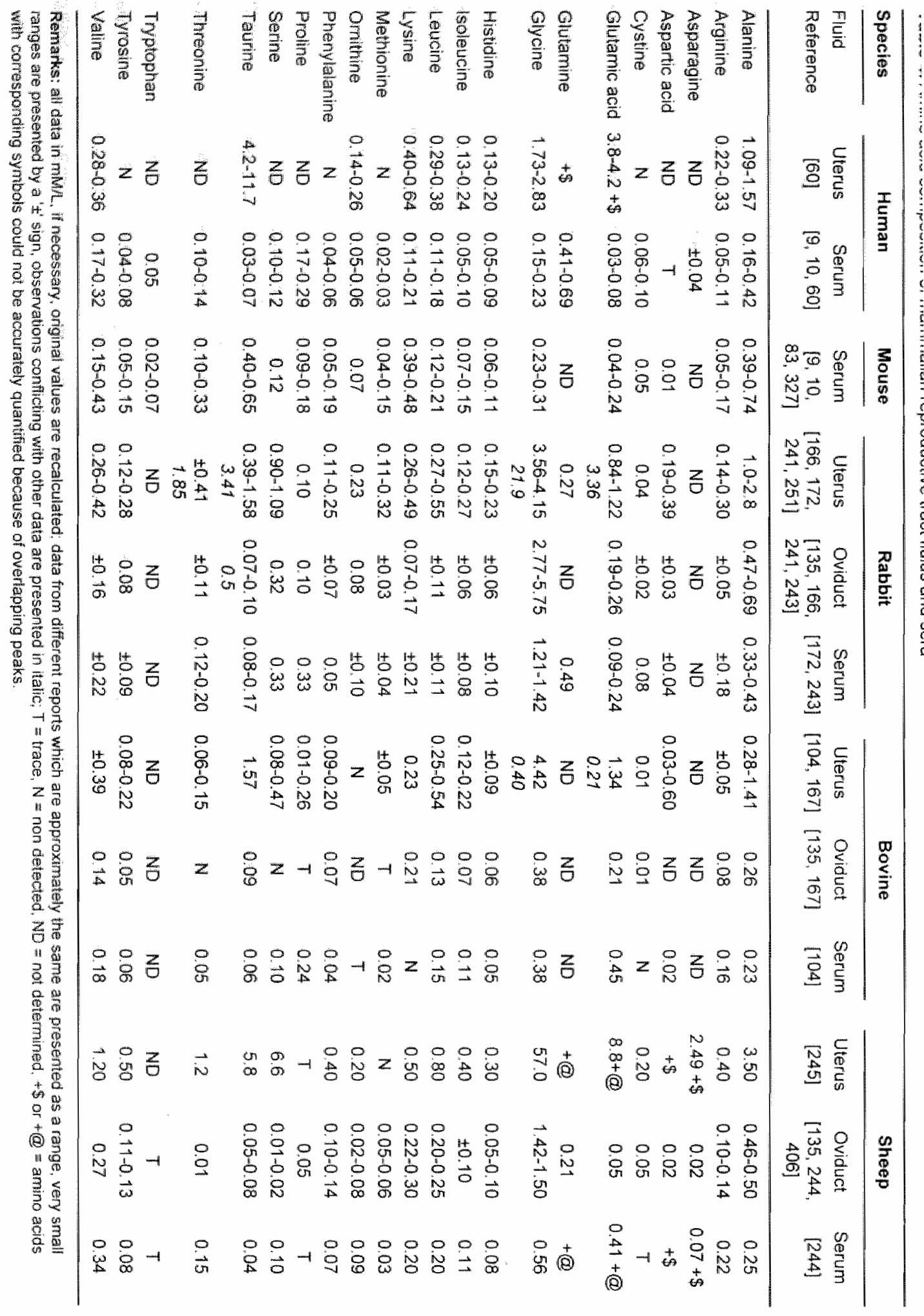


Table 5. Amino acid composition of embryo cuture media

\begin{tabular}{|c|c|c|c|}
\hline Medium & Ham's F10 & Memero B2 & HECM-6 \\
\hline Reference & {$[122]$} & {$[246]$} & {$[236,338]$} \\
\hline Year & 1963 & 1984 & \\
\hline Used in: & $\begin{array}{l}\text { human } \\
\text { mouse }\end{array}$ & human & $\begin{array}{l}\text { hantister } \\
\text { monkey }\end{array}$ \\
\hline Alarine & 0.10 & 0.76 & - \\
\hline Arginine & 1.21 & 0.29 & - \\
\hline Asparagine & 0.111 & 0 & 0.01 \\
\hline Aspartic acid & 0.10 & 0.17 & 0.01 \\
\hline Cysteine & 0.26 & 0.08 & 0,01 \\
\hline Cysteine S & & 0.07 & - \\
\hline Glutamic acid & 0.1 & 1.0 & 0.01 \\
\hline Gilutamine & 1.0 & 0.17 & 0.2 \\
\hline Gilycine & 0.1 & 5.33 & 0.01 \\
\hline Histidine & 0.14 & 0.16 & 0.01 \\
\hline isoleucine & 0.02 & 0.19 & - \\
\hline Leuicine & 0.10 & 0.23 & - \\
\hline Lysine & 0.20 & 0.24 & 0.01 \\
\hline Methiomine & 0.03 & 0.08 & - \\
\hline Phenylalanine & 0.03 & 0.15 & . \\
\hline Proline & 0.10 & 0.17 & 0.01 \\
\hline Serine & 0.10 & 0.14 & 0.01 \\
\hline Taurine: & 0 & 0.10 & 0.5 \\
\hline Threonine & 0.03 & 0.21 & - \\
\hline Tryptophan & 0.003 & 0.12 & - \\
\hline Tyrosine & 0.12 & $0: 14$ & - \\
\hline Valine & 0.03 & 0.64 & - \\
\hline
\end{tabular}

Remarks: all data in mM/L, if necessary, original values are recalculated. 
Differences between in vivo milieu and currently used in vitro culture conditions, and paradoxical observations between optimal in vittro development and composition of in vivo milleu

In most species, the rate of embryo development to the blastocyst stage within the oviduct in vivo surpasses that which can presently be obtained in vitro [27]. The contribution of the oviduct to embryonic development in vivo is not species specific. This has been demonstrated, for example, by transfer of bovine embryos to the sheep [100], or rabbit oviduct [43]. Even oviducts in organ culture have been shown to offer a more suitable environment for complete preimplantation development of embryos from several species than medium alone [316]. Also medium supplemented with uterine flushing has been shown to support rabbit embryonic development better than standard medium [107].

One would expect that culture systems will mimic as best as possible the physical or environmental conditions of the female reproductive tract, and that embryonic development in vitro would be optimal in media that would approach these conditions in vivo. At present, however, although much research is being devoted to the development of better and more physiological culture media, the best possible embryonic development in vitro of most studied species still takes place in media contrasting in composition with their natural environments. Paradoxically, some conditions that embryos encounter in vivo are even extremely toxic when used in vitro.

There are at least three major differences between most culture media and reproductive tract fluids.

1) The composition of oviductal and uterine fluid differs considerably from that of most culture media (see Tables 2 to 5), particularly with respect to the $\mathrm{Na}^{+} / \mathrm{K}^{+}$ratio, concentrations of $\mathrm{K}^{+}$, lactic acid glucose, and several amino acids, notably taurine, glutamine, and glycine. Effects of glucose and amino acids on embryonic development will be discussed later. One of the most striking differences between media and reproductive tract fluids is the difference in potassium content. In most culture media, the $\mathrm{K}^{+}$concentration is about equal to the serum value, whereas in reproductive tract fluids, the $K$ level has been reported to be several times as high (see Table 2). Surprisingly, in the mouse, these high $K^{*}$ concentrations in vivo are in contrast with the findings of most authors that high $K^{*}$ levels in the culture medium are detrimental to embryonic development in the mouse in vitro [87, $193,416]$. A minority of studies show a positive effect of potassium levels of $25 \mathrm{mM}$ [324], or little to no effect at all (in the range of $6-48 \mathrm{mM}$ [403], and 1.4-20 mM [331]). Also in sheep, $K^{*}$ concentrations of more than $13 \mathrm{mM}$ were found to be detrimental [405]. No effect of $\mathrm{K}^{*}$ concentrations upto $28 \mathrm{mM}$ were found when 2-cell hamster embryos were used $[30,234]$

2) The osmolality of reproductive tract fluids differs from that in culture media. Embryos of different species will develop to the blastocyst stage in a wide range of osmolalities:

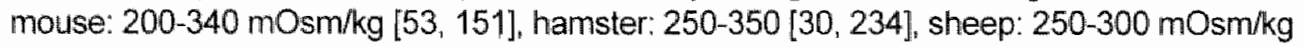
[405], cow: $250-300 \mathrm{mOsm} / \mathrm{kg}$ [216], rabbit: $230-339 \mathrm{mOsm} / \mathrm{kg}[208,264]$. Optimal in vitro development in several species has been shown to occur at reduced osmolality as compared to the serum value: typically in the range of $250-280 \mathrm{mOsm} / \mathrm{kg}$ (in the mouse $[151,194$, $393,413]$, hamster [234], pig [31], cow [216], rabbit [208]). In contrast, osmolality of reproductive tract fluids of several species has been shown to be higher than the value in serum 
(see Table 2), whereas such high osmolality is extremely toxic to embryos in witro [151, $208,216,393$ ]. Results of several studies indicate that increased osmolality per se, may not be detrimental to embryonic development, but that the higher $\mathrm{NaCl}$ concentration associated with increased osmolality is responsible for the impaired development (see bellow).

3) Specific so-called embryotrophic factors originating either from the embryos themselves, or from oviductal cells, have been described in reproductive tract fluids which are not present in culture media. Indications for embryo-derived factors can be found in studies demonstrating that either reduced incubation volumes or increased numbers of embryos incubated together have a positive effect on embryo development (in the mouse $[59,190,277,416]$, hamster $[283,336]$, human [7, 253], sheep [125]). In the oviduct, embryos develop in only a few microliters of fluid [201], while in vitro, embryos are cultured in relatively large volumes of medium, from $25 \mu l$ to upto $1 \mathrm{ml}$. Consequently, in vitro, any autocrine factor produced by the embryo will be diluted and possibly become ineffective. One of the likely candidates for such an autocrine factor is Platelet Activating Factor (PAF) wich is produced by embryos (in the mouse [277, 329], human [67]), and has been demonstrated to promote mouse embryo development $[270,277]$. Also epidermal growth factor (EGF) and transforming growth factor (TGF) are expressed in human embryos [65]. Furthermore, any paracrine factor produced by the female reproductive tract will also be absent in an in vitro system. Several growth factors like the insulin-like growth factors IGF-I and IGF-II have been found in pig oviductal fluid [294], while several growth factor receptors are expressed in preimplantation embryos in the human and other species [65, 341]. Indeed, some growth factors like colony stimulating growth factor (CSF-1) [37] have been shown to promote preimplantation development in vitro. Recently "an as yet unidentified high molecular weight factor has been detected which is produced by human oviductal cells and which promotes mouse embryonic development [212]. Also certain specific glycoproteins are synthesized by the oviductal secretory cells and secreted into the oviductal fluid. This has been observed in the human [224], rabbit [276], mouse [178, 179], hamster [322], sheep [118], pig [42], and baboon [106]. Some of these so-called oviductins are found sequestered within the perivitelline space (in the mouse [179]), whereas other oviductins bind to the zona pellucida (in the hamster [322]), and in the rabbit (where a thick mucin accumulates around the zona pellucida [276]) during their transit through the oviduct. The functions of these glycoproteins are not known, but they could well play a role in embryonic development [42]. A thorough discussion of this subject is however beyond the scope of this thesis.

\subsection{Recent improvements in culture systems}

In recent years, research into the relationship between embryos and the constituents of their culture environment has been intensified. Many studies have been performed to determine the basic requirements of embryos in culture, leading to a new generation of media and modifications of conventional media. In many animal species, developmental blocks were (at least partly) overcome by the use of these improved culture conditions. In this paragraph, a brief outline is given of the recent improvements of culture conditions. 


\section{Reducing oxygen radical stress}

Reactive oxygen species (ROS) have been implicated in the retardation of early embryo development in vitro in general, and in the process of developmental arrest of mouse embryos in particular [173] ROS have been shown to be elevated in in vitro cultured mouse embryos, at the time at which embryos become arrested, but not in in vivo developed embryos [265, 267]. ROS are highly reactive molecules capable of oxidizing the -SH groups in proteins, reacting with DNA and oxidizing polyunsaturated fatty acids in membranes [16, 140]. They can be grouped in free radical species, i.e. molecules characterized by the presence of one or more unpaired electrons (e.g. superoxide $\left(\mathrm{O}_{2}^{-} \cdot\right)$, hydroxyl radical $(\mathrm{OH} \cdot)$, peroxyl (ROO.); and non-radicals (e.g. hydrogen peroxide $\left(\mathrm{H}_{2} \mathrm{O}_{2}\right)$, ozone $\left(\mathrm{O}_{3}\right)$, singlet oxygen $\left({ }^{1} \mathrm{O}_{2}\right)$, hypochlorous acid (HOCl) (for reviews see $[16,138,140]$ ). Several ROS are generated in cells during normal metabolic processes: either accidentally, such as during the reduction of oxygen to water in the mitochondrial electron transport chain [16, 173], or deliberately, such as the production of several ROS species by activated phagocytes [16]. The toxicity of different ROS species varies. The most reactive and therefore extremely toxic ROS is the hydroxyl radical [16]. Other ROS, such as superoxide and hydrogen peroxide, are not very toxic themselves, but interact in the presence of traces of free transition metals, such as iron or copper, to produce hydroxyl radicals $[16,140,267]$. The micromolar traces of iron which are inadvertently added to culture media as impurities of most laboratory chemicals are sufficient to catalyse the formation of this extremely dangerous hydroxyl radical [173]. One of the biologically most important reactions involving ROS is the lipid peroxidation chain reaction which is the free radical oxidation of polyunsaturated fatty acids of the cell membrane [138].

Living organisms have several natural protection mechanisms against ROS. Intracellular enzymatic protection is provided by: superoxide dismutase (SOD), which speeds up the conversion of $\mathrm{O}_{2}{ }^{-} \cdot$ to $\mathrm{H}_{2} \mathrm{O}_{2}$; and catalase and glutathione peroxidase, which both converts $\mathrm{H}_{2} \mathrm{O}_{2}$ to $\mathrm{H}_{2} \mathrm{O}$ [16]. Furthermore, many compounds known as antioxidants are present in cells and body fluids, like vitamins $C$ and $E$, uric acid, glutathione, transferrin, albumin, etc. [140].

Protection of embryos against damage by ROS when cultured in vitro can be achieved in several ways. Supplementing the medium with SOD has been shown to be beneficial for embryonic development in the rabbit [205], and mouse [202, 273]. However, in the bovine $[213,214]$, and sheep [405], no beneficial effect was found of SOD. It has been speculated that exogenous SOD can only have a limited effect, if any, as it can only remove superoxides in the culture medium and not intracellular superoxides, because SOD, as well as superoxides, do not readily cross cell membranes [173].

Removal of traces of iron from the culture medium using chelators such as EDTA and transferrin $[1,109,240,265,266,268,269]$ has indeed been shown to promote development in vitro and to overcome the 2-cell block in mouse embryos. Proof that transferrin is acting by chelation was provided by dialysis of medium against the protein, thereby rendering the dialysed medium non-arresting [268].

Reduction of the oxygen concentration in the gasphase has been speculated to reduce ROS production and damage. Indeed, a reduced oxygen concentration of $5 \%$ has been shown to result in a slightly decreased fomation of reactive oxygen species in mouse embryos as compared to $20 \%$ oxygen [132]. Low oxygen levels are also encountered by embryos developing in vivo: in the oviduct and uterus of various mammalian species oxygen concentrations have been reported to be around $11-60 \mathrm{mmHg}$, which corresponds to about $1.5-9 \%$ 
$\mathrm{O}_{2}[108,221,233,427]$. In vitro, the use of $5 \%$ oxygen has indeed been shown to be beneficial for embryo development in the mouse [126, 281, 311,385], hamster [234], rabbit [206], human [271, 272], rat [184], sheep [375], cow [115, 213, 375], and goat [25]. However, other studies have failed to demonstrate the beneficial effect of low $\mathrm{O}_{2}$ in the mouse $[5$. 269], human [81, 88], cat [174], and sheep [36].

\section{Co-culture}

Many studies demonstrate a positive effect of co-culture of embryos with somatic cells in the mouse [278], pig [6], sheep [117], cow [58, 102, 103], human [45, 247]. A wide variety of different cell types, including fibroblasts, oviduct epithelium, cumulus cells, and monkey kidney (Vero) cells have been used (see [29] for references). The effects of co-culture have been speculated to be due to the following reasons $[29,386]$ : (i) provision of biophysical conditions similar to those in the oviduct and uterus; (ii) detoxification of the culture medium by e.g. chelation of heavy metal ions; (iii) reduction of the concentration of ceitain constituents of the medium that inhibit embryo development, e.g. glucose; (iv) secretion of certain "embryotrophic' factors or nutrients and substrates, like glycine [256], or taurine and hypotaurine $[135,278]$, by oviductal cells that stimulate embryo development. However, other reports do not find significant improvements of the co-culture system [386], and some investigators question whether co-culture is advantageous at all $[28,29,386]$. Certainly, for the advancement of basic knowledge about embryonic development, the co-culture system is too complicated and influenced by too many ill-defined factors [28]. Furthermore, the use of co-culture for human IVF has the distinct disadvantage of the risk of introducing disease organisms into the embryo culture environment, either viral material, or prion proteins, when bovine cells are used $[28,29,229]$.

\section{Reduction of the glucose and/or phosphate concentration}

In many recent studies, it has been found that glucose is detrimental to the first cleavage stages of preimplantation development and that it is imvolved in cleavage arrest in vitro in the mouse $[54,56,63]$, hamster $[337,343,344,345]$, rat $[184,317]$, cow $[96,183,256$, $365]$, sheep [376], and human [70,310]. However, the inhibitory effect of glucose is not confirmed by all authors (in the human [419], rat [431], mouse [361]). Although marked differences in the substrate requirements of embryos of different species have been described, in most mammalian species studied, glucose metabolism is low in the first few cleavage stages and increases steeply in late preimplantation development (see [22] and [29] for reviews). Glucose exhibits its negative effect on early development in most species studied when inorganic phosphate is also present in concentrations usually found in conventional media $[254,337,343,344,345]$. In the presence of phosphate, the negative effect of glucose is already clearly noticeable at concentrations of $0.1 \mathrm{mM}$ in the hamster [337], and $1 \mathrm{mM}$ in the human [70]. In the hamster 4-cell embryo, phosphate is also inhibitory in the absence of glucose even when present in only 1 um concentration [254]. In contrast, another divalent anion (sulphate) caused no inhibition of 4-cell embryo development at concentrations as high as $5.6 \mathrm{mM}$ [254]. The inhibitory effects of phosphate and glucose are not found in all species, e.g. in the pig, no effects were noted [292]. Furthermore, recent studies have shown that the inhibitory effects of glucose and phosphate are significantly diminished 
in the presence of amino acids in the culture medium (in the mouse [126], hamster [23]).

It is still unclear whether or not the findings of optimal in vitro development in media with low levels of glucose have to be regarded as artifacts of in vitro culture. Glucose as well as phosphate are certainly present in the oviductal fluid of all species studied (see Table 2), however, the concentration of glucose is well below that in serum in all species studied.

\section{Reduction of the sodium concentration}

Increasing the osmolality from 280 (the usual value in conventional in vitro culture media) to $390 \mathrm{mOsm} / \mathrm{kg}$ (being approximately the mouse oviduct value, see Table 3) with mannitol or $\mathrm{NaCl}$ has been found to be detrimental to mouse embryos [393]. However, the effect of the high level of $\mathrm{NaCl}$ was far more detrimental than that of mannitol [393]. This toxic effect of high $\mathrm{NaCl}$ levels has been confirmed in other studies. A moderately high $\mathrm{NaCl}$ concentration has been found to be detrimental to microfilament organization in porcine oocytes matured in vitro [116].

Recently it has been shown that reducing the $\mathrm{NaCl}$ concentration from $125 \mathrm{mM}$ to 85 $\mathrm{mM}$ could overcome the 2-cell block in random bred mouse embryos [193], resulted in higher rates of blastocyst formation $[40,193,194,195]$, as well as higher rates of mRNA synthesis [154] and protein synthesis [13]. Reduction of the concentrations of $\mathrm{NaCl}$ was demonstrated to be also beneficial in embryonic development in the pig [32], cow [216], and rabbit [207, 208].

Supplementing media with organic osmolytes, such as glycine [207, 393], betaine [40], inositol [207], and sorbitol [32, 116], provides partial protection for embryos of different species against the high $\mathrm{NaCl}$ concentrations. In the cow, however, no beneficial effect of betaine or inositol was found in media with high $\mathrm{NaCl}$ concentrations [216]. No effects, or even detrimental effects, were noted when either glycine [207, 393], or inositol [207] were added to media with low $\mathrm{NaCl}$ concentrations. Inclusion of betaine in medium with high $\mathrm{NaCl}$ levels of $125 \mathrm{mM}$ has been shown to maintain the intracellular concentrations of sodium and potassium more closely to those present in embryos cultured in low $\mathrm{NaCl}$ $(85 \mathrm{mM})$, and in embryos developing in vivo $[40,154]$. Betaine also has a stimulatory effect on protein synthesis [13], but not on mRNA synthesis [154].

\section{Inclusion of amino acids}

Although it has been shown that preimplantation embryos of many species can develop to the blastocyst stage in media that contain no free amino acids, recent studies show that supplementation of mixtures of amino acids to culture media is beneficial for embryonic development in vitro in the mouse $[124,192,240,399]$, cow $[215,365]$, sheep $[125,406]$, hamster [236], and rat [431]. Of these mixtures of amino acids some were found to inhibit development (leucine, tyrosine, valine, isoleucine, phenylalanine, arginine, methionine, or cysteine at $0.5 \mathrm{mM}$; isoleucine, phenylalanine, and tryptophan at $0.05 \mathrm{mM}$ in the hamster [236]), whereas others were found to be beneficial for development (notably glycine and taurine at 0.05 and $0.5 \mathrm{mM}$ in the hamster [236]). Amino acids can serve as osmoregulators, $\mathrm{pH}$ regulators, and energy sources in preimplantation embryos [124]. Glutamine is metabolized by embryos, as well as by many other somatic cells, in the absence of glucose, or even 
prefer this amino acid as energy source $[29,318]$. Glutamine, together with lactate, helps support in vitro development of hamster embryos [235]. It even supported development of hamster embryos from the 2-cell to the blastocyst stage when used as the sole energy source in the medium [235]. Mouse embryos [55,64, 195], and pig 1-and 2-cell embryos [292] can utilize glutamine. In 2-and 4-cell cattle embryos, glutamine is even preferentially metabolized [321]. Glycine has been speculated to act as an osmolyte (see above). The effect of taurine will be described later in this thesis.

Care must be taken when amino acids are used in in vitro culture, as detrimental effects of amino acids in the medium have been described, which can be attributed to ammonium production from the spontaneous degradation of amino acids during culture [124].

\subsection{Taurine}

\section{Introduction}

Taurine (2-aminoethane sulfonic acid) is a $\beta$-amino acid which was first isolated from the bile of the ox, Bos taurus [162]. It is found in high concentrations in algae and in the animal kingdom, but is low or absent in the bacterial and plant kingdoms [162]. In many animals, including mammals, it is one of the most abundant of the low-molecular-weight organic compounds found in tissues, with highest concentrations (upto $60 \%$ of the total free amino acid pool) in the heart, the brain and the retina of the eye [162]. Examples of intracellular taurine concentrations are: $50 \mathrm{mM}$ in human neutrophils $[133,335], 50-70 \mathrm{mM}$ in retina [359], $40 \mathrm{mM}$ in rat heart cells [162], $26 \mathrm{mM}$ in human leucocytes [162], $18 \mathrm{mM}$ in human spermatozoa [401], $7.6 \mathrm{mM}$ in rabbit oocytes, $2.1 \mathrm{mM}$ in rabbit morulae (while only 0.02 $\mathrm{mM}$ in rabbit blastocysts) [251]. In mouse oocytes, $6565 \mathrm{fmol} /$ oocyte taurine was found [340], wich amounts to $\approx 24 \mathrm{mM}$ when calculated on the basis of an oocyte volume of 268 $\mathrm{pl} /$ oocyte [353]. During preimplantation development of mouse embryos from the 2-cell to the blastocyst stage, either in vitro in medium containing taurine, or in vivo, taurine is accumulated [399, 400]. Taurine concentrations in blood plasma, cerebrospinal fluid, and extracellular fluid are much lower, typically in the range of 10-100 $\mu \mathrm{M}$ [162] (and see Table 4). Uterine fluids of several mammal ian species are characterized by taurine concentrations in the millimolar range, e.g. upto $11.7 \mathrm{mM}$ in the human uterine fluid [60] (and see Table 4). Remarkably, in oviductal fluids, taurine is found only in micromolar concentrations, more or less comparable to those found in serum in some species (rabbit, cow, ewe: see Table 4, and monkey: 122-157 $\mu \mathrm{M}$ [241]), or somewhat higher (pig: $236 \mu \mathrm{M}$ [135] vs $55 \mu \mathrm{M}$ in serum [77]). A probable source of taurine in oviductal fluid are the oviduct epithelial cells [135]. When cultured in vitro, oviduct epithelial cells of the cow, sow, goat and rabbit, have all been shown to synthesize and secrete significant amounts of taurine into the culture medium [135]. Also in male reproductive tract fluids, taurine can be found in high concentrations, e.g. $0.32-1.59 \mathrm{mM}$ in human seminal fluid $[153,158], 47 \mathrm{mM}$ in mouse seminal fluid [162], and $10 \mathrm{mM}$ in pig epididymal fluid [158]. Also milk is characterized by high taurine concentrations, e.g. $0.34 \mathrm{mM}$ in the human, $0.75 \mathrm{mM}$ in the mouse, and $2.8 \mathrm{mM}$ in the cat [359]. 
Hypotaurine is a precursor of taurine, and is rapidly oxidized to taurine, both in vivo and in vitro [162]. Hypotaurine concentrations are generally low; in different cell types it is present at only $1-2 \%$ of the taurine concentration [133,162]. The male reproductive system is however an exception as high concentrations of hypotaurine are found, e.g. $26 \mathrm{mM}$ in guines pig semen [162] and $45 \mathrm{mM}$ in pig epididymal tissue [158].

Taurine can be synthesized by oxidation of the sulfur-containing amino acids methionine and cysteine through cysteine sulfinate and hypotaurine to taurine [162]. Cysteine-sulfinate decarboxylase is the rate-limiting enzyme for taurine biosynthesis [359]. Some mammals have high activities of this enzyme and a great capacity for taurine biosynthesis (e.g. rats); whereas other animals (e.g. cats and humans) are unable to synthesize enough taurine and have to rely on dietary sources to maintain their body loads $[162,359]$. Consequently, the taurine concentration in serum in the cat has been shown to vary considerably when fed with diets containing different amounts of taurine [359]. But also in mice and rats, the administration of large doses of taurine in the diet result in a great increase in the plasma taurine concentration [379].

Over the physiological pH range, taurine occurs as a zwitterion "which results in a low lipophilicity [162]. As a result, biological membranes are almost impermeable to taurine, and as a consequence, cells can maintain very high concentrations of taurine with negligible diffusion of taurine through the cell membrane [162]. Taurine is considered to be biochemically inert in mammals. Marnmals are unable to oxidize the sulfur in taurine and thus are unable to use it as an energy source [162]. Furthermore, taurine is not an amino acid which is incorporated in proteins, although some minute amounts of taurine-containing peptides are found in the brain [162]. When taken up by cells, taurine is incorporated into a mobile large cytosolic pool [424]. It is found in onlly very limited concentrations in other cellular fractions than the cytosol like the plasmalemma and several types of granules [133], and has little to non observable interaction with macromolecular cell components [424]. Taurine is capable of binding to membrane components, although these interactions are fairly weak [162]. Taurine can form metal complexes with various transition metals such as zinc, copper, and iron, however, these complexes are far less stable than those of other amino acids such as glycine [424].

\section{Effect of taurine on organisms and cells: some examples}

The effects of taurine on cells, tissues and organisms are manifold and a list of phenomena with which taurine has been associated can be found in a recent review by Huxtable [162].

Feeding cats with a low-taurine diet results in decreased concentrations of taurine throughout the body, accompanied by malfunctioning of a number of body systems, including the visual system, and cardiovascular system [359]. Furthermore, their reproductive performance is poor, with frequent spontaneous resorptions and abortions of fetuses, and a higher incidence of abnormal fetuses, notably with abnormalities of the brain [359]. Also in the human and monkey, infants who were fed with synthetic infant formulas without taurine had reduced plasma and tissue taurine concentrations and abnormalities in their visual system as compared to infants fed on formulas supplemented with taurine [359, 360].

Taurine as well as hypotaurine were found to be effective as 'sperm motility factor' which hamster spermatozoa require to maintain motility when incubated in vitro $[203,241,260]$. Also in the mouse, taurine supports sperm motility in vitro, although its presence is not obligatory [114]. Furthermore, taurine and hypotaurine appear to stimulate capacitation 
in the hamster $[204,241,260]$, and human $[62,257]$, and to stimulate fertilization in vitro in the hamster [203], and in the cow [17]. Both required catecholamines to elicit the greatest response $[17,203]$. Taurine also appears to stimulate fertilization in vitro in the hamster [203], mouse [114], albeit to a low degree in either species. In the human, incubating spermatozoa in medium with $1 \mathrm{mM}$ taurine has been shown to increase the penetration of zona-free hamster oocytes in comparison with controls [62]. However, in a small series, the addition of both hypotaurine $(10 \mu \mathrm{M})$ and epinephrine (a catecholamine) did not improve the motility nor the in vitro fertilizing capacity of spermatozoa from subfertile males [226].

\subsection{Aims of the study}

It is clear that, after more than 40 years of animal research and 20 years of experience with human IVF, the culture of preimplantation mammalian embryos in vitro is still suboptimal, and the requirements for optimal early embryonic development are still poorly understood. Furthermore, little is known about the effects of in vitro culture of preimplantation embryos on subsequent postimplantation development. The ultimate goal of this study is therefore to contribute to the understanding of the molecular mechanisms involved in preimplantation embryonic development and of the interactions between the developing embryo and its surrounding environment. Such an understanding is a prerequisite for improved, and safer, culture conditions in human IVF, resulting in higher pregnancy rates. Also, improved culture conditions would permit a longer duration of in vitro culture which is necessary for a better assessment of the developmental capacity of individual embryos. This would permit the transfer of less, but more viable embryos, to the uterus without a reduction of pregnancy rates, thus reducing the rate of multiple pregnancies which are an important risk factor in IVF. Furthermore, the generation of later stage embryos with a higher viability would be important for the further development of preimplantation genetic diagnosis (PGD) which requires extended periods of successful in vitro culture in order for the diagnostic processes to be completed.

The amino acid taurine was chosen as the subject of study. This amino acid is absent from most embryo culture media, whereas it is present in high concentrations both in reproductive tract fluid of several species, as well as in embryos, suggesting a physiological function of taurine. The purpose of this study is to investigate the effect of taurine on preimplantation embryo development in vitro, and to examine the mechanisms by which taurine may be acting. 


更

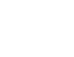
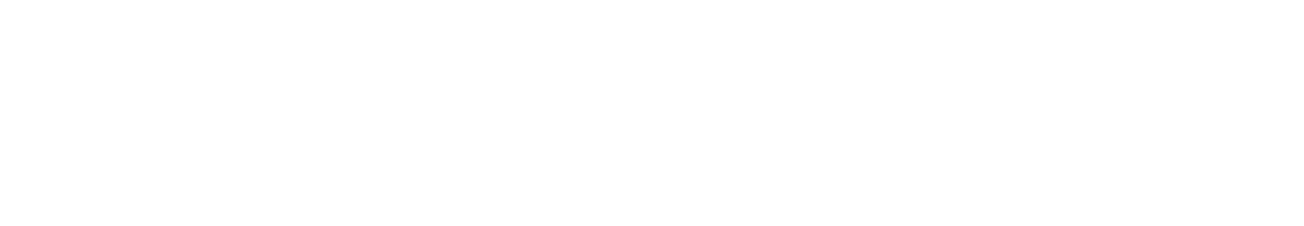


\section{Positive effect of taurine on preimplantation development of mouse embryos in vitro.}

J.C.M. Dumoulin ${ }^{1}$, J.L.H. Evers ${ }^{1}$, M. Bras ${ }^{1}$, M.H.E.C. Pieters ${ }^{2}$, J.P.M. Geraedts ${ }^{2}$

${ }^{1}$ Department of Obstetrics and Gynaecology, Academic Hospital Maastricht,

University of Limburg, Maastricht, The Netherlands; and ${ }^{2}$ Department of Genetics and Cell Biology, University of Limburg, Maastricht, The Netherlands

Published in:

Journal of Reproduction and Fertility, 94, 373-380 (1992) 


\section{Summary}

The effect of various taurine concentrations in modified Tyrode's medium on in vitro fertilization of mouse oocytes was examined. No significant difference in fertilization rate was found at concentrations of $0,0,1,1,5,10$ and $20 \mathrm{mM}$ taurine. In a second series of experiments, the effect of taurine on preimplantation embryonic development after fertilization in vitro was studied. At concentrations of 1,5,10 and $20 \mathrm{mM}$ taurine, significantly more two-cell embryos reached the blastocyst stage compared with medium without taurine. Culture in the presence of $5 \mathrm{mM}$ or $10 \mathrm{mM}$ taurine resulted in blastocysts with the highest mean number of cells. The positive effect of taurine on the embryonic development was found to be more pronounced both in a second medium (human tubal fluid medium) wich has a higher potassium concentration than Tyrode's medium, and in a modified Tyrode's medium with an increased potassium concentration. In addition to these in vitro studies, it is reported that taurine comprised about $59 \%$ of the total free amino acid content in mouse oviduct flushings, compared with $17 \%$ in mouse serum.

\section{Introduction}

Taurine and its precursor hypotaurine are sulfur-containing B-amino acids, and they are present at relatively high concentrations in female reproductive tract fluids of several mammals (Meizel et al., 1980; Casslén, 1987; Miller \& Schultz, 1987), in human semen (Hernvann et al., 1986) and in spermatozoal acrosomes (Velázquez et al., 1986).

Much is already known about the role of taurine in the processes of sperm capacitation and in vitro fertilization (IVF) for different species. Hamster spermatozoa require taurine or hypotaurine in the culture medium to maintain their motility and viability during in vitro capacitation (Mrsny et al., 1979). Also, the fertilizing capacity of hamster spermatozoa in vitro is enhanced by taurine and hypotaurine (Leibfried \& Bavister, 1981, 1982). In the cow, the presence of hypotaurine in the medium stimulates in vitro fertilization (Ball et al., 1983). However, mouse spermatozoa do not need the addition of taurine to exhibit their full fertilizing ability (Fraser, 1986). Although it has been reported that human spermatozoa capacitate faster in medium with taurine added (Mortimer, 1986; Chan, 1985), their fertilizing ability in vitro does not seem to be increased by taurine (Mahadevan \& Trounson, 1985).

However, the role of taurine in mammalian embryonic development during the preimplantation stages is less clear. The purpose of the present study was first to examine the effect of taurine on in vitro culture of preimplantation mouse embryos. Second, reproductive tract fluids of female mice were analysed for the presence of taurine. 


\section{Materials and methods}

Modified Tyrode's medium (T6) (Quinn et al., 1984) was used as culture medium. For in vitro fertilization, the medium was supplemented with $30 \mathrm{mg}$ Fraction $\mathrm{V}$ bovine serum albumine/ml (BSA, Sigma No. A7906, St.Louis, MO, USA); $5 \mathrm{mg} \mathrm{BSA/ml} \mathrm{was} \mathrm{used} \mathrm{for}$ the embryo culture. Media with different taurine concentrations were prepared by mixing a stock-solution of $20 \mathrm{mM}$ taurine in culture medium (Sigma, No. T7146) with medium without taurine. The osmolality of all media was adjusted to $280-285 \mathrm{mOs} / \mathrm{kg}$ before use, the $\mathrm{pH}$ was 7.5 after equilibration in an atmosphere of $5 \% \mathrm{CO}_{2}$ in air.

For all experiments (C57BL/6 $\times$ DBA/2)F, hybrid female mice (B6D2F1) were purchased from Charles River Wiga (Sulzfeld, Germany). Oocytes were obtained by superovulating 7-11-week-old females with 10iu pregnant mares' serum gonadotrophin (PMSG, Sigma) and $48 \mathrm{~h}$ later 10iu human chorionic gonadotrophin (hCG, Sigma). Sixteen hours after hCG injection, the females were killed by cervical dislocation. Their oviducts were dissected and transferred to Hepes-buffered T6 (Quinn et al., 1984). The cumulus masses containing the aocytes were released from the swollen ampullae of the oviducts, washed once and transferred to Multidish 4-well dishes (Nunc, Life Technology BV, Breda, The Netherlands) containing $1 \mathrm{ml}$ of the fertilization medium.

Caudal epididymal spermatozoa were obtained from 12-18-week-old CD-1 males. After incision of the tissues, the spermatozoa were allowed to disperse into T6 medium supplemented with $30 \mathrm{mg} \mathrm{BSA} / \mathrm{ml}$. After $30 \mathrm{~min}$, the epididymal tissue was removed and the spermatozoa were allowed to capacitate for a further $90 \mathrm{~min}$ at $37^{\circ} \mathrm{C}$. The oocytes were inseminated with a calculated amount of the sperm suspension to give a final concentration of approximately 2000000 motile sperm $/ \mathrm{ml}$.

Experiments to study the effect of taurine on fertilization and embryonic development in vitro were of a randomized block design (Fleiss, 1986). Oocytes from different females were not pooled, but were inseminated separately. The embryos from each female were distributed over a set of the different experimental media and were not pooled with embryos from other females. In this way, the comparison between different experimental media is repeated in every female used. To obtain at least five oocytes in every experimental medium from each female, only oocytes from females who produced $>30$ oocytes were used.

Twenty-four hours after insemination, normal-appearing two-cell embryos, which were considered fertilized, were counted. At $120 \mathrm{~h}$ after insemination, the numbers of blastocysts were assessed. The percentages of embryos completing preimplantation development were calculated on the basis of the fertilization rate. The mean percentages \pm standard error of the mean (SEM) of fertilization (number of two-cell embryos:number of oocytes) and of embryonic development (number of blastocysts number of two-cell embryos) per female were calculated for every experimental group. Statistical analysis of the data was performed using an analysis of variance (ANOVA). When treatment effects were significant, multiple-comparison tests were used to determine wich treatment means were different (Fleiss, 1986). In experiments 1 and 2 , in which comparisons were made between groups cultured in the presence of several taurine concentrations and a control group cultured without taurine, Dunnett"s procedure was used. In experiments 3 and 4 , in which only a few comparisons between the group means were of interest, the Bonferroni criterion was used. 


\section{Experiment 1: dose-response of fertilization in vitro to taurine}

Four replicate experiments using four to six females per experiment were performed. $A$ sperm suspension from four males was divided among insemination media containing taurine in six different concentrations $(0,0.1,1,5,10$ and $20 \mathrm{mM})$ and capacitated for further $90 \mathrm{~min}$. Oocytes were freed from cumulus cells using hyaluronidase, and divided per female among the six insemination media. Five hours after insemination, oocytes of each experimental group were rinsed once and transferred to medium without taurine.

\section{Experiment 2: dose-response of embryonic development to taurine}

Five replicate experiments using five to nine females per experiment were performed. Media with the same taurine concentrations as in Expt 1 were used. Five hours after insemination in medium withoult taurine, oocytes were divided at random among medium without taurine and the five taurine-containing media. All the embryos, from two experiments, developing a distinct blastocoel at $120 \mathrm{~h}$ after insemination were fixed and stained with 4'6-diamidino-2phenylindole (DAPI) according to the method of Mori et al. (1988). This DNA-staining technique allows an accurate count of the number of nuclei, and thus of the number of cells in each embryo.

\section{Experiment 3: comparison of two culture media of different inorganic composition supplemented with taurine}

In this experiment, T6 medium and human tubal fluid medium (HTF) (Quinn et al., 1985) were used for the culture of embryos. Four replicate experiments using four to six females per experiment were performed. Five hours after insemination in T6 medium without taurine, the oocytes were randomly divided among T6 and HTF medium without taurine and T6 and HTF medium with $5 \mathrm{mM}$ taurine.

\section{Experiment 4: comparison of T6 medium with two $\mathrm{K}^{+}$concentrations supplemented with taurine}

Three replicate experiments using four to six females per experiment were performed using standard T6 medium (1.4 $\left.\mathrm{mM} \mathrm{K}^{*}\right)$ and T6 with $5.0 \mathrm{mM} \mathrm{K}$ for the culture of embryos. Osmolality of the $T 6$ with added $\mathrm{K}^{+}$was adjusted to $280 \mathrm{mOs} / \mathrm{kg}$ by replacing a small amount of medium by water. Five hours after insemination in T6 medium without taurine, the oocytes were randomly divided among $\mathrm{T} 6$ and $\mathrm{T} 6$ plus $5 \mathrm{mM} \mathrm{K}$, both with, and without, $5 \mathrm{mM}$ taurine.

\section{Experiment 5: the presence of taurine in mouse oviduct fluid}

Mice were induced to ovulate by injection of 3 iu PMSG and then 3 iu HCG, $48 \mathrm{~h}$ later. Oviduct flushings and serum were collected at $40 \mathrm{~h}$ after $\mathrm{HCG}$ injection. After anaes-thetizing the mice with ether, blood samples were collected by puncture of the retro-orbital plexus. The blood was allowed to clot and serum was separated from cells by centrifugation (1200 g. $10 \mathrm{~min}$ ). The mice were killed by cervical dislocation, and both oviducts together with a small portion of the uterus near the uterotubal junction $(0.1-0.2 \mathrm{~mm})$ were dissected. After rinsing the oviducts in $5 \%$ dextrose (Sigma) and blotting them on filter paper to remove most of the adhering peritoneal fluids, they were transferred to a drop of $150 \mu \mathrm{l}$ dextrose solution. Part of this fluid was used to flush the oviducts using a plastic tuberculin syringe 
attached to a blunt hypodermic needle with an outer diameter of $0.21 \mathrm{~mm}$ (Hamilton $\mathrm{N}_{73} 3 \mathrm{~s}_{\mathrm{s}}$ v. Oortmerssen, Den Haag, The Netherlands) introduced into the ampullar end of the oviduct. These manipulations were performed under a stereomicroscope. Flushings were completed within 10 min of death of the animal. The fluid used for flushing the oviducts was centrifuged at $2000 \times \mathrm{g}$ for $10 \mathrm{~min}$ to remove any cellular debris and the supernatant was stored at $-20^{\circ} \mathrm{C}$.

Amino acid analysis was performed with an amino acid analyser (LKB/Biochrom model 4151 , Cambridge, UK) according to the method of Blom \& Huijmans (1985) using norleucine as an internal standard.

\section{Results}

\section{Experiment 1: dose-response of fertilization in vitro to taurine}

From 20 females, 779 oocytes were obtained (mean number of oocytes \pm standard deviation (SD) per female: $39.0 \pm 5.6$ ) and divided among the six media. No significant differences were observed between the number of two-cell embryos, counted at $24 \mathrm{~h}$ after insemination, in medium without taurine and the five media with different taurine concentrations (Table 1).

Table 1. Effect of taurine on the fertilization in vitro of mouse oocytes

\begin{tabular}{lcc}
\hline $\begin{array}{l}\text { Taurine } \\
(\mathrm{mM})\end{array}$ & $\begin{array}{c}\text { Two-cell } \\
\text { formation }(\%)^{\mathrm{a}}\end{array}$ & $\begin{array}{c}\text { Mean fertilization rate } \\
\text { per female } \pm \text { SEM }^{\mathrm{B}}\end{array}$ \\
\hline 0 & $85: 133(64)$ & $0.64 \pm 0.05$ \\
0.1 & $79: 126(63)$ & $0.62 \pm 0.06$ \\
1.0 & $82: 132(62)$ & $0.62 \pm 0.05$ \\
5.0 & $83: 130(64)$ & $0.64 \pm 0.04$ \\
10.0 & $85: 131(65)$ & $0.65 \pm 0.06$ \\
20.0 & $74.127(58)$ & $0.59 \pm 0.06$ \\
\hline
\end{tabular}

${ }^{2}$ Total number of two-cell embryos: total number of oocytes.

"Means and SEM are based on 20 replicates: the oocytes of each of 20 females were divided among the six media with different taurine concentrations, inseminated and cultured to the two-cell stage separately. ANOVA: not significant. 


\section{Experiment 2: dose-response of embryonic development to taurine}

For these experiments, 34 females were used. Five hours after insemination in medium without taurine, a mean number of $42.7 \pm 10.5$ oocytes per female (total number of oocytes: 1451) was divided among the six media. After $24 \mathrm{~h}$, the numbers of two-cell embryos were not significantly different in the six media (data not shown). Table 2 shows that, with respect to the mean number of blastocysts per female developing from two-cell embryos, the means of the groups cultured in media with taurine concentrations of $1-20 \mathrm{mM}$ are significantly different from the mean of the control group (no taurine). The mean cell number of blastocysts, as estimated by the number of nuclei that developed in media with 5 and $10 \mathrm{mM}$ taurine was significantly higher than in medium without taurine (Table 3 ).

Table 2. Effect of various taurine concentrations in the culture medium on the deveiopment of mouse embryos to the blastocyst stage

\begin{tabular}{lrc}
\hline $\begin{array}{l}\text { Taurine } \\
(\mathrm{mM})\end{array}$ & $\begin{array}{c}\text { Blastiocyst } \\
\text { formation }(\%)^{\mathrm{a}}\end{array}$ & $\begin{array}{c}\text { Mean blastocyst formation } \\
\text { per female } \pm \text { SEM }^{\mathrm{a}}\end{array}$ \\
\hline 0 & $99 / 165(60)$ & $0.64 \pm 0.04$ \\
0.1 & $117 / 173(68)$ & $0.70 \pm 0.04$ \\
1.0 & $131 / 167(78)$ & $0.82 \pm 0.03^{\mathrm{C}}$ \\
5.0 & $121 / 157(77)$ & $0.79 \pm 0.04^{\mathrm{c}}$ \\
10.0 & $117 / 153(76)$ & $0.80 \pm 0.04^{\mathrm{C}}$ \\
20.0 & $130 / 165(79)$ & $0.80 \pm 0.04^{\mathrm{C}}$ \\
\hline
\end{tabular}

${ }^{3}$ Total number of blastocysts total number of two-cell embryos.

bMeans and SEM are based on 34 replicates: after in vitra fertilization in medium withoult taurine, the oocytes of each of 34 females were divided among the six media with different taurine concentrations and cultured separately.

GNOVA: $P<0.01$, treatment means indicated are significantly different from the control group.

Table 3. Cell numbers of mouse blastocysts after development of the embryos in T6 media with various taurine concentrations.

\begin{tabular}{lcc}
\hline $\begin{array}{l}\text { Taurine } \\
\text { (mM) }\end{array}$ & $\begin{array}{c}\text { Number of blastocysts } \\
\text { successfully analysed }\end{array}$ & $\begin{array}{c}\text { Number of cells } \\
\text { Mean } \pm \text { SEM }^{\mathrm{a}}\end{array}$ \\
\hline 0 & 33 & $54.7 \pm 4.0$ \\
0.1 & 41 & $62.0 \pm 3.5$ \\
1.0 & 36 & $52.6 \pm 3.1$ \\
5.0 & 42 & $67.9 \pm 3.4^{\mathrm{a}}$ \\
10.0 & 41 & $64.8 \pm 3.2^{\mathrm{a}}$ \\
20.0 & 26 & $58.3 \pm 4.1$ \\
\hline
\end{tabular}

ANOVA: $P<0.05$, treatment means indicated are significantly different from the control group. 


\section{Experiment 3: comparison of two culture media of different inorganic composition supplemented with taurine}

For these experiments, 18 females were used. Five hours after insemination in medium without taurine, a mean number of $41.3 \pm 8.4$ (SD) oocytes per fernale (total number of oocytes: 744) was divided among the two types of culture medium, with and without $5 \mathrm{mM}$ taurine. This concentration of taurine was chosen because it resulted in blastocysts with the highest mean number of cells (Table 3). After $24 \mathrm{~h}$, the numbers of two-cell embryos were not significantly different in the four groups (data not shown). For both types of medium, embryo development in taurine-supplemented medium resulted in a significantly higher blastocyst formation (Table 4).

\section{Experiment 4: comparison of T6 medium with two $\mathrm{K}^{+}$concentrations supplemented with taurine}

For these experiments, 17 females were used. Five hours after insemination in medium without taurine, a mean number of $41.9 \pm 6.4$ (SD) oocytes per female (total number of oocytes: 712 ) was divided among the two T6 media with different $\mathrm{K}^{+}$concentrations, with and without $5 \mathrm{mM}$ taurine. The numbers of two-cell embryos at $24 \mathrm{~h}$ after insemination were not significantly different in the four groups (data not shown). Embryonic development in T6 with $5 \mathrm{mM} \mathrm{K}^{+}$without taurine was retarded (Table 5) as compared to T6 without extra potassium. For both $\mathrm{K}^{+}$concentrations, embryo development in taurine-supplemented medium resulted in a significantly higher blastocyst formation (Table 5).

Table 4. Effect of $5 \mathrm{mM}$ taurine in two media with different inorganic composition on the development of mouse zygotes to the blastocyst stage

\begin{tabular}{|c|c|c|c|}
\hline Medium & $\begin{array}{c}\text { Taurine } \\
(\mathrm{m} M)\end{array}$ & $\begin{array}{c}\text { Blastocyst } \\
\text { formation }(\%)^{\mathrm{a}}\end{array}$ & $\begin{array}{c}\text { Mean blastocyst formation } \\
\text { per female } \pm \mathrm{SEM}^{\mathrm{b}}\end{array}$ \\
\hline T6 & $\begin{array}{l}0 \\
5\end{array}$ & $\begin{array}{l}80: 119 \quad(67) \\
93: 116 \quad(80)\end{array}$ & $\begin{array}{l}0.64 \pm 0.05 \\
0.78 \pm 0.04^{c}\end{array}$ \\
\hline HTF & $\begin{array}{l}0 \\
5\end{array}$ & $\begin{array}{ll}54: 123 & (44) \\
81: 118 & (69)\end{array}$ & $\begin{array}{l}0.43 \pm 0.05^{\mathrm{C}} \\
0.70 \pm 0.04^{\mathrm{d}}\end{array}$ \\
\hline
\end{tabular}

\footnotetext{
a Total number of blastocysts:total number of zygotes.

b Means and SEM are based on 18 replicates: the zygotes of each of 18 females were divided among the four media and cullured separately.

ANOVA: $P<0.001$; ${ }^{c}$ significantly" different from T6 medium without taurine; "significantly different from HTF medium without taurine.
} 
Table 5. Effect of $5 \mathrm{mM}$ taurne in T6 media with different potassium levels on the development of mouse zygotes to the blastocyst stage

\begin{tabular}{cccc}
\hline $\begin{array}{c}\text { Potassium } \\
(\mathrm{mM})\end{array}$ & $\begin{array}{c}\text { Taurine } \\
(\mathrm{mM})\end{array}$ & $\begin{array}{c}\text { Blastocyst } \\
\text { formation }(\%)^{\mathrm{m}}\end{array}$ & $\begin{array}{c}\text { Mean blastocyst formation } \\
\text { per female } \pm \text { SEM }\end{array}$ \\
\hline 1.4 & 0 & $86: 122(70)$ & $0.67 \pm 0.08$ \\
14 & 5.0 & $108: 129(84)$ & $0.84 \pm 0.04^{\mathrm{C}}$ \\
5.0 & 0 & $67: 124(54)$ & $0.51 \pm 0.06^{\mathrm{C}}$ \\
5.0 & 5.0 & $91: 122(75)$ & $0.74 \pm 0.04^{\mathrm{d}}$ \\
\hline
\end{tabular}

Total number of blastocysts total number of zygotes.

'Means and SEM are based on 17 replicates: the zygotes of each of 17 females were divided anong the four media and cultured separately.

ANOVA $P<0.001$. 'significantly different from the mean blastocyst formation in T6 medium without taurine: ${ }^{\mathrm{d}}$ significantly different from T6 medium with extra $K^{*}$ and without taurine.

\section{Experiment 5: the presence of taurine in mouse oviduct fluid}

Collection of nonhaemolysed serum and oviduct-flushing fluid was succesful in five mice. In the $150 \mu \mathrm{l}$ fluid with which both oviducts of one mouse were flushed, a total mean concentration of $558 \pm 121 \mu \mathrm{mo} / / \mathrm{l}$ free amino acids was found. The mean concentration of taurine in the oviduct-flushing samples was $329 \pm 70 \mu \mathrm{mol} /( \pm \mathrm{SD}$ ). As oviduct fluid volume measurements were not made, only the relative composition (\%) of amino acids found in the oviduct flushings is tabulated in Table 6 , together with the relative composition of the same amino acids found in serum. Amino acids found in serum that could not be demonstrated in the oviduct flush samples were not taken into account. Although amino acid concentrations varied considerably among mice (e.g. minimum/maximum values of taurine concentration in serum and oviduct flushes of the five mice are 373-912 $\mu \mathrm{mol} / \mathrm{I}$ and $233-401 \mu \mathrm{mol} / \mathrm{l}$, respectively), the variation in amino acid composition was very small, both in serum and in oviduct flushings. 
Table 6. Amino acid concentration and composition in serum and oviduct fushing fluid in mice

\begin{tabular}{|c|c|c|c|c|c|}
\hline \multirow[b]{3}{*}{ Amino acid } & \multirow{3}{*}{\multicolumn{3}{|c|}{$\begin{array}{c}\text { Concentration } \\
\text { in serum } \\
\text { Mean } \mu \mathrm{mol} / / \pm \mathrm{SD}\end{array}$}} & \multicolumn{2}{|c|}{ Composition } \\
\hline & & & & Serum & Oviduct flushings \\
\hline & & & & \multicolumn{2}{|c|}{$(\% \text { of total } \pm \text { SEM })^{\mathrm{a}}$} \\
\hline Taurine & 590 & \pm & 204 & 17 & $59 \pm 1$ \\
\hline Aspartic acid & 18 & \pm & 7 & $<1$ & 4 \\
\hline Threonine & 151 & \pm & 47 & 4 & 1 \\
\hline Serine & 169 & \pm & 65 & 4 & 2 \\
\hline Glutamic acid & 42 & \pm & 16 & 1 & 9 \\
\hline Glutamine & 766 & \pm & 309 & $21 \pm 1$ & 5 \\
\hline Proline & 79 & \pm & 29 & & \\
\hline Glycine & 437 & \pm & 173 & 12 & 10 \\
\hline Alanine & 428 & \pm & 136 & $12 \pm 1$ & 5 \\
\hline Valine & 227 & \pm & 79 & 6 & 1 \\
\hline Methionine & 66 & \pm & 22 & & \\
\hline Isoleucine & 112 & \pm & 43 & 3 & 1 \\
\hline Leucine & 163 & \pm & 66 & 5 & 1 \\
\hline Tyrosine & 63 & \pm & 23 & & \\
\hline Phenylalanine & 74 & \pm & 27 & 2 & 1 \\
\hline Ornithine & 52 & \pm & 21 & & \\
\hline Lysine & 389 & \pm & 153 & $11 \pm 1$ & 1 \\
\hline Histidine & 54 & \pm & 19 & & \\
\hline Arginine & 176 & \pm & 61 & & \\
\hline Total & 4055 & \pm & 1451 & & \\
\hline
\end{tabular}

The percentage of the total amino acid content measured (only amino acids that were found both in serum and in oviduct flushings are taken into account); SEM are not shown when they are bellow $0.5 \%$

\section{Discussion}

The results indicate that capacitation and IVF in the presence of taurine do not affect fertilization rate in mice at any of the concentrations tested. This is consistent with the observations of Fraser (1986), who reported that mouse spermatozoa do not require taurine to exhibit their maximum fertilizing ability and showed that, although addition of $0.1,0.3$ or $1.0 \mathrm{mM}$ taurine in the absence of BSA resulted in higher fertilization rates, this increase was not found in media supplemented with BSA.

The inclusion of taurine in the culture medium resulted in significantly more two-cell embryos reaching the blastocyst stage for all tested taurine concentrations of $1 \mathrm{mM}$ and higher. Embryos cultured in the presence of 5 and $10 \mathrm{mM}$ taurine resulted in blastocysts with a higher mean number of cells compared with blastocysts cultured in medium without taurine.

To test whether the observed positive effect of taurine was a phenomenon specific for T6 culture medium, we compared the development of mouse embryos in T6 medium and HTF medium, with and without taurine. In the HTF medium, the positive effect of taurine was even more pronounced than in T6 medium. HTF has been shown by Quinn et al. (1985) to be a more suitable medium than T6 for human IVF and for culturing mouse one-cell 
embryos. Contrary to the findings of Quinn et al., comparing T6 and HTF without taurine, significantly fewer blastocysts developed in HTF medium than in T6 medium. Quinn ef al. postulated that the high $\mathrm{K}^{*}$ level $(5.06 \mathrm{mM})$ in HTF medium compared with the $\mathrm{K}^{*}$ level $(1.42 \mathrm{mM})$ in T6 is responsible for the better results in the HTF medium. However, our results agree with the results of Wiley et al. (1986) who found that more blastocysts developed in $T 6$ medium with $1.4 \mathrm{mM} \mathrm{K}$ than in $T 6$ with $6.0 \mathrm{mM} \mathrm{K}$

Results from our investigation of the interactive effect between taurine and $K^{+}$on the development of mouse embryos in $T 6$ medilum with the standard $K^{*}$ concentration and T6 medium with an increased $(5.0 \mathrm{mM}) \mathrm{K}^{+}$concentration, both with and without taurine, also demonstrate that $K^{+}$, and not some other component of the HTF medium, is responsibie for the differences in embryonic development in T6 and HTF medium.

Taurine and $\mathbb{K}^{+}$are known to interact in sperm capacitation and fertilization processes (Meizel, 1985). Although their exact roles are not clear, both compounds seem to exert their effect by influencing the activity of the enzym $\mathrm{Na}^{+}-\mathrm{K}^{+}-\mathrm{ATPase}$. $\mathrm{Na}^{+}-\mathrm{K}^{+}$-ATPase is a plasma-membrane enzyme that controls intracellular $K^{*}$ levels. The activity of this enzyme is inhibited in a low K*-environment (Thomas, 1972). Mrsny and Meizel (1985) showed that taurine decreases the $\mathrm{Na}^{+}-\mathrm{K}^{*}$-ATPase activity of sperm cell membranes in a dosedependent manner. High $\mathrm{K}^{+}$levels have been shown to be detrimental to sperm motility in vitro (Fraser, 1983). Studies by Meizel et al. (1980) have shown that, in the presence of $3.1 \mathrm{mM} \mathrm{K}$, addition of $0.5 \mathrm{mM}$ taurine is needed to preserve hamster sperm motility during in vitro capacitation. In medium with a very low $\mathrm{K}^{+}$concentration, the addition of taurine is not needed (Mrsny and Meizel, 1985). It has been suggested that taurine may protect the spermatozoa against high $\mathrm{K}^{+}$concentrations by reducing the $\mathrm{Na}^{*}-\mathrm{K}^{*}$-ATPase activity and consequently the influx of extracellular $\mathrm{K}^{+}$(Mrsny and Meizel, 1985).

Both taurine and $\mathrm{K}^{*}$ are present in high concentrations in mammalian reproductive tract fluids. We found in the mouse that taurine comprised about $17 \%$ of the total free amino acid content in serum, whereas it amounted to $59 \%$ in the oviduct flushing samples. The relative proportions of the amino acids found in serum are comparable to those found by Schultz et al. (1981). Human uierine fluid has also been shown to contain high concentrations of taurine, varying from 3 to $17 \mathrm{mmol} /$, i.e. up to 400 -fold higher than that in blood plasma (Casslen, 1987). The concentration of taurine is highest during the luteal phase of the menstrual cycle (Cassien, 1987). The $\mathrm{K}^{*}$ concentration in human uterine fluid has been shown to be approximately $20 \mathrm{mM}$ at midcycle, which is about five times higher than that in human plasma (Casslén, 1984). Different $K^{*}$ concentrations in the human oviduct have been reported. Lippes et al. (1972) found $K^{*}$ concentrations between $7.7 \mathrm{mM}$ and $9.9 \mathrm{mM}$, depending on the stage of the menstrual cycle, whereas Borland et al. (1980) found a mean concentration of $21 \mathrm{mM} \mathrm{K}^{+}$. In the mouse, the $\mathrm{K}^{+}$concentration in oviduct fluid was found to vary from $18 \mathrm{mM}$ to $30 \mathrm{~m} \mathrm{M}$, depending on the stage of the oestrus cycle and the segment of the oviduct studied (Borland et al., 1977; Roblero et al. , 1976). During pseudopregnancy, mouse uterine fluid has a very high $\mathrm{K}^{+}$content, ranging from $35 \mathrm{mM}$ on day 1 to $75 \mathrm{mM}$ on day 5 (Walles \& Edirisinghe, 1989).

The ligh combined concentration of taurine and $\mathrm{K}^{+}$in reproductive tract fluids suggests that, in vivo, taurine might also protect the spermatozoa from the high $\mathrm{K}^{*}$ levels by reducing the $\mathrm{Na}^{*}-\mathrm{K}^{+}$-ATPase activity (Mrsny and Meizel, 1985). Not only do mammalian sperm capacitation and fertilization take place in uterine and oviductal fluids, but these fluids also make up the environment in which the embryo develops during the preimplantation stages. It is possible that taurine influences embryonic development in the same manner as it influences sperm motility, capacitation and fertilization, i.e. by protection against the high 
$K$ concentrations found in reproductive tract fluids. Findings of a greater stimulating effect of taurine in the media containing higher $\mathrm{K}^{+}$concentration are consistent with such a hypothesis. It remains to be shown whether the favourable role of taurine in embryonic development is exerted by protecting embryos against high $\mathrm{K}^{+}$concentrations by decreasing the $\mathrm{Na}^{*}-\mathrm{K}^{+}-\mathrm{A}$.TPase activity of embryonic membranes.

We thank Dr Jolande A. Land for helpful discussions concerning this manuscript and Jaap. A. Bakker for the amino acid analysis.

\section{References}

Ball, G.D. Leibfried, M.L. "Lenz, R.W. Ax, R.L., Bavister, B.D. \& First, N.L. (1983) Factors affecting succesful in vitro fertilization of bovine follicular oocytes. Biol. Reprod. 28, 717 725 .

Blom W. Huhimans J. (1985) Differential diagnosis of (inherited) aminomacid metabolism or transport disorders. Science Tools, 32, 10-22.

Borland, R.M. Hazra, S. Biggers ${ }_{n}$ J.D. \& Lechene, C.P. (1977) The elemental composition of the environments of the gametes and preimplantation embryo during initiation of pregnancy. Biol. Reprod. 16, 147-157.

Bortand, R.M., Biggers, J.D., Lechene, C.P. \& Taymor, M.L. (1980) Elemental composition of fluid in the humath Fallopian tube. J. Reprod. Fert 58, 479-482

Casslèn, B. \& Nilsson, B. (1984) Human uterine fluid, examined in undiluted samples for osmolarity and the concentrations of inorganic ions, albumin, glucose, and urea. Am. I. Obstel Gynecol. 150,877 881 .

Casslén. B.G.(1987) Free amino acids in human uterine fluid. J. Reprod. Med. 32,181-184.

Chan, S.Y.W.(1985) Taurine and human spermatozoal capacitation. Cell Bol. Intern. Rep.9,127-130

Fleiss, J.L. (1986) The design and analysis of clinical experiments. Wiley \& Sons, New York.

Fraser, L.R. (1983) Potassium ions modulate expression of mouse sperm fertilizing ability, acrosome reaction and hyperactivated motility in vitro. J. Reprod. Fert. 69,539-553.

Fraser, L.R.(1986) Both taurine and albumin support mouse sperm motility and fertilizing ability in vitro but there is no obligatory requirement for taurine. Reprod. Fert. 77,271-280.

Hernvann, A., Goinzales, J., Troupel, S. \& Galli, A.1986) Amino acid content of human semen in normal and infertility cases. Andrologia 18,461-469.

Leibfried, M.L. \& Bavister, B.D.(1981) The effects of taurine and hypotaurine on in vitro fertilization in the golden hamster. Biol Reprod 4,57-63.

Leibfried M.L. \& Bavister, B.D.(1982) Effects of epinephrine and hypotaurine on in-vitro fertilization in the golden hamster. J.Reprod. Fert. 66,87-93

Lippes, J., Enders, R.G., Pragay, D.A. \& Bartholomew, W.R. (1972) The collection and analysis of human fallopian tubal fluid. Contraception $5,85-94$.

Mahadevan, M.M. \& Trounson, A.O.(1985) Remowal of the cumulus oophorus from the humarl oocyle for in vitro fertilization. Fert. Steril $43,263-267$

Meizel, S.(1985) Molecules that initiate or thelp stimulate the acrosome reaction by their interaction with the mammalian sperm surface. Am.J.Anat. 174,285-302.

Meizel. S., Lui, C.W. Working. P.K. M Mrsy, R.J.(1980) Taurine and hypotaurine: their effects on motility, capacitation and the acrosome reaction of hamster spem in witro and their presence in sperm and reproductive tract fluids of several mammals. Develop., Growth and Differ. 22,483-494.

Miller, J.G.O. Schultz, G.A. (1987) Amino acid content of preimplantation rabbit embryos amd fluids of the reproductive tract. Biol. Reprod. 36,125-129.

Mori, C. Hashimoto, H. \& Hoshino, K. (1988) Fuorescence microscopy of nuclear DNA in docytes and zygotes during in vitro fertilization and development of early embryos in mice. Biol Reprod. 39,737-742.

Mortimer, D.(1986) Elaboration of a new culture medium for physiological studies on human sperm motility and capacitation. Human Reprod. 1,247-250.

Mrsny, R.J., Waxman, L. \& Meizel, S.(1979) Taurime maintains and stimulates motility of hamster sperm during capacitation in witro. J. Exp. Zool 210,123-128.

Mrsny, R.J \& Meizel, S. (1985) Inhibition of hamster sperm $\mathrm{Na}^{*} \mathrm{~K}^{*}$-ATPase activity by taurine and hypotaurine. Life Sci. $36,271-275$ 
Qunn, P. Warnes, G.M. Kerin, J.F.\& Kirby, C.(1984) Culture factors in relation to the succes of human in vitro fertilization and embryo transfer. Fert. Steril, 41,202-209.

Quinn, P. Kerin, J.F. \& Warnes, G.M.(1985) Improved pregnancy rate in human in vitro fertilization with the use of a medium based on the composition of human tubal fluid. Fert. Steril, 44,493-498.

Roblero, L., Biggers, J.D. \& Lechene, C.P. (1976) Electron probe analysis of the elemental microenwirenmont of oviducal mouse embryos. J. Reprod. Fert: $46,431-434$.

Schultz, G.A. Kaye, P.L., Mckay, D.J \& Johnson, M.H. (1981) Endogenous amino acid pool sizes in mouse eggs and preimplantation embryos. $\Perp$ Reprod. Fert $61,387-393$.

Thomas, R.C. (1972) Electrogenic sodium pump in nerve and muscle cells. Physiol. Rev. 52, 563-594.

Velázquez, A., Delgado, N.M. \& Rosado, A.(1986) Taurine content and amino acid composition of human acrosome. Life Sci, 38,991-995.

Wales, R.G. \& Edirisinghe, W.R. (1989) Volume of fluid and concentration of cation and energy substrates in the uteri of mice during early pseudopregnancy. Reprod. Fertil. Dev. 1,171-178.

Wiley, L.M. Yamami, S. \& Van Muyden، D. (1986) Effect of potassium concentration, type of protein supplement, and embryo density on mouse preimplantation development in vitro. Fert. Steril. 45, 111-119. 


\section{Chapter 3}

\section{Temporal effects of taurine on mouse preimplantation development in vitro.}

John C.M. Dumoulin ${ }^{1}$, Johannes L.H. Evers`, Jaap A. Bakker ${ }^{2}$, Marijke Bras ${ }^{1}$, Math H.E.C. Pleters ${ }^{2}$, Joep P.M. Geraedts ${ }^{2}$

${ }^{1}$ Department of Obstetrics and Gynaecology, Academic Hospital Maastricht, University of Limburg, 6202 AZ, Maastricht and ${ }^{2}$ Department of Cell Biology and Genetics, University of Limburg, 6216 EA Maastricht, The Netherlands

Published in:

Human Reproduction, 7, 403-407, 1992 


\section{Summary}

Previously it has been shown that significantly more 2-cell mouse embryos reach th blastocyst stage when cultured in medium supplemented with taurine. In this study, in-viti fertilized zygotes from a hybrid mouse strain were used to examine the temporal effec of $10 \mathrm{mM}$ taurine on embryoric development in vitro during the preimplantation perio Taurine exerted its beneficial effect exclusively during the first 2 days post-inseminatio The effect of taurine on blastocyst formation appeared to be restricted mostly to the perio of 20 to $48 \mathrm{~h}$ after fertilization, during which time mouse embryos are at the two-cell stag. Although more blastocysts were found when embryos were cultured in taurine-containin medium from 5 to $20 \mathrm{~h}$ post-insemination, this difference was not significant compare to the number of blastocysts when embryos were cultured without taurine. Taurine dit not appear to affect the two-cell block of mouse embryos from random-bred strains.

\section{Introduction}

Taurine (2-aminoethanesulphonic acid) is a sulphur-containing $B$-amino acid which i: ubiquitously present in many mammalian tissues (Jacobsen and Smith, 1968). It is foun at high concentrations in human semen (Hernvann et al., 1986), human sperm acrosomes (Velázquez et al., 1986) and female reproductive tract fluids of several marmmalian species (Meizel et al., 1980; Cassién, 1987; Miller and Schultz, 1987; Dumoulin et al., 1992). Although: taurine has a role in electrolyte distribution (Welty et al., 1976) and osmoregulation (Thurston et al. 1981) in body fluids and tissues, the exact cellular function(s) of taurine are yet to be elucidated.

In the hamster, taurine was required in the medium in order to maintain sperm motility and to obtain optimal conditions for fertilization in vitro (Mrsny et al., 1979 ; Leibfried and Bavister, 1981, 1982). Less is known about the role of taurine in embryonic development during the preimplantation stages. In a previous study, a beneficial effect of taurine on the in-vitro preimplantation development of mouse zygotes was observed (Dumoulin el al., 1992).

The aim of the present study was to determine whether the presence of taurine was beneficial to mouse embryos at a specific time during preimplantation development. We also investigated whether taurine had any effect on the two-cell block of random-bred mouse embryos.

\section{Materials and methods}

\section{In vitro fertilization (IVF) and embryo culture}

For the first two experiments, examining the effect of taurine at different stages of preimplantation embryonic development (C57BI $\times$ DBA)F, hybrid female mice were used. For the experiments examining the effect of taurine on the two-cell block, random-bred CD-1 and NMRI females were used as 'blocking' mouse strains. In all experiments, CD-11 males were used. The mice were obtained from Charles River (Wiga, Sulzfeld, Germany). 
The in vitro fertilization (IVF) and embryo culture methods used have been described rreviously (Dumoulin et al., 1992). Briefly, oocytes were obtained after superovulating emale mice with $10 \mathrm{IU}$ pregnant mare's serum gonadotrophin (PMSG) and $10 \mathrm{U} U \mathrm{U}$ human shorionic gonadotrophin ( $h \mathrm{CG}$ ). After a $2 \mathrm{~h}$ sperm capacitation period, oocytes were nseminated with $2 \times 10^{6}$ motile caudal epididymal spermatozoa from a CD-1 male. Human ubal fluid (HTF) medium (Quinn et al., 1985) was used in all experiments. For IVF, the nedium contained $30 \mathrm{mg} / \mathrm{ml}$ bovine serum albumin (BSA) but for culturing of embryos, $5 \mathrm{mg} \mathrm{BSA} / \mathrm{ml}$ was used. Oocytes from different females were inseminated separately. Five I after insemination, oocytes from each female were distributed at random among the different experimental groups and were not pooled with oocytes from other females. In his way, the comparison between experimental groups was repeated in every female used.

Twenty-four hours after insemination, normal appearing two-cell embryos were counted. Jnly results from females who produced more than five two-cell embryos in each experimental group were used. At $125 \mathrm{~h}$ after insemination, the numbers of blastocysts were assessed. The percentages of embryos completing preimplantation development were calculated on the basis of the fertilization rate. The mean percentages \pm SEM (standard error of the nean) of embryonic development (number of blastocysts: per number of two-cell embryos) jer female was calculated for every experimental group. Statistical analysis of the data Nas performed using analysis of variance (ANOVA). When the effects of treatment were significant $(P<0.05)$, the multiple comparisons test according to Tukey was used to determine which means were significantly different (Fleiss, 1986).

\section{Effect of taurine on preimplantation embryos at different stages.}

To test whether taurine exerted its effect on embryo development during the early or the late preimplantation period, one group of embryos from each female was cultured in medium containing taurine from 5 to $48 \mathrm{~h}$ post-insemination, while a second group of embryos was cultured from $48 \mathrm{~h}$ until the end of the culture period in medium with taurine. Two other groups of embryos cultured with and without taurine added in the medium during the whole preimplantation period were used as controls. The embryos of the two control groups were transferred to fresh medium at the same time as embryos in the other two groups. In all experiments, the taurine concentration used was $10 \mathrm{mM}$.

The first series of experiments indicated an effect of taurine during the first 2 days of in vitro culture after insemination, so experiments were undertaken to establish whether the effect of taurine was maximal during the first or second day of culture. From 5 to 20 h post-insemination, one group of embryos from each female was cultured in medium containing taurine, while a second group was cultured from 20 to 48 hours post-insemination in medium with taurine. Two other groups of embryos were used as control groups as stated above.

\section{Effect of taurine on the two-cell block in vitro}

The effect of taurine on early and late preimplantation development of embryos from two random-bred strains was investigated. The experiments were conducted as explained above. In a second series of experiments, the effect of taurine was compared with the effect of $0.1 \mathrm{mM}$ ethylenediaminetetraacetic acid (EDTA). The two-cell block in-vitro of random-bred mouse embryos can be avoided by using this chelating agent (Abramczuk et al., 1977). 


\section{Results}

\section{Effect of taurine on early and late stages of preimplantation development}

Four replicate experiments (using seven or eight female mice per experiment) were performed. For eight females, inseminating and distributing the oocytes among the experimental groups did not result in at least five two-cell embryos in each group. The results of those females therefore were not included in these experiments. From the 21 remaining females, 876 oocytes were obtained (mean number of oocytes per female \pm standard deviation (SD) $41.7 \pm 11.5$ ), which were divided, $5 \mathrm{~h}$ after insemination, among the four groups. The mean fertilization rate per female (total number of two-cell embryos/total number of oocytes, counted at $24 \mathrm{~h}$ after insemination) was $0.75 \pm 0.24$; no significant difference between the four groups was observedl (data not shown).

Table 1 shows that the presence of $10 \mathrm{mM}$ taurine either in the first 2 days post-insemination, or throughout the preimplantation period, gave high rates of development of the zygotes into blastocysts compared to development in medium without taurine. The beneficial effect of taurine was already noticeable at the four-cell stage. The presence of taurine only from $48 \mathrm{~h}$ post-insemination onwards did not result in a higher rate of blastocyst formation.

Table 1. Effect of taurine on early and late stages of preimplantation development of mouse zygotes from a hybrid strain cultured in vitro

\begin{tabular}{|c|c|c|c|c|}
\hline \multirow{2}{*}{$\begin{array}{l}\text { Period of } \\
\text { culture } \\
\text { in } 10 \mathrm{mM} \\
\text { taurine } \\
\end{array}$} & \multirow[b]{2}{*}{$\begin{array}{l}\text { No, two-cell } \\
\text { embryos }\end{array}$} & \multicolumn{3}{|c|}{ Mean embryonic development per female $\pm S E M^{C}$} \\
\hline & & $\begin{array}{l}\text { Day } 3^{\text {b }} \\
\text { four }- \text { cell embryos }\end{array}$ & $\begin{array}{l}\text { Day } 4^{b} \\
\text { morullae }\end{array}$ & $\begin{array}{l}\text { Day } 5^{\text {b }} \\
\text { blastocysts }\end{array}$ \\
\hline No taurine & 160 & ${ }^{9} 0.69 \pm 0.06$ & ${ }^{1} 0.38 \pm 0.06$ & $0.19 \pm 0.05$ \\
\hline $5-125$ & 163 & ${ }^{2} 0.84 \pm 0.06$ & ${ }^{2} 0.70 \pm 0.07$ & ${ }^{2} 0.57 \pm 0.07$ \\
\hline $5-48$ & 173 & ${ }^{2} 0.90 \pm 0.03$ & ${ }^{2} 0.83 \pm 0.04$ & ${ }^{2} 0.59 \pm 0.05$ \\
\hline $48-1.25$ & 167 & ${ }^{1} 0.68 \pm 0.05$ & ${ }^{10} 0.50 \pm 0.05$ & ${ }^{10} 0.29 \pm 0.04$ \\
\hline
\end{tabular}

"Howrs post-insemination.

DDays post-insemination, day of insemination is day" 1 .

${ }^{C}$ ANOVA: $P<0.001$, within a column, means with different superscripts are significantly different.

\section{Effect of taurine during the first two cleavage divisions}

Five replicate experiments (using five to seven females per experiment) were performed. The results from six females were not included in these experiments because of an insufficient number of two-cell embryos. From the 25 remaining females, 973 oocytes were obtained (mean number of oocytes per female $\pm \mathrm{SD}=38.9 \pm 9.8$ ) and divided among the four groups at $5 \mathrm{~h}$ after insemination. The mean fertilization rate per female was $0.82 \pm 0.19$. No significant differences in the fertilization rate between the four groups were observed (data not shown). 
Culturing embryos in the presence of taurine between 20 and $48 \mathrm{~h}$ after insemination gave results comparable to those obtained by culturing embryos in the presence of taurine during the complete preimplantation period (Table 2). As with the effect of taurine on the early and late stages of preimplantation development, this beneficial effect was already noticeable at the four-cell stage. The presence of taurine between 5 and $20 \mathrm{~h}$ after insemination also resulted in a higher frequency of blastocyst formation as compared to medium without taurine, but the difference was not significant.

Table 2. Effect of taurine during the first two cleavage divisions of mouse zygotes from a hybrid strain cultured in viltro

\begin{tabular}{|c|c|c|c|c|}
\hline \multirow{2}{*}{$\begin{array}{l}\text { Period of } \\
\text { culture } \\
\text { in } 10 \mathrm{mM} \\
\text { taurine }\end{array}$} & \multirow[b]{2}{*}{$\begin{array}{l}\text { No. two-cell } \\
\text { embiryos. }\end{array}$} & \multicolumn{3}{|c|}{ Mean embryonic development per female \pm SEM ${ }^{\circ}$} \\
\hline & & $\begin{array}{l}\text { Day } 3^{\mathrm{b}} \\
\text { four-cell embryos }\end{array}$ & $\begin{array}{l}\text { Day } 4^{\$} \\
\text { morulae }\end{array}$ & $\begin{array}{l}\text { Day } 5^{10} \\
\text { blastocysts }\end{array}$ \\
\hline No taurine & 199 & ${ }^{1} 0.77 \pm 0.05$ & $0.49 \pm 0.05$ & $0.34 \pm 0.05$ \\
\hline $5-125$ & 191 & $20.94 \pm 0.02$ & ${ }^{2} 0.82 \pm 0.04$ & ${ }^{2} 0.69 \pm 0.04$ \\
\hline $5-20$ & 199 & $1.20 .81 \pm 0.04$ & $0.62 \pm 0.05$ & $1.20 .46 \pm 0.04$ \\
\hline $20-48$ & 195 & $10.93 \pm 0.03$ & ${ }^{2} 0.82 \pm 0.04$ & ${ }^{2} 0.63 \pm 0.05$ \\
\hline
\end{tabular}

Hours post-insemination.

Days post-insemination, day of insemination is day 1.

AlwOVA: $P<0.001$ : within a column, means with different supersicripts are significantly different.

\section{Effect of taurine on the two-cell block in vitro}

To examine the effect of taurine on the early and late stages of preimplantation development of zygotes from random-bred mouse strains, three replicate experiments were performed using per experiment three to five of the two mice strains. The results of one CD-1 and four NMRI females were not included in these experiments because of an insufficient number of 2-cell embryos. From the remaining nine CD-1 and $10 \mathrm{NMRI}$ females. 343 and 469 oocytes were abtained respectively (mean number of oocytes per female $\pm S D=C D-1,38.1 \pm 13.3$; NMRI, $46.9 \pm 15.8$ ) and divided among the four experimental groups at $5 \mathrm{~h}$ after insemination. The mean fertilization rate per female $\pm S D$ was $0.76 \pm 0.20$ for CD-1 and $0.59 \pm 0.25$ for $\mathrm{NMRI}$; no significant differences in the fertilization rate among the four groups were observed (data not shown). As shown in Table 3, the blastocyst formation rate of the in vitro fertilized zygotes of the random-bred mice was very low. Most of the embryos remained 'blocked' at the 2-cell stage. The presence of taurine did not have any significant effect on blastocyst formation in any of the culture periods. 
To investigate further the effect of taurine on the 2-cell block in vitro, one group of embryos was cultured in the presence of EDTA in the next experimental series. Three replicate experiments (using three to four CD-1 females per experiment) were performed. The results of two females were not included in these experiments because of an insufficient number of 2-cell embryos. From the nine remaining females, 384 oocytes were obtained (mean number of oocytes per female $\pm S D=42.7 \pm 12.7$ ) and divided among the three groups at $5 \mathrm{~h}$ after insemination. The mean fertilization rate per female was $0.91 \pm 0.10(\mathrm{SD})$. Table 4 shows that supplementation of the medium during the entire culture period with EDTA resulted in a high blastocyst formation, whereas the embryos cultured in the presence of taurine could not overcome the 2-cell block.

Table 3. Effect of taurine on early and late stages of preimplantation development of mouse zygotes from random-bred strains cultured in vitro

\begin{tabular}{|c|c|c|c|c|}
\hline \multirow{2}{*}{$\begin{array}{l}\text { Period of } \\
\text { culture } \\
\text { in } 10 \mathrm{mM} \\
\text { taurine }^{\mathrm{B}}\end{array}$} & \multirow[b]{2}{*}{$\begin{array}{l}\text { No two-cell } \\
\text { embryos }\end{array}$} & \multicolumn{3}{|c|}{ Mean embryonic development per female $\pm S E M^{c}$} \\
\hline & & $\begin{array}{l}\text { Day } 3^{\mathrm{b}} \\
\text { fouri-cell embryos }\end{array}$ & $\begin{array}{l}\text { Dalay } 4^{\text {to }} \\
\text { morulae }\end{array}$ & $\begin{array}{l}\text { Day } 5^{\text {b }} \\
\text { blastocysts }\end{array}$ \\
\hline \multicolumn{5}{|l|}{ CD-1 mice } \\
\hline No taurine & 71 & $0.29 \pm 0.09$ & $0.20 \pm 0.08$ & $0.02 \pm 0.02$ \\
\hline $5-125$ & 52 & $0.32 \pm 0.09$ & $0.18 \pm 0.06$ & $0.07 \pm 0.03$ \\
\hline $5-48$ & 65 & $0.42 \pm 0.07$ & $0.26 \pm 0.08$ & $0.14 \pm 0.06$ \\
\hline $48-125$ & 59 & $0.23 \pm 0.08$ & $0.10 \pm 0.04$ & $0.00 \pm 0.00$ \\
\hline \multicolumn{5}{|l|}{ NMRI mice } \\
\hline No taurine & 71 & $0.34 \pm 0.05$ & $0.16 \pm 0.06$ & $0.07 \pm 0.05$ \\
\hline $5-125$ & 77 & $0.38 \pm 0.02$ & $0.22 \pm 0.04$ & $0.09 \pm 0.05$ \\
\hline $5-48$ & 62 & $0.49 \pm 0.05$ & $0.26 \pm 0.05$ & $0.12 \pm 0.04$ \\
\hline $48-125$ & 65 & $0.36 \pm 0.03$ & $0.17 \pm 0.04$ & $0.09 \pm 0.05$ \\
\hline
\end{tabular}

${ }^{a}$ Hours post-insemination.

"Days post-insemination "day of insemination is day 1.

ANOVA: not significant.

Table 4. Effect of taurine on the two-cell block of mouse zygotes from random-bred strains cultured in vitro

\begin{tabular}{|c|c|c|c|c|}
\hline \multirow{2}{*}{$\begin{array}{l}\text { Supplement } \\
\text { to the } \\
\text { culture } \\
\text { medium }\end{array}$} & \multirow[b]{2}{*}{$\begin{array}{l}\text { No. two-cell } \\
\text { embryos }\end{array}$} & \multicolumn{3}{|c|}{ Mean embryonic development per female $\pm S E M^{D}$} \\
\hline & & $\begin{array}{l}\text { Day } 3^{\text {a }} \\
\text { four-cell embryos }\end{array}$ & $\begin{array}{l}\text { Day } 4^{a} \\
\text { morulae }\end{array}$ & $\begin{array}{l}\text { Day } 5^{\mathrm{a}} \\
\text { blastocysts }\end{array}$ \\
\hline Nane & 100 & $0.26 \pm 0.11$ & $0.11 \pm 0.05$ & $10.03 \pm 0.02$ \\
\hline $10 \mathrm{mM}$ taurine & 97 & ${ }^{1} 0.27 \pm 0.06$ & $0.18 \pm 0.04$ & $10.09 \pm 0.05$ \\
\hline $0.1 \mathrm{mM}$ EDTA & 107 & ${ }^{2} 0.75 \pm 0.09$ & ${ }^{2} 0.70 \pm 0.09$ & ${ }^{2} 0.51 \pm 0.11$ \\
\hline
\end{tabular}

Days post-insemination, dlay of insemination is day 1.

BANOVA: P $<0.001$ within a column, means with different superscripts are significantly different. EDTA = ethylenediaminetetraacetic acid. 


\section{Discussion}

In the experiments using embryos from a hybrid strain, comparing the two control groups of embryos cultured with and without $10 \mathrm{mM}$ taurine throughout the preimplantation period, culture in medium with taurine resulted in a significantly higher rate of blastocyst formation. This finding confirms our earlier observations (Dumoulin et al . 1992).

The blastocyst formation rate in medium without taurine was rather low. In our experience, mouse embryo development in HTF medium is lower than in T6 medium (Dumoulin et al. 1992). In the present study, we chose HTF because the effect of taurine is more pronounced in this medium than in T6 medium.

Taurine exerts its beneficial effect on mouse embryo development exclusively in the first two days post-insemination. Within this time periad "the effect of taurine on the blastocyst formation appears to be restricted mostly to the period of $20-48$ h after fertilization: $a$ time period which coincides roughly with the two-cell stage. In the mouse, the first cleavage division takes place at 18-22 h after insemination in vitro (Howlett and Bolton, 1985), whereas at $48 \mathrm{~h}$ after insemination most embryos will be at the early 4 -cell stage (Flach et al., 1982).

It is not unlikely that a compound which exerts such a marked effect on mouse embryo development during the 2-cell stage, should also influence the 2-cell block in vitro. This developmental block, which mouse embryos from random-bred strains exhibit at the late two-cell stage, is probably related to the activation of the embryonic genome which is known to be occurring at that time (Goddard and Pratt, 1983; Bavister, 1988\%. However, it is clear from the results presented here that taurine has no effect on the 2 -cell block in vitro. Thus taurine appears to exert its beneficial effect on mouse embryonic development by a mechanism different from that responsible for the blocking of random-bred mouse embryos.

It is well known that embryonic development can be influenced by a brief exposure of the embryo to a certain stimulus at a confined, critical, developmental stage. Indeed, embryonic development is a dynamic process. During the preimplantation period as the embryo is transported through the oviduct, it has to adapt to constantly changing environmental conditions, in terms of volume, ionic and nutrient composition (Leese, 1988). Concentrations of $\mathrm{K}^{+}$(Borland et all., 1977; Wales and Edirisinghe, 1989), mutrients (Gardner and Leese, 1990; Wales and Edirisinghe, 1989) and amino acids (Casslén, 1987, Miller and Schultz, 1987) vary strongly between different regions of the tract, different days of the cycle and different days after fertilization. Taurine has been found in human uterine fluid in high concentrations, varying from $7.7 \mathrm{mM} / \mathrm{l}$ in the follicular phase of the menstrual cycle, to $4.2 \mathrm{mM} / \mathrm{l}$ at mid-cycle and $11.7 \mathrm{mM} / \mathrm{l}$ in the luteal phase, (Casslen, 1987).

The embryo itself undergoes major changes between the early cleavage and the blastocyst stage and has special requirements at every developmental stage for certain compounds in its surrounding milieu. During this period of just a few days, mammalian embryos are known to switch from maternal to embryonic genome control (Bolton et al., 1984) and from energy metabolism based on pyruvate to one based upon glucose (Gardner and Leese, 1986). During the 1- and 2-cell stages, mouse embryonic development is very sensitive to adverse in- vitro culture conditions such as fluctuations of $\mathrm{pH}$ (Davidson et al., 1988a), osmolality (Davidson et al., 1988b) and the presence of certain compounds such as purines Nureddin et al. 1990).

The fact that conventional in vitro culture conditions cannot provide embryos with the right stimuli or compounds at the right time is illustrated by the developmental block many mammalian embryos show in vitro (Bavister, 1988). Embryonic development in conventional culture media is either limited, as in the human (Bolton et al., 1989\%, or stops at the 2-cell 
stage (rat), 4-cell stage (pig) or 8- to 16-cell stage (cattle and sheep) (Bavister, 1988). In mice, the development of embryos from random-bred strains is arrested at the two-cell stage (Goddlard and Pratt, 1983).

The precise nature of the action of taurine on the mouse embryonic development is as yet unknown. Taurine has been shown that to decrease the activity of the plasma membrane $\mathrm{Na}^{+}-\mathrm{K}^{+}$-ATPase of hamster spermatozoa in a dose-dependent manner (Mrsny and Meizel, 1985). These authors suggested that taurine protects spermatozoa against high $\mathrm{K}^{*}$ concentrations by reducing the $\mathrm{Na}^{+}-\mathrm{K}^{*}-\mathrm{ATP}$ ase activity and consequently the influx of extracellular $\mathrm{K}$. Whether the stimulating effect of taurine on mouse embryonic development is exerted by the same mechanism remains to be determined.

Taurine is present in high concentrations in fluids of the mammalian reproductive tract. In the mouse, taurine was found to comprise $\approx 17 \%$ of the total free amino acid content in serum, whereas it amounted to $59 \%$ in samples obtained from oviduct flushing (Dumoulin et al., 1992). Since, to our knowledge, no data are available on the exact concentration of taurine in the oviductal fluid of the mouse, no comparison can be made between our in-vitro concentration of $10 \mathrm{mM}$ and the in-vivo concentration. Some evidence, however, that this taurine concentration is not unphysiological, can be derived from the data on the taurine concentration in human uterine fluid (varying from $4.2 \mathrm{mM}$ to $11.7 \mathrm{mM}$; Casslén, 1987). As $\mathrm{K}^{*}$ is also present in high concentrations in mammalian reproductive tract fluids (Borland et al., 1977; Wales and Edirisinghe, 1989), it can be hypothesized that taurine protects embryos against high $\mathrm{K}^{+}$levels in vivo. We are currently investigating the interaction of taurine and $\mathrm{K}^{+}$during the in vitro development of mouse embryos.

\section{References}

Abramczuk, J, Solter, D. and Koprowski,H. (1977) The beneficial effect of EDTA on development of mouse one-cell embryos in chemically defined medium. Dev. Biol., 61, 378-383.

Bavister, B.D. (1988) Role of oviductal secretions in embryonic growth in wivo and in vitro. Theriogenology 29, 143-154.

Bolton, V.N. Dades, P.J. and Johnson, M.H. (1984) The relationship between cleavage. DNA replication, and gene expression in the mouse 2-cell embryo. J, Embryol exp. Morph., 79, 139-163

Bolton, V.N. Hawes,S.M., Taylor, C.T. and Parsons, J.H. (1989) Development of spare human preimplantation embryos in vitro: an analysis of the correlations among gross morphology, cleavage rates. and development to the blastocyst. J. In Vitro Fert Embryo Transfer, 6, 30-35.

Borland, R.M., Hazra, S., Biggers, J.D. and Lechene,C.P. (1977) The elemental composition of the environments of the gametes and preimplantation embryo during the initiation of pregnancy. Biol. Reprodl., $16,147-157$.

Casslén, B. G. (1987) Free amino acids in human uterine fluid. J. Reprod. Med, 32, 181-184

Davidson, $A$, Vermesh, M. Lobo, R.A. and Paulson, R.J. (1988a) Mouse embryo culture as quality control for human in vitro fertilization: the one-cell versus the two-cell model. Fertil. Steril, 49, 516-521

Davidson, A. Vermesh,M., Lobo,R.A. and Paulson .R.J. (1988b) The temporal effects of changes in in vitro fertilization culture media on the one-cell mouse embryo system. J. In Vitro Fert. Embryo Transfer $5,149-152$

Dumoulin,J.G.M., Evers,J.L.H. Bras,M., Pieters,M.H.E.C. and Geraedts,J.P.M. Positive effect of taurine on preimplantation development of mouse embryos in vitro. J.Reprod. Fertil., in press.

Flach,G., Johnson,M.H., Braude,P.R., Taylor,R.A.S. and Bolton, V.N. (1982) The transition from maternal to embryonic control in the 2-cell mouse embryo. EMBO J., 1, 681-686

Fleiss, J.L. (1986) The design and analysis of clinical experiments. Wiley \& Sons, New York.

Gardner,D.K. and Leese,H.J. (1986) Non-invasiwe measurement of nutrient uptake by single cultured pre-implantation mouse embryos. Hum. Reprod., 1, 25-27. 
Gardner, D.K. and Leese, H.J. (1990) Concentrations of nutrients in mouse oviduct fluid and their effects on embryo development and metabolism in vitro. J Reprod Fert., 88, 361-368.

Goddard,M.J. and Pratt,H.P.M. (1983) Control of events during early cleavage of the mouse embryo: an analysis of the 2-cell block'. J Embryol.exp. Morph., 73, 111-133

Hernvanrs, A, Gonzales,J., Troupel, S, and Galli,A. (1986) Amino acid content of human semen in normal and infertility cases. Andrologia $18,461-469$.

Howlett, S.K. and Bolton, V.N. (1985) Sequence and regulation of morphological and molecular events during the first cell cycle of mouse embryogenesis. $J$. Embryol. exp. Morph. 87, 175-206.

Jacobsen,J.G. and Smith,L.H. (1968) Biochemistry and physiology of taurine and taurine derivatives. Physiol. Rev, 48, 424-511

Leese,H.J. (1988) The formation and function of oviduct fluid. J Reprod Fert, 82, 8.43-856.

Leibfried,M.L. and Bavister,B.D. (1981) The effects of taurine and hypotaurine on in vitro fertilization in the golden hamster. Biol. Reprod., 4, 57-63.

Leibfried, M.L. and Bavister, B.D. (1982) Effects of epinephrine and hypotaurine on in-vitro fertilization in the golden hamster. J Reprod. Fert., 66, 87-93.

Meizel,S. Lui, C.W. Working,P.K. and Mrsmy, R.J. (1980) Taurine and hypotaurine: their effects on motility, capacitation and the acrosome reaction of hamster sperm in witro and their presence in sperm and reproductive tract fluids of several mammals. Develop. Growth and Differ., 22, 483-494.

Miller, J.G.O. and Schultz,G.A. (1987) Amino acid content of preimplantation rabbit embryos and fluids of the reproductive tract. Biol. Reprod., 36, 125-129.

Mrsny,R.J., Waxman,L. and Meizel,S. (1979) Taurine maintains and stimulates motility of hamster sperm during capacitation in vitro. J. Exp. Zool., 210, 123-128.

Mrsny,R.J. and Meizel,S. (1985) Inhibition of hamster sperm Na", $\mathrm{K}^{*}$-ATPase activity by taurine and hypotaurine. Life Sci. 36, 271-275.

Nureddin,A., Epsaro $E$. and Kiessling,A.A. (1990) Purines inhibit the develapment of mouse embryos in vitro. J.Reprod. Fert., 90, 455-464.

Quinn,P., Kerin, J.F. and Warnes, G.M. (1985) Improved pregnancy rate in human in vitro fertilization with the use of a medium based on the composition of human tubal fluid. Fertil. Steril., 44, 493-498.

Thurston, J.H. Hauhart, R.E. and Naccarato,E.F. (9981) Taurine: possible role in asmotic regulation of mammalian heart. Science, 214, 1373-1374.

Velázquez,A., Delgado, N.M. and Rosado,A, (1986) Taurine content and amino acid composition of human acrosome. Life Sci, 38, 991-995.

Wales, R.G. and Edirisinghe, W.R. (1989) Volume of fluid and concentration of cation and energy substrates in the uteri of mice during early pseudopregnancy. Reprod. Fertil. Dev., 1, 171-178.

Welty, J.D. McBroom,M.J., Appelt,A.W. Peterson,M.B. and Read,W.O. (1976) Effect of taurine on heart and brain, electrolyte imbalances. In Huxtable, R. and Barbeau,A. (eds.), Taurine. Raven Press, New York, p. 155. 
(2)

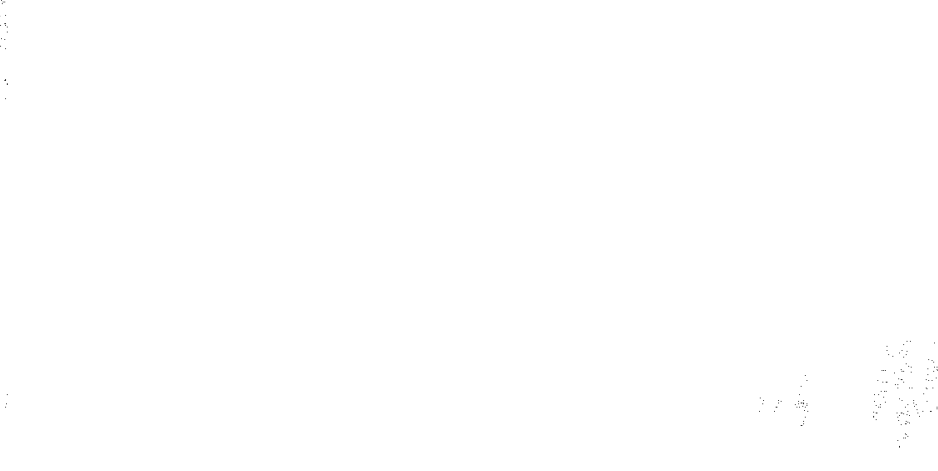




\section{Chapter 4}

\section{Modulation of embryonic $\mathrm{Na}^{+}-\mathrm{K}^{+}-\mathrm{ATPase}$ activity and mouse preimplantation development in vitro in media containing high concentrations of potassium.}

John C.M. Dumoulin', Johannes L.H. Evers', Anton H.J.C. Michiels', Math H.E.C. Pieters', Marijke Bras", Jolande A. Land ${ }^{1}$ and Joep P.M. Geraedts ${ }^{2}$

Departments of 'Obstetrics/Gynaecology and ${ }^{2}$ Molecular Cell Biology/Genetics, Academic Hospital Maastricht, University of Limburg, Maastricht, The Netherlands.

Published in:

Molecular Reproduction and Development, 36, 320-327 (1993) 


\section{Summary}

The effect of various potassium concentrations (ranging from $1.4 \mathrm{mM}$ to $30 \mathrm{mM} \mathrm{K}$ ) in modified Tyrode's medium on the culture of mouse zygotes obtained after in vitro fertilization to the blastocyst stage was examined. A clear dose-dependent negative effect of increasing $K+$ concentrations on the preimplantation embryonic development in vitro was found. We have previously shown that significantly more two-cell embryos reach the blastocyst stage when cultured during the second day postinsemination in medium supplemented with taurine. Because taurine, an amino acid that abounds in the reproductive tract, has been reported to inhibit the enzyme $\mathrm{Na}^{*}-\mathrm{K}^{*}$-adenosine triphosphatase ( $\mathrm{Na}^{*}-\mathrm{K}^{*}$-.ATPase), we used two other conditions known to inhibit the $\mathrm{Na}^{*}-\mathrm{K}^{*}$-ATPase to study their effect on mouse embryo development. Culturing embryos during a short period (the second day postinsemination) in low extracellular $K^{*}$ concentrations $(1.4 \mathrm{mM}$ ) or in medium supplemented with ouabain $(50 \mu \mathrm{M})$ showed positive effects similar to those of culturing in medium with taurine (10 $\mathrm{mM}$ ). This beneficial effect of ouabain was found in various $K^{*}$ concentrations tested, including the high concentrations present in the oviduct. Although the effects of low $\mathrm{K}^{+}$and taurine can possibly be ascribed to their other cellular effects, the effect of ouabain shows that inhibition of the $\mathrm{Na}^{*}-\mathrm{K}^{*}-\mathrm{ATP}$ ase during the two-cell stage in the mouse is beneficial for further embryonic development to the blastocyst stage.

\section{Introduction}

Taurine is a sulfur-containing B-amino acid ubiquitously present in many mammalian tissues (Jacobsen and Smith, 1968; Huxtable, 1992). It is the most abundant free amino acid in cardiac tissue (Huxtable, 1976) and is also present at high concentrations in female reproductive tract fluids of several mammalian species (Meizel et al., 1980; Cassièn, 1987; Miller and Schultz, 1987; Dumoulin et al., 1992b).

It has been reported that in the hamster taurine is required in the medium to maintain spermatozoal motility and to obtain optimal fertilization conditions in vitro (Mrsny et al. 1979; Leibfried and Bavister, 4981, 1982). The in vitro development of hamster embryos was shown to be absolutely dependent on hypotaurine, a precursor of taurine (Barnett and Bavister, 1992). In a previous study (Dumoulin et al., 1992b), we have shown that, also in the mouse, supplementing the culture medium during the preimplantation period with taurine leads to a higher incidence of blastocyst formation. This beneficial effect of taurine on mouse embryonic development was found to be more pronounced in medium with $5 \mathrm{mM} \mathrm{K}$ " compared to medium with $1.4 \mathrm{mM} \mathrm{K}$. In a related study, the temporal effects of taurine on mouse preimplantation development were examined (Dumoulin et al. 1992a): taurine was found to exert its beneficial effect exclusively during the first 2 days of embryonic development, the effect being most pronounced on the second day postinsemination (pi).

Although it has been shown that taurine has a role in electrolyte distribution (Welty ef al. , 1976) and osmoregulation (Thurston et al., 1981) in body fluids and tissues, the exact cellular function(s) of taurine is yet to be elucidated. Mrsny and Meizel (1985) showed that taurine decreased the sperm-membrane enzyme $\mathrm{Na}^{*}-\mathrm{K}^{*}$-ATPase activity in a dose-dependent manner. $\mathrm{Na}^{*}-\mathrm{K}^{+}-\mathrm{ATP}$ ase is a membrane-bound enzyme controlling the intracellular $\mathrm{Na}^{+}$ and $\mathrm{K}^{+}$levels by exchanging extracellular $\mathrm{K}^{+}$ions for intracellular $\mathrm{Na}^{+}$ions (Rossier et al., 1987). This enzyme plays an important role in late preimplantation development; it has 
been shown to be involved in the fluid accumulation resulting in the formation of the blastocoel cavity (Biggers et al. 1988 ). The activity of the $\mathrm{Na}^{*}-\mathrm{K}^{*}$-ATPase can directly be modulated by its ligands, $\mathrm{Na}^{+}, \mathrm{K}^{*}$, and ATP, and indirectly by hormones and growth factors (Rossier et al., 1987). The enzyme can be inhibited by low extracellular potassium concentrations (Eisner and Lederer, 1979) and by the cardioactive steroid ouabain (Anner, 1985).

The environment in which the embryonic development in the mammalian reproductive tract takes place is characterized by high concentrations of $K^{*}$ ions. In the human, the concentration of $\mathrm{K}^{+}$in oviduct fluid (Borland et al., 1980) as well as in uterine fluid (Casslén and Nilsson, 1984) has been shown to be in the range of $20 \mathrm{mM}$, which is about five times. higher than the concentration in human plasma. In the mouse, the $K^{+}$concentration in oviduct fluid was found to vary during the oestrus cycle from $18 \mathrm{mM}$ to $30 \mathrm{mM}$ (Roblero et al. 1976 ; Borland et all. 1977). During pseudopregnancy, mouse uterine fluid had a very high $\mathrm{K}^{+}$ content, ranging from $35 \mathrm{mM}$ on day 1 to $75 \mathrm{mM}$ on day 5 (Wales and Edirisinghe, 1989). In contrast, the in vitro development of mouse one-cell embryos to the blastocyst stage is optimal in media with low $\mathrm{K}^{*}$ concentrations (Wiley, 1984; Wiley et al., 1986; Lawitts and Biggers, 1991). In that taurine is also present in high concentrations in mammalian reproductive tract fluids, it has been hypothesized that taurine might protect spermatozoa and embryos against the high $\mathrm{K}^{+}$levels by reducing the $\mathrm{Na}^{*}-\mathrm{K}^{+} \mathrm{ATP}$ ase activity and thereby the influx of extracellular $\mathrm{K}^{+}$(Mrsny and Meizel, 1985; Dumoulin et al., 1992b).

The first aim of the present study was to examine the effect of culturing mouse embryos during a short time period in the early preimplantation period (the second day pi) under two conditions known to inhibit the $\mathrm{Na}^{+}-\mathrm{K}^{*}$-ATPase (low extracellullar $\mathrm{K}^{*}$ concentrations and ouabain) on their subsequent development in medium containing $5 \mathrm{mM} \mathrm{K}$, a concentration similar to that in serum and in most embryo culture media. The second aim was to evaluate the effect of taurine, ouabain, and low extracellular $\mathrm{K}^{*}$ (applied again only during the second day pi) on mouse embryonic development in various potassium concentrations, including the high concentrations present in the oviduct.

\section{Materials and methods}

\section{In vitro fertilization (IVF) and embryo culture}

In all experimental series, mouse zygotes were obtained after IVF and distributed to different treatments at $5 \mathrm{~h}$ pi. Our IVF and embryo culture methods have been described previously (Dumoulin et al., 1992a, b). Briefly, oocytes from (C57BI x DBA) $\mathbb{F} 1$ females were obtained after superovulation with $10 \mathrm{IU}$ pregnant mare's serum gonadotropins (PMSG) and 10 IU human chorionic gonadotropins (hCG). Oocytes were inseminated with 2 million motile caudal epididymal sperm from one CD-1 male, which were capacitated for $2 \mathrm{~h}$. All mice used in this study were obtained from Charles River Wiga (Sulzfeld, Germany). Chemicals were obtained from Sigma (St. Louis, MO) unless stated otherwise. The basic recipe of all media used was that of T6 medium (Quinn et al., 1985), except for $\mathrm{NaCl}$ and $\mathrm{KCl}$. The concentrations of these ions in the different experiments are described below. The osmolality of all media was adjusted to $280-285 \mathrm{mOsm} / \mathrm{kg}$ before use. For IVF, standard T6 medium $(1.4 \mathrm{mM} \mathrm{KCl})$ was used in all experiments, supplemented with $30 \mathrm{mg} / \mathrm{ml}$ bovine serum albumin (BSA). For embryo culture, $5 \mathrm{mg} / \mathrm{ml}$ BSA was used. Three experimental series were performed as described below. In each series, several replicate experiments were performed on different days. Oacytes and embryos from different females were not pooled 
but inseminated and cuftured separately. In this way; the comparison between different experimental media is repeated in every femalle used. Five hours pi, zygotes of each female were washed once and distributed at random over a set of the different experimental media. Twenty-four hours $\mathrm{pl}$, normally appearing two-cell embryos were counted for the calculation of the fertilization rate. Only results from females who produced more than five two-cell embryos in each experimental group were used. At $120 \mathrm{~h}$ pi, the numbers of blastocysts were assessed.

\section{Experimental design.}

In all experimental series, the period in which embryos were subjected to experimental conditions known to inhibit the $\mathrm{Na}^{*}-\mathrm{K}^{*}$-ATPase was $22-46 \mathrm{~h}$ pi. In series $1 \mathrm{~A}$, all groups of embryos were cultured in medium containing $5 \mathrm{mM} \mathrm{K} \mathrm{K}^{+}$from $5-22 \mathrm{~h}$ pi and from $46-120$ h pi. In the period 22-46 h pi, the groups of embryos were transferred to medium containing either of the following $\mathrm{K}^{*}$ concentrations: $0.6,0.9,1.1,1.4$, or $5.0 \mathrm{mM}$. In series $1 \mathrm{~B}$, all groups of embryos were cultured in medium containing $5 \mathrm{mM} \mathrm{K}$ from 5 to $120 \mathrm{~h}$ pi. In the period $22-46 \mathrm{~h}$ pi, the embryos were transferred to fresh medium containing ouabain in either of the following concentrations: $0,5,50$, or $500 \mu \mathrm{M}$. Series $1 \mathrm{C}$ was conducted exactly as series $1 \mathrm{~B}$ exept that the effect of ouabain was studied in more detail using the following concentrations: $0,25,50$, and $100 \mu \mathrm{M}$. All embryos from this series developing a distinct blastocoel at $120 \mathrm{~h}$ pi were fixed and spread on microscope slides and stained with Giemsa [British Drug Houses (BDH) Poole, England] as described by Kola and Folb (1985). The number of nuclei stained with Giemsa was taken as the number of cells of the blastocyst. The mitotic index was defined as the number of metaphases per blastocyst divided by the number of cells per blastocyst. Averages were calculated for all embryos of the experimental groups.

In series $2 \mathrm{~A}$, oocytes from each female were divided into five groups and cultured during from 5 to $120 \mathrm{~h}$ pi in either of the following $\mathrm{K}^{+}$concentrations: 1.4 (standard T6), 5,10 , 20 , or $30 \mathrm{mM}$. NaCl was added to each medium until the sum of $\mathrm{Na}^{+}$and $\mathrm{K}^{+}$was 150.5 $\mathrm{mM}$ (as in standard T6). Between 22 and $46 \mathrm{~h}$ pi, embryos were cultured in fresh medium with the same constitution. Series $2 \mathrm{~B}$ was conducted exactly as series $2 \mathrm{~A}$ exept that in the period $22-46 \mathrm{~h}$ pi $10 \mathrm{mM}$ taurine was added to the five different $\mathrm{K}^{*}$-media, and the osmalality of these media was adjusted to $280-285 \mathrm{mOsm} / \mathrm{kg}$ by replacing a small amount

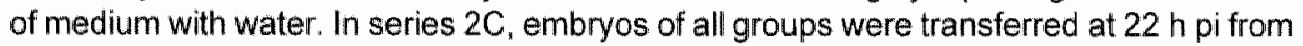
their media containing various $\mathrm{K}^{+}$concentrations to low- $\mathrm{K}^{+}$medium $(1.4 \mathrm{mM})$ and were transferred back to their original media at $46 \mathrm{~h}$ pi. Series $2 \mathrm{D}$ was conducted exactly as series $2 A$ exept that in the period $22-46$ h pi 50 HM ouabain was added to the five different $K^{*}$-media.

In series $3 A-C$, oocytes were divided into faur groups, two groups being cultured in $10 \mathrm{mM} \mathrm{K}^{*}$, the other two in $20 \mathrm{mM} \mathrm{K}^{+}$. Between 22 and $46 \mathrm{~h}$ pi for each $\mathrm{K}^{+}$concentration. one group was cultured in fresh medium with the same $\mathrm{K}^{+}$concentration, while the other group was treated as follows: in series $3 \mathrm{~A}$, culture in fresh medium with the same constitution with $10 \mathrm{mM}$ taurine added; in series $3 \mathrm{~B}$, culture in low-K* medium (1.4 mM); and, in series $3 C$, culture in fresh medium of the same constitution with $50 \mu \mathrm{M}$ ouabain added. 


\section{Statisticall analysis}

The mean percentages \pm standard errors of the mean (SEM) of embryonic development (No. blastocysts/No. two-cell embryos) per female were calculated for every experimental group. For statistical analysis, the data were subjected to arcisine transformation and an analysis of variance (ANOVA) for a randomized blocks experiment was used (Fleiss, 1986). When the ANOVA test showed significant differences $(P<0.05)$, differences between individual treatments were evaluated using the multiple comparisons test according to Tukey for experiments in which many treatment means were compared or the Bonferroni test for experiments in which only a few possible comparisons were of interest (Fleiss, 1986).

\section{Results}

From a totall of 172 females, a mean of $44.9 \pm 12.1$ (SD) oocytes was obtained per female. The mean fertilization rate per oocyte per female in all experiments was $0.71 \pm 0.16$ (SD), ranging from 0.56 to 0.80 in the different experimental series. A total of 34 females were excluded, since inseminating and distributing the oocytes among the experimental groups did not result in at least five two-cell embryos in each group. In none of the experimental series did the fertilization rate differ significantly between the experimental groups (data not shown).

\section{Series $1 \mathrm{~A}-\mathrm{C}$}

In these three series of experiments, the effect of two experimental conditions (low $\mathrm{K}^{*}$ concentrations and supplementation of the medium with ouabain), applied only during the second day pi; on embryo development was studied. The development of embryos cultured from 22 to $46 \mathrm{~h}$ pi in media containing low concentrations of potassium is shown in Figure 1A. Embryos cultured during this short period in $1.4 \mathrm{mM} \mathrm{K} \mathrm{K}^{+}$yle lded the highest blastocyst rates, whereas almost all embryos cultured in $0.6 \mathrm{mM} \mathrm{K}$ remained arrested in the two-cell stage. As can be seen in Figure 1B, culturing embryos in the presence of $50 \mu \mathrm{M}$ ouabain from 22 to $46 \mathrm{~h}$ pi resulted in a significantly higher incidence of blastocyst formation compared to culturing without ouabain, whereas in $500 \mu \mathrm{M}$ ouabain most embryos were degenerated on day $3 \mathrm{pi}$. In series $1 \mathrm{C}$, all three tested oulabain concentrations resulted in a higher incidence of blastocyst formation. The viability of blastocysts resulting from the culture in the presence of ouabain was examined by counting the cell number per embryo. Neither the mean cell number of blastocysts, as judged by the number of nucleil, nor the mean mitotic index were significantly different in any of the ouabain concentrations tested (Table 1). 

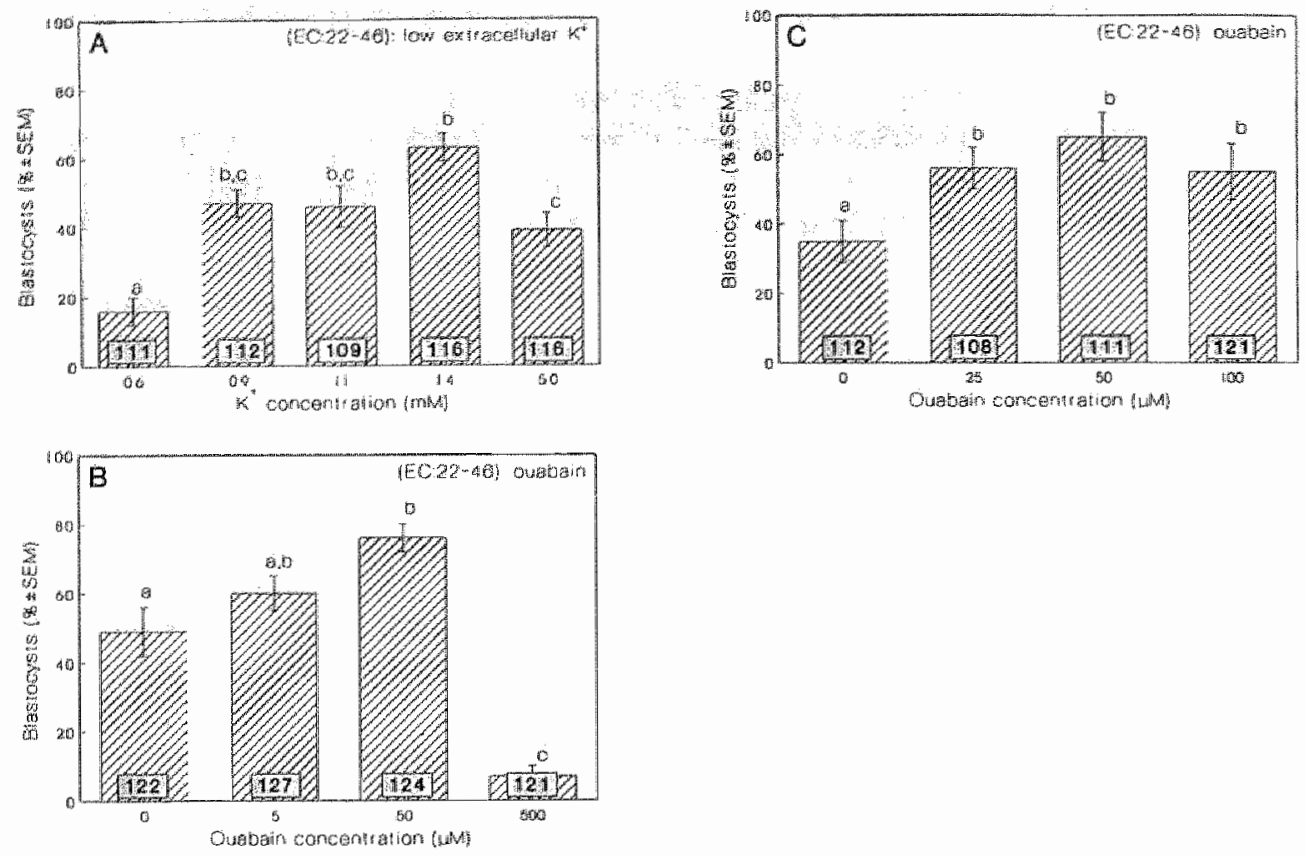

Fig. 1. Series $1 \mathrm{~A}-\mathrm{C}$ : effect of $\mathrm{Na}^{+}-\mathrm{K}^{*}-\mathrm{ATP}$ ase inhibiting conditions on mouse embryonic development in vitro. Embryos were cultured from 5-22 and 46-120 hirs in medium containing $5 \mathrm{mM} \mathrm{K} \mathrm{K}^{*}$ and during the period of 22-46 hrs pi exposed to the following experimental conditions (EC:22-46): A) media containing 0.6, 0.9,1.1, 1.4 and $5.0 \mathrm{mM} \mathrm{K}^{*}$; B) $0,5,50$ and $500 \mu \mathrm{M}$ ouabain added to the medium containing $5 \mathrm{mM} \mathrm{K} ;$, C) $0,25,50$ and $100 \mu \mathrm{M}$ ouabain added to the medium containing $5 \mathrm{mM} \mathrm{K}$. Each bar represents the mean incidence of blastocyst formation \pm SEM per cohort of 2-cell embryos per female for the different treatment groups. Values in each bar = total number of 2-cell embryos cultured in each group. Within each figure, treatment means with different letters are significantly different (ANOVA, Tukey, $P<0.05$ ).

Table 1. Cell numbers of mouse blastocysts after development of the embryos in media with $5 \mathrm{mM} \mathrm{K}$ and, between 22 and $46 \mathrm{~h}$, with various ouabain concentrations

\begin{tabular}{rcccc}
$\begin{array}{l}\text { Oubain } \\
\begin{array}{l}\text { concentration } \\
(\mu \mathrm{M})\end{array}\end{array}$ & $\begin{array}{c}\text { No. of } \\
\text { blastocysts } \\
\text { fixed }\end{array}$ & $\begin{array}{c}\text { No. of blastocysts } \\
\text { successfully } \\
\text { analyzed }\end{array}$ & $\begin{array}{c}\text { Number } \\
\text { of cells } \\
\text { (mean } \pm \text { SEM) }\end{array}$ & $\begin{array}{c}\text { Mean } \\
\text { mitotic index }\end{array}$ \\
\hline 0 & 45 & 29 & $57.5 \pm 3.8$ & $0.021 \pm 0.003$ \\
25 & 63 & 33 & $49.2 \pm 3.1$ & $0.026 \pm 0.005$ \\
50 & 74 & 40 & $52.0 \pm 2.9$ & $0.018 \pm 0.003$ \\
100 & 67 & 30 & $60.4 \pm 4.9$ & $0.026 \pm 0.005$ \\
\hline
\end{tabular}

"ANOVA, not significant. 


\section{Series $2 A-D$}

The effect of various $\mathrm{K}^{*}$ concentrations on the culture of mouse zygotes is shown in Figure 2. A marked dose-dependent negative effect of increasing $\mathrm{K}^{*}$ concentrations on the incidence of blastocyst formation was found.

Having established in experiment 1 and in earlier studies (Dumoulin et al., 1992) that exposing embryos in the period of $22-46 \mathrm{~h}$ pi to experimental conditions known to inhibit the $\mathrm{Na}^{+}-\mathrm{K}^{*}$-ATPase resulted in a better embryonic development in medium with $5 \mathrm{mM} \mathrm{K}$ * it was of interest to determine whether these treatments would protect the embryos against high concentrations of potassium. As can be seen in Figure 2 , all three experimental conditions appear to protect embryos against the inhibitory effect of high $\mathrm{K}^{*}$. The combination of 1.4 $\mathrm{mM} \mathrm{K}{ }^{+}$and ouabain resulted in very low blastocyst rates, with most embryos arresting in the two-cell stage. To examine the interaction between the three experimental conditions and high $\mathrm{K}^{+}$more closely, experimental series 3 was performed.
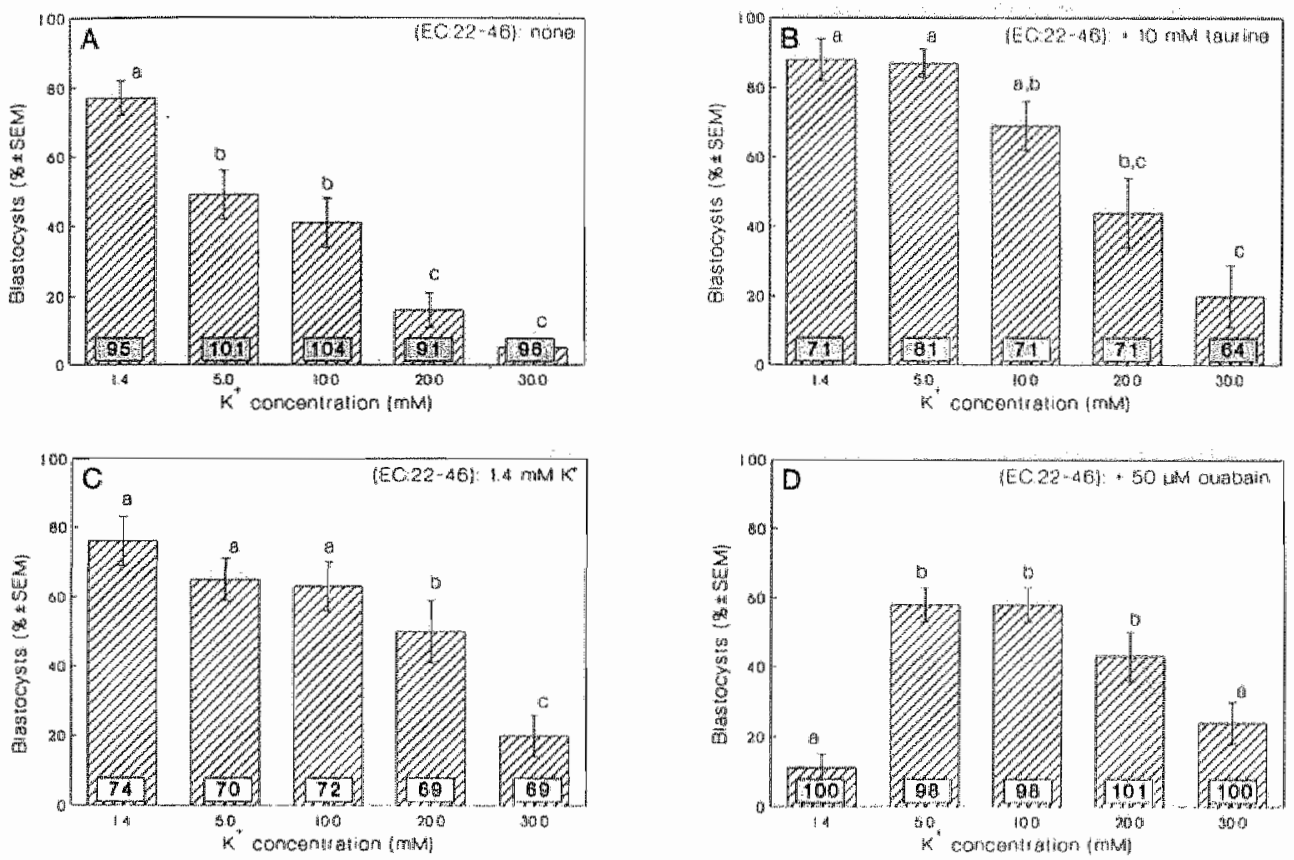

Fig. 2. Series 2A-D: effect of Na+-K"-ATPase inhibiting conditions on the dose-response of mouse embryonic development in vitro to potassium. Embryos were cultured from $5-22$ and $46-120$ hrs in different $K^{*}$ concentrations and during the period of $22-46$ hrs pi exposed to the following experimental conditions (EC:22 -46): A) fresh medium; B) $10 \mathrm{mM}$ taurine added to the different $\mathrm{K}^{+}$-containing media; $\mathrm{C}$ ) all groups cultured in $1.4 \mathrm{mMM} \mathrm{K}^{*}$ containing medium; D) $50 \mu \mathrm{M}$ ouabain added to the different $\mathrm{K}^{*}$-containing media. Each bar represents the mean incidence of blastocyst formation \pm SEM per cohort of 2-cell embryo per fernale for the different treatment groups. Values in each bar = total number of 2 -cell embryos cultured in each group. Within each figure, treatment means with different letters are significantly different (ANOVA, Tukey, $P<0.05$ ). 


\section{Series $3 \mathrm{~A}-\mathrm{C}$}

For all three experimental conditions, a second series of experiments was performed with media containing high $\mathrm{K}^{*}$ concentrations ( 10 or $20 \mathrm{mM}$ ) to compare directly in the same experiment the effect of these treatments with control groups. To exclude the possibility that the transfer of embryos itself was responsible for any difference found, the embryos in the control groups from both $\mathrm{K}^{i}$ concentrations were transferred to fresh medium at the same time. Only two $\mathrm{K}^{+}$concentrations were chosen, because, with our experimental design of distributing the zygotes of each female over a set of the experimental media and culturing them per female separately, only a limited number of experimental groups can be studied.
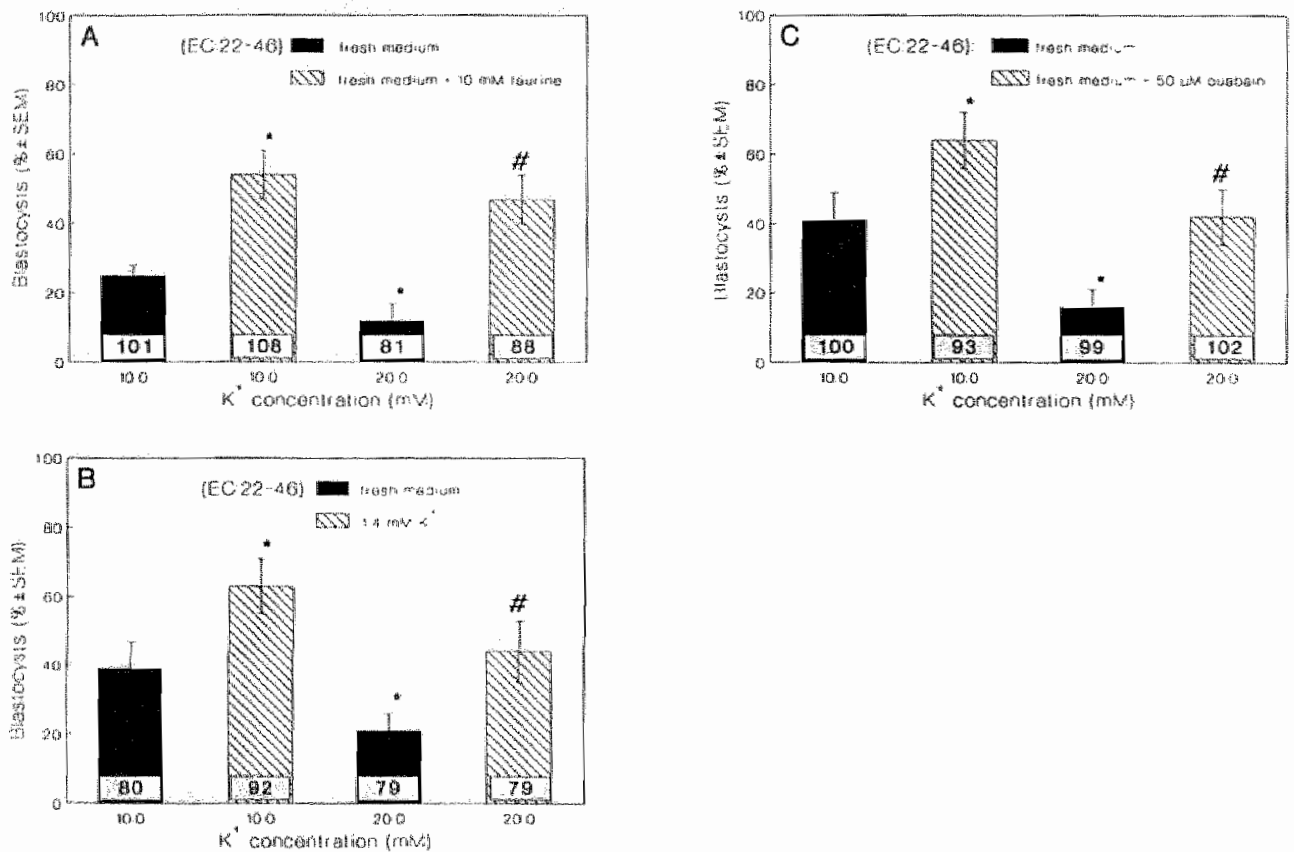

Fig. 3. Series 3A-C direct comparison of $\mathrm{Na}^{4}-\mathrm{K}^{*}-\mathrm{ATP}$ ase inhibiting conditions on mouse embryonic development in vitro to high $K^{*}$-containing media. Embryos were cultured from $5-22$ and $46-120$ hrs in medium containing either $10 \mathrm{mM} \mathrm{K}$ or $20 \mathrm{mM} \mathrm{K}$; during the period of $22-46 \mathrm{hrs}$ pi one of the 2 groups cultured in each $\mathrm{K}^{*}$ concentration was cultured in fresh medium containing the same $K^{4}$-concentration, whille the other group was exposed to the poilowing experimental conditions (EC:22-46):

A) $10 \mathrm{mM}$ taurine added to the media; B) embryos cultured in $1.4 \mathrm{mM} \mathrm{K}$-containing medium; C) 50 MM oulabain added to the media. Each bar represents the mean incidence of blastocyst formation \pm SEM per cothort of 2-cell embryo per fentale for the different treatment groups. Values in each bar = lotal number of 2 -cell embryos cultured in each group. Within each figure, treatment means indicated by * are significantly different from the mean incidence of blastocyst formation in medium containing $10 \mathrm{mM} \mathrm{K}^{*}$ during the whole culture period without exposure to an experimental condition; mean indicated by \# are significantly different from the mean incidence of blastocyst formation in medium containing $20 \mathrm{mM} \mathrm{K}$ during the whole culture period without exposure to an experimental condition (ANOVA, Bonferroni, $P<0.05$ ) 
Although the practical disadvantage is apparent, this randomized blocks design was chosen because in this way all experimental groups can be compared with control groups from the same mice, avoiding between-animal or unknown technical differences between experiments. These factors play an important role, as can be concluded from the considerable differences in the incidence of blastocyst formation in groups that were cultured in the same media and under the same conditions but in other experimental series (e.g., incidence of blastocyst formation in the same medium without ouabain in experiments $1 \mathrm{~B}$ and $1 \mathrm{C}$ is $0.49 \pm 0.07$ and $0.35 \pm 0.06$, respectively). For both $K^{*}$ concentrations, embryo development in all three $\mathrm{Na}^{*}-\mathrm{K}^{+}$-ATPase inhibiting conditions resulted in a significantly higher incidence of blastocyst formation compared to their controls (Fig. $3 \mathrm{~A}-\mathrm{C}$ ).

\section{Discussion}

As is shown by our experiments, mouse embryos cultured in vitro are very sensitive to high $\mathrm{K}^{+}$concentrations. This finding is consistent with earlier studies (Wiley, 1984; Wiley et al., 1986; Lawitts and Biggers, 1991; Dumoulin et al., 1992b). The different $\mathrm{K}^{*}$ concentrations chosen correspond with the concentrations found in several culture media [1.4 $\mathrm{mM} \mathrm{K}^{+}$for T6 (Quinn et al., 1985); $5 \mathrm{mM} \mathrm{K}^{+}$for Earle's, M16, BWW, and HTF (Quinn et al., 1985); $10 \mathrm{mM} \mathrm{K}^{+}$for B2 (Menezo et all. 1984)] and biological fluids [5 $\mathrm{mM} \mathrm{K}$ for human and mouse blood serum (Borland et al., 1977, 1980), and 20 and $30 \mathrm{mM} \mathrm{K}^{+}$for human and mouse oviducal fluid (Borland et al., 1977, 1980; Roblero et al., 1976)]. Thus, paradoxically, in $\mathrm{K}^{+}$concentrations that mouse embryos experience in vivo, the in vitro embryonic development is almost completely inhibited.

In earlier studies (Dumoulin et al., 1992a,b), it was shown that taurine has a beneficial effect on mouse embryonic development in vitro and provides at least a partial protection against high $\mathrm{K}^{*}$ concentrations. Since it has been shown by Mrsny and Meizel (1985) that taurine can inhibit the $\mathrm{Na}^{+}-\mathrm{K}^{*}$-ATPase in human sperm, we hypothesized that, under our culture conditions, inhibition of this enzyme in embryos would result in better embryonic development. In the first series of experiments, the effects of two other experimental conditions that are known to inhibit this enzyme were evaluated (low extracellular $K^{+}$concentration and ouabain), and their optimal concentrations were established. The time period chosen for the culturing of the embryos under the experimental conditions was $22-46 \mathrm{~h}$ pi, because embryos seem to profit most from taurine during their second day of in vitro development, when they are at the two-cell stage, for their subsequent development to the blastocyst stage (Dumoulin et al. 1992a). The $\mathrm{K}^{+}$concentration of $5 \mathrm{mM}$ was chosen because the effect of taurine is more pronounced in this concentration than in standard 76 medium with $1.4 \mathrm{mM} \mathrm{K}^{+}$(Dumoulin et al., 1992b). Low $\mathrm{K}^{*}$ and ouabain had similar positive effects as taurine on embryonic development. Furthermore, the viability of blastocysts, resulting from the culture in the presence of ouabain, was not different from those cultured without ouabain, as shown by the mean number of cells per blastocyst and the mean mitotic index.

Although a comparison of our results with those of other authors is difficult because of the differences in embryonic stages used and different culture periods in low $\mathrm{K}^{+}$or ouabain, the optimal concentrations we found for low $\mathrm{K}^{+}$and ouabain are comparable to those found by others. Wales (1970) found optimal blastocyst formation when mouse embryos were cultured in medium containing $1 \mathrm{mM} \mathrm{K}$ from the two-cell stage onwards, and almost no development when media were used containing $<0.6 \mathrm{mM} \mathrm{K}$. Wiley (1984) found that culture 
of mouse embryos from the morulae stage onwards in medium containing $10 \mu \mathrm{M}$ ouabain accelerated and in $100 \mu \mathrm{M}$ ouabain delayed the formation of blastocysts. The optimal concentrations of the three experimental conditions in experiment 1 and in previous experiments (Dumoulin et al., $1992 \mathrm{~b}$ ), were used in series 2 and 3 to evaluate their effect on the culture of embryos at several $K^{*}$ concentrations. As can be seen in Figures 2 and 3 , culturing mouse embryos for the rellatively short period of $22-46 \mathrm{~h}$ pi in the presence of $10 \mathrm{mM}$ taurine, $1.4 \mathrm{mMK}$ or 50 HM ouabain has a positive effect on the development of the embryos and renders them less sensitive to high $K^{+}$concentrations. Thus the presence of high taurine concentrations in the oviduct (Meizel et al., 1980; Casslen, 1987; Miller and Schultz, 1987 ; Dumoulin et al., 1992b) can partially explain why embryos are able to develop in vivo in an environment that contains high $\mathrm{K}^{+}$concentrations.

Why the transient inhibition of $\mathrm{Na}^{*}-\mathrm{K}^{*}$-ATPase by ouabain during this short period of 22-46 h pi, which coincides with the two-cell stage, leads to such a marked positive effect on subsequent embryonic development in vitro is as yet unclear. The $\mathrm{Na}^{*}-\mathrm{K}^{+}$-ATPase is an enzyme located in the plasma membrane of most, if not all, mammalian cells (Schuurmans Stekhoven and Bonting: 198\%). In preimplantation mouse two-cell embryos isotope flux measurements indicated the presence of a oulabain-sensitive $\mathrm{Na}^{*}-\mathrm{K}^{+}$-ATPase (Powers and Tupper, 1977). The enzyme itself could be identified first in the late morula stage using enzyme histochemistry (Vorbrodt et al., 1977). The sudden large increase in $\mathrm{Na}^{*}-\mathrm{K}^{*}-\mathrm{ATP}$ ase levels in this embryonic stage was confirmed in later studies using immunofluorescence (Watson and Kidder, 1988) and Western blotting (Gardiner et al., 1990) techniques. In the morula stage the enzyme was detected throughout the cytoplasm of each blastomere, while in the blastocyst the sudden abundant expression of $\mathrm{Na}^{+}-\mathrm{K}^{+}$-ATPase was accompanied by an abrupt change in distribution of the enzyme to a ring encircling the blastocoel (Watson and Kidder, 1988). Together with the findings that the fluid accumulation in the blastocoelic cavity can be blocked by $1 \mathrm{mM}$ ouabain (DiZio and Tasca, 1977) and that blastocyst formation is delayed or inhibited by $0.1 \mathrm{mM}$ ouabain (Wiley, 1984), this observation is consistent with the hypothesis that $\mathrm{Na}^{*}-\mathrm{K}^{*}$-ATPase is involved in the process of cavitation by pumping $\mathrm{Na}^{*}$ into the blastocoel against its concentration gradient, resulting in an osmotic flow of water into the cavity (DiZio and Tasca, 1977; Wiley. 1984; Watson and Kidder, 1988).

In that the only known effect of ouabain on cells is the inhibition of the enzyme $\mathrm{Na}^{+}-\mathrm{K}^{*}$ ATPase (Anner, 1985; Sweadner, 1989), the effect of ouabain on the embryo development that we found indicates the presence of $\mathrm{Na}^{*}-\mathrm{K}^{*}$-ATPase in the two-cell mouse embryo. These results are in agreement with the results from Powers and Tupper (1977) and of Gardiner et al. (1990), who could detect the enzyme in these early embryonic stages. The detected $\mathrm{Na}^{+}-\mathrm{K}^{+}-\mathrm{ATP}$ ase activity is probably the "housekeeping" level of activity, present in the plasma membrane of all cells (Schuurmans Stekhoven and Bonting, 1981). The techniques used by Vorbrodt et al. (1977) and Watson and Kidder (1988), who identified the enzyme for the first time only in the late morula stage, were probably not sensitive enough to detect these very low levels of $\mathrm{Na}^{*}-\mathrm{K}^{*}$-ATPase activity.

The inhibitory effect of taurine on the $\mathrm{Nla}^{*}-\mathrm{K}^{+}$-ATPase is more complex, and other effects of taurine on cells and tissues are extremely diverse. Taurine is involved in osmoregulation in tissues, stabilization of membranes, protection of cells from self-destruction during processes that generate oxidants, stimulation of certain metabolic actions such as glycolysis, and ion regulation (Huxtable, 1992; Wright et al. 1986; Huxtable and Sebring, 1989). The underlying biochemical mechanism of all these diverse effects is not well understood. In that taurine is present in mammalian heart at very high concentrations and has antiarrhythmic properties, much attention has been paid to a possible regulating role of taurine in ionic 
membrane transport (Huxtable, 1976). Taurine has a role in reversing potassium efflux from heart cells subjected to electrolyte imbalance inducing conditions such as high glucose concentrations (Welty et al., 1976). Also, taurine was shown to produce responses similar to those of ouabain on mammalian hearts (Dietrich and Diacono, 1971; Huxtable, 1976). Mrsny and Meizel (1985) showed that taurine has a inhibitory effect on $\mathrm{Na}^{+}-\mathrm{K}^{+}$-ATPase present in crude homogenates prepared from hamster sperm consisting of sperm membrane vesicles together with soluble and cytoplasmic components. However, Akera et all. (1976) did not find an inhibitory effect of taurine on partially purified $\mathrm{Na}^{*}-\mathrm{K}^{+}$-ATPase from rat brain. It is possible that the inhibiting effect of taurine requires the presence of other membrane or cytoplasmic factors. Taurine also has a role in reversing calcium efflux from heart cells subjected to electrolyte imbalance inducing conditions (Welty et all, 1976). In that taurine has been shown to affect many more calcium-dependent processes in the heart, a hypothesis was proposed by Huxtable and Sebring (1989) in which the biochemical basis of the action of taurine resides in an interaction of taurine with calcium-binding sites on the phospholipid components of intracellular membranes, resulting in a modulation of movement and availability of calcium in the cytoplasm.

Low- $K^{+}$media cause the systolic tension of isolated atria from guinea pig hearts to increase (Godfraind and Ghysel-Burton, 1980), and this effect was shown to be inversely related to the tested $\mathrm{K}^{+}$concentrations of 1.5-6.0 mM. This inotropic effect of low- $\mathrm{K}^{+}$solutions has been reported to be due solely to their inhibition of the $\mathrm{Na}^{*}-\mathrm{K}^{*}$-ATPase (Eisner and Lederer, 1979).

Although it has thus been shown that the three experimental conditions we used (ouabain, taurine, and low $\mathrm{K}^{+}$) can inhibit the $\mathrm{Na}^{+}-\mathrm{K}^{+}$-ATPase in a variety of cell types, it is not clear from our experiments whether they exert their positive effect on mouse embryonic development by the same mechanism. An indication that different mechanisms are involved in the effects of taurine and ouabain can be seen in the data of experiment 2: the culture of embryos in a combination of ouabain and low $\mathrm{K}^{+}$resulted in an almost complete loss of viability, whereas the combination of taurine and low $\mathrm{K}^{+}$yielded the highest blastocyst rates observed in all our experiments. Probably, in our experiments, the inhibition of the $\mathrm{Na}^{*}-\mathrm{K}^{+}-\mathrm{ATP}$ ase does not in itself produce a positive effect on embryonic development. Many other membrane transport systems are driven by the $\mathrm{Na}^{*}$-gradient that is upheld by the $\mathrm{Na}^{+}-\mathrm{K}^{+}$-ATPase, and an inhibition of $\mathrm{Na}^{+}-\mathrm{K}^{+}$-ATPase has indirect effects on the transport of molecules such as glucose, $\mathrm{H}^{+}$, and $\mathrm{Ca}^{+*}$. When the active transport of $\mathrm{Na}^{+}$and $\mathrm{K}^{+}$ions by the $\mathrm{Na}^{*}-\mathrm{K}^{+}$-ATPase is inhibited, $\mathrm{Na}^{+}$tends to flow into the cell and $\mathrm{K}^{+}$out of the cell by passive ion-channels because of their steep concentration gradients. The higher intracellular $\mathrm{Na}^{+}$concentration will slow down the $\mathrm{Na}^{*}$-cotransport systems (Scott, 1987).

It can be hypothesized that, analogous to the correcting role taurine plays with respect to the calcium and potassium efflux from heart celis subjected to electrolyte imbalanceinducing conditions (Welty et al., 1976), taurine, oulabain, and low K* correct an existing electrolyte imbalance in mouse embryos cultured in vitro, either by the direct inhibition of the $\mathrm{Na}^{*}-\mathrm{K}^{*}$-ATPase or by other mechanisms. It could be argued that this hypothetical electrolyte imbalance exists only in embryos cultured in vitro and is created by our suboptimal culture conditions. However, the presence of taurine, at high concentrations, in the mammalian reproductive tract, with its inhibitory effect on the $\mathrm{Na}^{+}-\mathrm{K}^{*}$-ATPase, shows the potential beneficial effect of this amino acid on early embryonic development in vivo. 


\section{References}

Akera T, Ku D, Brody TM (1976): Alterations of ion movements as a mechanism of drug-induced arrtyythmias and inotropic responses. In R Huxtable and A Barbeau (eds)." "Taurine". New York: Ra Press, pp 121-134.

Anner BM (1985): The receptor function of the $\mathrm{Na}^{*}, \mathrm{~K}^{*}$ activated adenosine triphosphatase system. Biochem J 227:1-11.

Barnett DK, Bawister $\mathrm{BD}(1992)$ : Hypotaurine requirements for in vitro development of golden hamste one-cell embryos into morulae and blastocysts, and production of term offspring from in vitro fertifized o Biol Reprod 47: 297-304.

Biggers JD, Bell JE, Benos DJ (1988): Mammalian blastocysts: transport functions in a developing epithelium. Am J Physiol 255: C419-C432.

Bortand RM, Hazra S, Biggers JD, Lechene CP (1977): The elemental composition of the environmer of the gametes and preimplantation embryo during the initiation of pregnancy. Biol Reprod 16:147-1

Borland RM; Biggers JD, Lechene CP. Taymor ML (1980): Elemental composition of fluid in the huma Fallopian tube. J Reprod Fert 58:479-482.

Casslen BG (1987): Free amino acids in human uterine fluid. J Reprod Med 32:181-184.

Cassien B. Nilsson B (1984): Human uterine fluid, examined in undiluted samples for osmolarity and $t$ concentrations of inorganic ions, albumin, glucose, and urea. Am J Obstet Gynecol 150:877-881.

Dietrich J. Diacono J (1971) Comparison between ouabain and taurine effects on isolated rat and guinea-pig hearts in low calcium medium. Life Sci 10 (Part 1):499-507.

DiZio SM, Tasca RJ (1977) Sodium-dependent amino acid transport in preimplantation mause embryc Dev Biol 59:198-205.

Dumaulin JCM, Evers JLH, Bakker JA, Bras M, Pieters MHEC. Geraedts JPM (1992a): Temporal effects of taurine on mouse embryo development in vitro. Hum Reprod 7:403-407.

Dumoulin JCM, Evers JLH, Bras M, Pieters MHEC, Geraedts JPM (1992b): Positive effect of taurine c preimplantation development of mouse embryos in vitro. J Reprod Fertil 94:373-380.

Eisner DA, Lederer WJ (1979): The role of the sodium pump in the effects of potassium-depleted solutions on mammalian cardiac muscle. J Physiol 294:279-301.

Fleiss JlL (1986): "The design and analysis of clinical experiments". New York: Wiley \& Sons.

Gardiner CS, Williams JS, Menino AR (1990): Sodium/potassium adenosine triphosphatase $\alpha$ - and B-subunit and $\alpha$-subunit mRNA levels during mouse embryo development in vitro. Biol Reprad $43: 788-7 s$

Godfraind T, Ghysel-Burton J (1980): Independence of the positive inotropic effect of ouabain from the inhibition of the heart $\mathrm{Na}^{+} / \mathrm{K}^{+}$pump Proc Natl Acad Sci USA 77:3067-3069.

Huxtable RJ (1992): Physiological actions of taurine. Physiol Rev 72:101-163.

Huxtable R (1976): Metabolism and function of taurine in the heart. in R Huxtable and A Barbeau (eds) "Taurine". New York: Raven Press, pp 99-119.

Huxtable R, Sebring LA (1989): Taurine and the heart: the phospholipid connection. In H lwata, JB Lombardini and T Segawa (eds): "Taurine and the heart". Boston: Kluwer Acad Publ, pp $31-42$ Jacobsen JG, Smith LH (1968): Biochemistry and physiology of taurine and taurine derivatives. Physio
Rev 48:424-511.

Kola I. Folb PI (1985): The effects of cyclophosphamide on alkaline phosphatase activity and on in vitr post-implantation murine blastacyst development. Develop Growth and Differ 27:645-651. Lawitts JA. Biggers JD (1991): Overcoming the 2-cell block by modifying standard components in a
mouse embryo culture medium. Biol Reprod 45:245-251.

Leibfried ML, Bavister BD (1981): The effects of taurine and hypotaurine on in vitro fertitization in the golden hamster. Biol Reprod 4:57-63. Leibfried ML, Bavister BD (1982): Effects of epinephrine and hypotaurine on in-vitro fertilization in the
golden hamster. J Reprod Fert 66:87-93.

Meizel S, Lui CW. Working PK. Mrsny RJ (1980): Taurine and hypotaurine: their effects on motility,

capacitation and the acrosome reaction of hamster sperm in vitro and their presence in sperm and reproductin
tract fluids of several mammals. Develop Growth and Differ $22: 483-494$.

Menezo $Y$, Testart $J$ "Perrone $D(1984)$ : Serum is not necessary in human in vitro fertilization, early embryo culture, and transfer. Fertil Steril 42:750-756.

Miller JGO, Schultz GA (1987): Amino acid content of preimplantation rabbit embryos and fluids of the
reproductive tract. Biol Reprod 36:125-129. 
Mrsny RJ, Waxman $L_{v}$ Meizel $S$ (1979): Taurine maintains and stimulates motility of hamster sperm during capacitation in vitro. $J$ Exp Zool 210:123-128.

Mrsny RJ, Meizel S (1985): Inhibition of hamster sperm Na* $\mathrm{K}^{*}$-ATPase activity by taurine and hypotaurine. Life Sci 36:271-275.

Powers RD, Tupper JT (1977): Developmental changes in membrane transport and permeability in the early mouse embryo. Dev Biol 56:306-315.

Quinn P, Kerin JF. Warnes GM (1985): Improved pregnancy rate in human in vitro fertilization with the use of a medium based on the composition of human tubal fluid. Fertil Steril 44:493-498.

Roblero L, Biggers JD, Lechene CP (1976): Electron probe analysis of the elemental microenvironment of oviducal mouse embryos. J Reprod Fert 61:387-393.

Rossier BC. Geering K, Kraehenbuhl JP (1987): Regulation of the sodium pump: how and why? Trends Biochem Sci 12: 483-487.

Schuurmans Stekhoven F, Bonting SL (1981): Transport adenosine triphosphates: properties and functions. Physiol Rev 61:1-76.

Scott DM (1987): Sodium cotransport systems: cellular, molecular and regulatory aspects. BioEssays 7:71-78.

Sweadner KJ ("1989) Isozymes of the Na*/K*-ATPase. Biochim Biophys Acta 988:185-220.

Thurston JH, Hauhart RE "Naccarato EF (1981): Taurine: possible role in osmotic regulation of mammalian heart. Science 214:1373-1374.

Vorbrodt A, Konwinski M. Solter D, Koprowski H (1977) Ultrastructural cytochemistry of membranebound phosphatases in preimplantation mouse embryos. Dev Biol 55:117-134.

Wales RG (1970): Effects of ions on the development of the pre-implantation mouse embryo in vitro. Aust $J$ biol Sci 23:421-429.

Wales RG, Edirisinghe WR (1989): Volume of fluid and concentration of cation and energy substrates in the uteri of mice during early pseudopregnancy. Reprod Fertil Dev 1:171-178.

Watson AJ, Kidder GM (1988) Immunofluorescence assessment of the timing of appearance and cellular distribution of $\mathrm{Na} / \mathrm{K}$-ATPase during mouse embryogenesis. Dev Biol 126:80-90.

Welty JD, McBroom MJ, Appelt AW, Peterson MB, Read WO (1976) Effect of taurine on heart and brain. electrolyte imbalances. In R Huxtable and A Barbeau (eds): "Taurine". New York: Raven Press, pp 155-163.

Wiley LM (1984): Cavitation in the mouse preimplantation embryo: Na/K-ATPase and the origin of nascent blastocoele fluid. Dev Biol 105:330-342.

Wiley LM, Yamami $S$, Van Muyden D (1986): Effect of potassium concentration, type of protein supplement, and embryo density on mouse preimplantation development in vitro. Fertil Steril 45:111-119. Wright CE, Tallan HH, Lin YY. (1986): Taurine: biological update. Ann Rev Biochem 55:427-453. 


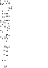
:

$$
\text { I }
$$
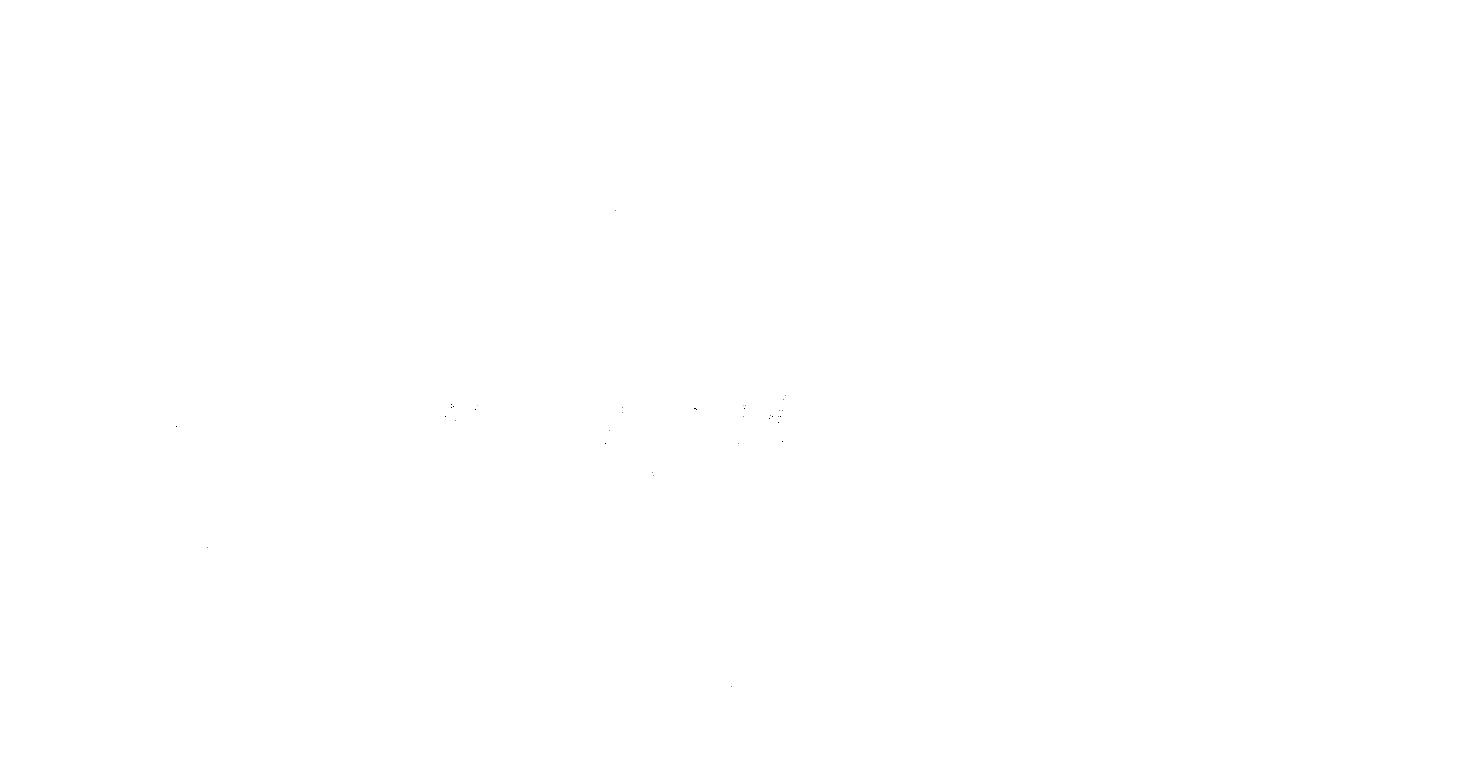

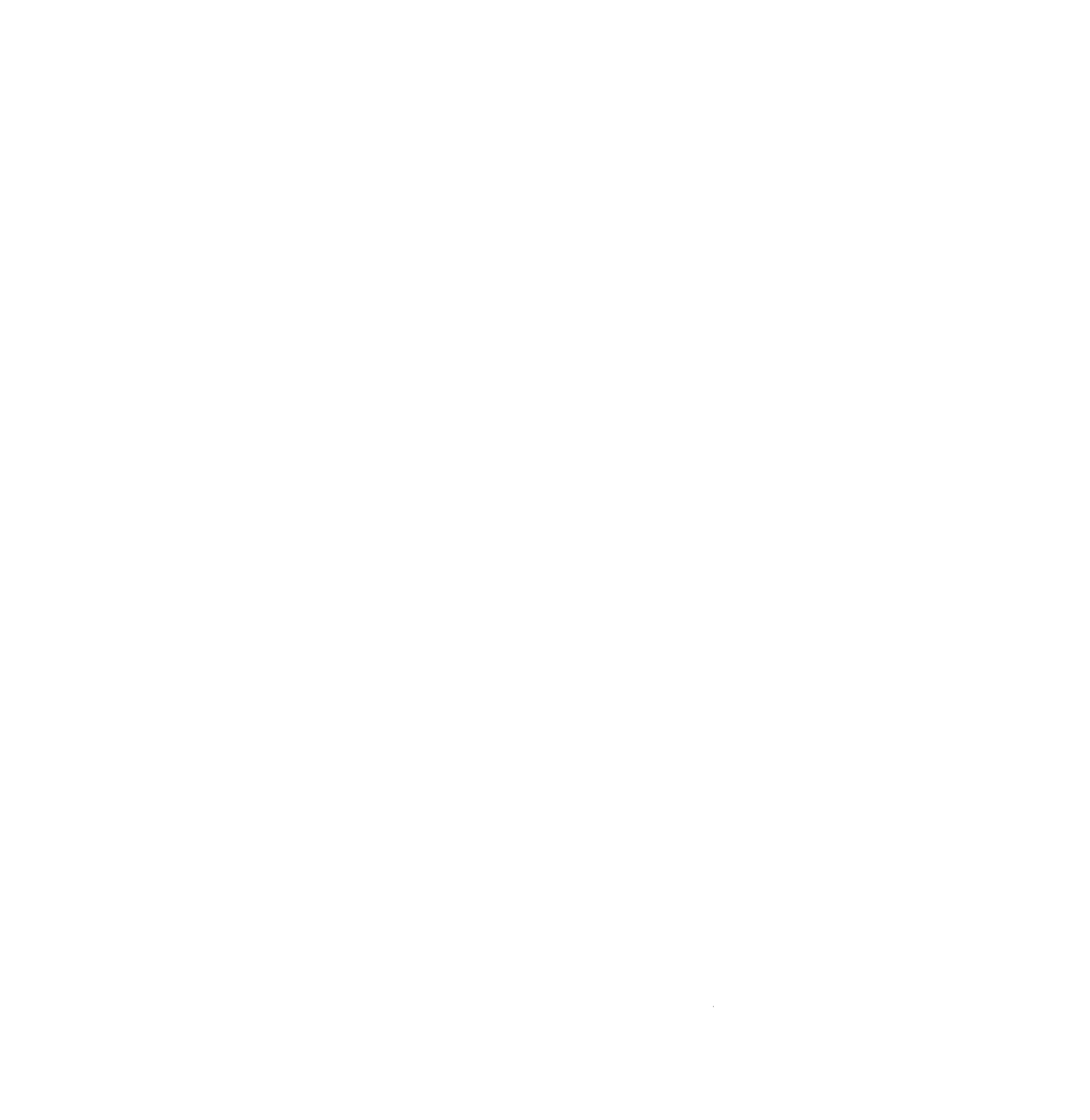




\section{Chapter 5}

\section{Temporal effects of ouabain on in-vitro development of mouse zygotes.}

John C.M. Dumoulin ${ }^{1}$, Anton H.J.C. Michiels ${ }^{2}$, Marijke Bras ${ }^{1}$, Math H.E.C. Pieters ${ }^{1}$, Joep P.M. Geraedts ${ }^{2}$ and Johannes L.H. Evers ${ }^{\Uparrow}$

Departments of ${ }^{1}$ Obstetrics and Gynaecology, Academic Hospital Maastricht, University of Limburg, P.O. Box 5800, 6202 AZ Maastricht and ${ }^{2}$ Molecular Cell Biology and Genetics, University of Limburg, P.O. Box 616, 6200 MD Maastricht, The Netherlands

Published in:

Human Reproduction, 8, 1469-1474, 1993 


\section{Summary}

Ouabain is a specific inhibitor of $\mathrm{Na}^{+}-\mathrm{K}^{+}$-ATPase, an enzyme which controls the intracellular $\mathrm{Na}^{+}$and $\mathrm{K}^{*}$ levels. In this study, in-vitro fertilized zygotes from a hybrid mouse strain were used to examine the temporal effects of $50 \mu \mathrm{M}$ ovlabain on embryonic development in vitro during the preimplantation period. A higher incidence of blastocyst formation at the end of the culture period was found when embryos were cultured in the presence of ouabain between 22 to $46 \mathrm{~h}$ post-insemination, or any other period that included this time period. When zygotes from randomly bred mice were used, inhibition of $\mathrm{Na}^{*}-\mathrm{K}^{*}$-ATPase with cuabain clearly promoted development through the 2-cell block in vitro. As $\mathrm{Na}^{+}-\mathrm{K}^{*}-\mathrm{ATP}$ ase is the most important regulator of intracellular electrolyte concentrations in mammalian cells, these results suggest that an ionic imbalance exists in embryos cultured in conventional media which can be positively influenced by inhibiting this enzyme.

\section{Introduction}

The $\mathrm{Na}^{+}-\mathrm{K}^{+}$-ATPase is a membrane-bound enzyme controlling intracellular $\mathrm{Na}^{+}$and $\mathrm{K}^{+}$ levels (Rossier et al, 1987). It is present in most, if not all, mammalian cells (Schuurmans Stekhoven and Bonting, 1981), including mouse 2-cell embryos (Powers and Tupper, 1977; Gardiner et al., 1990). The activity of $\mathrm{Na}^{*}-\mathrm{K}^{*}$-ATPase can be directly modulated by its ligands $\mathrm{Na}^{*}, \mathrm{~K}^{*}$, and ATP, and indirectly by hormones and growth factors (Rossier et al., 1987). The cardio-active steroid ouabain is a specific inhibitor of this enzyme (Anner, 1985). The $\mathrm{Na}^{+}-\mathrm{K}^{+}$-ATPase activity can also be decreased in a dose-dependent manner by taurine, as was shown by Mrsny and Meizel (1985). Taurine is a sulphur-containing B-amino acid present in many mammalian tissues (Jacobsen and Smith, 1968; Huxtable, 1992). It is also present at high concentrations in female reproductive tract fluids of several mammalian species (Meizel et al., 1980; Casslèn, 1987; Miller and Schultz, 1987; Dumoulin et al., 1992a). In a previous study (Dumoulin et al., 1992a), we have shown that supplementing the culture medium of mouse embryos during the preimplantation period with taurine leads to a higher frequency of blastocyst formation. Taurine exerted its beneficial effect exclusively during the first 2 days post-insemination (Dumoulin et al., 1992b). Within this period, the effect of taurine on blastocyst formation appeared to be restricted predominantly to the period of the second day post-insemination.

In a preliminary study on the effect of ouabain on embryonic development of mouse embryos (Dumoulin et al., 1992c, 1993), we found that inhibition of $\mathrm{Na}^{+}-\mathrm{K}^{+}-\mathrm{ATPase}$ by ouabain gave similar positive effects on the growth of zygotes to the blastocyst stage as taurine did under our in-vitro culture conditions. The concentration of $50 \mu \mathrm{M}$ ouabain was found to be optimal.

In the present study we investigated whether the inhibition of $\mathrm{Na}^{+}-\mathrm{K}^{+}-\mathrm{ATPase}$ by ouabain was beneficial to mouse embryos at a specific time during preimplantation development in vitro. We also studied the effect of ouabain on the occurrence of the 2 -cell block in randomly bred mouse embryos. 


\section{Materials and methods}

\section{In vitro fertilization (IVF) and embryo culture}

To examine the effect of ouabain on different preimplantation embryonic stages (C578) $x(B A) F_{1}$ hybrid female mice were used. To examine the effect of ouabain on the 2-eell block, randomly bred Swiss female mice were used as the "blocking" strain. In all experiments, Swiss males were used. The mice were obtained from Iffa Credo (Broekman, Someren, The Netherlands).

The IVF and embryo culture methods used were as described previously (Dumoulin et al., 1992a). Briefly, oocytes were obtained after superovulating female mice with 10 IU pregnant mare's serum gonadotrophin (PMSG) and $10 \mathrm{IU}$ human chorionic gonadotrophins (HCG). Oocytes from different females were inseminated seperately with $2 \times 10^{2}$ motile caudal epididymal spermatozoa. At $5 \mathrm{~h}$ post-insemination, oocytes from each female were distributed at random among the different treatment groups for further culture. Human tubal fluid (HTF) medium (Quinn et al., 1985) was used in all experiments. For IVF, the medium contained $30 \mathrm{mg} / \mathrm{ml}$ bovine serum albumin (BSA), and for culturing of the embryos $5 \mathrm{mg} / \mathrm{ml}$ BSA was used. In most experiments the embryos were cultured in an atmosphere of $5 \%$ $\mathrm{CO}_{2}$ in air, and in some experiments in an atmosphere of $5 \% \mathrm{CO}_{2}, 5 \% \mathrm{O}_{2}$ and $90 \% \mathrm{~N}_{2}$. At $26 \mathrm{~h}$ post-insemination, normal appearing 2 -cell embryos were counted. At regular intervals during the 5 day culture period, embryonic developmental stages were scored. Three experimental series were performed as described below using only a few females at a time in each series. This procedure was repeated on different days with mice from different batches to minimize the possibility of an unknown factor influencing the results.

\section{Effect of ouabain on preimplantation embryos at different stages}

In a first series of experiments, oocytes from each female were distributed over a set of four treatment groups at $5 \mathrm{~h}$ post-insemination, and were not pooled with embryos from other females. Only results from females who produced more than five 2-cell embryos in each treatment group were used. At $46 \mathrm{~h}$ post-insemination, each of the four groups of embryos was transferred to fresh medium. Two groups were cultured during the whole preimplantation period in medium with or without ouabain, respectively. The other two groups were either cultured from 5 to $46 \mathrm{~h}$ post-insemination, or from 46 to $120 \mathrm{~h}$ post-insemination in medium containing ouabain. In all experiments, the ouabain concentration used was $50 \mu \mathrm{mol} / \mathrm{l}$ (Dumoulin et al., 1992c, 1993).

In the second series of experiments, oocytes from three females were pooled at $5 \mathrm{~h}$ post-insemination and distributed over a set of 10 treatment groups. Of these 10 groups, five were cultured in the presence of $50 \mu \mathrm{M}$ ouabain during the following periods (h postinsemination); $5-22,22-46,46-70,70-94$ and $5-120$, respectively. The other five groups were transferred to fresh medium without ouabain during the same periods as above. 


\section{Effect of ouabain on the 2-cell block in vitro}

Oocytes from each female from a randomly bred strain were distributed over a set of four treatment groups. During the whole preimplantation period, one group was cultured in medium without supplements, a second group in medium supplemented with $50 \mu \mathrm{M}$ ouabain, a third group in medium with $0.1 \mathrm{mM}$ ethylenediamine tetra-acetic acid (EDTA), and the fourth group was cultured in medium without supplements but in an atmosphere of $5 \% \mathrm{O}_{20}, 5 \%$ $\mathrm{CO}_{2}$ and $90 \% \mathrm{~N}_{2}$.

\section{Statistics}

The mean percentage \pm SEM of embryonic development (no. of embryos at particular embryonic stage/no. of 2-cell embryos) per female (or per group of three females in second experimental series) was calculated for every treatment group. These data were subjected to arcsine transformation and analysed using an analysis of variance (ANOVA) for a randomized blocks experiments (Fleiss, 1986). When the ANOVA test showed significant differences $(P<0.05)$, differences between treatments were evaluated using either the multiple comparisons test according to Tukey (when all treatment groups were compared to one another), or according to Bonferroni (when only the pairwise comparison of groups undergoing treatments during the same period was of interest) (Fleiss, 1986)

\section{Results}

\section{Effect of ouabain on preimplantation embryos at different stages}

To investigate the effect of ouabain on early and on late preimplantation development, oocytes from 18 females were used. Results from two females were not included since inseminating and distributing the oocytes over the four treatment groups did not result in at least five 2-cell embryos in each group. From the 16 remaining females, 685 oocytes were obtained (mean number of oocytes per female \pm SD: $42.8 \pm 12.3$ ) and divided, $5 \mathrm{~h}$ post-insemination, over the four groups. The total fertilization frequency per female (no. of 2-cell embryos/no. of oocytes, counted at $24 \mathrm{~h}$ post-insemination) was $0.83 \pm 0.15$ (SD); no significant differences between the four groups were observed (data not shown).

As can be seen from Table 1, the presence of $50 \mu \mathrm{M}$ ouabain either in the first 2 days post-insemination or throughout the complete preimplantation period, gave better rates of development of the zygotes into blastocysts as compared to the development in medium without ouabain. The beneficial effect of ouabain was already noticeable at the 4-cell stage. The presence of ouabain from $46 \mathrm{~h}$ post-insemination onwards only did not result in a higher incidence of blastocyst formation than in the control. 
Table 1. Effect of ouabain on early and late preimplantation development of mouse zygotes from a hybrid strain cultured in witro

\begin{tabular}{|c|c|c|c|c|}
\hline \multirow{2}{*}{$\begin{array}{l}\text { Period of } \\
\text { culture } \\
\text { in } 50 \text { uM } \\
\text { ouabain }\end{array}$} & \multirow[b]{2}{*}{$\begin{array}{l}\text { No. of } 2 \text {-cell } \\
\text { embryos }\end{array}$} & \multicolumn{3}{|c|}{ Mean embryonic development $\pm S E M^{b}$} \\
\hline & & $\begin{array}{l}\text { Day } 3^{c} \\
\text { 4-cell embryos }\end{array}$ & $\begin{array}{l}\text { Day } 4^{\circ} \\
\text { morutae }\end{array}$ & $\begin{array}{l}\text { Day } 5^{\circ} \\
\text { biastocysts }\end{array}$ \\
\hline No ouabain & 145 & $d_{0.74} \pm 0.03$ & $0.71 \pm 0.04$ & ${ }^{d} 0.66 \pm 0.04$ \\
\hline $5-120$ & 145 & $0.90 \pm 0.02$ & ${ }^{e} 0.87 \pm 0.03$ & ${ }^{\mathrm{e}} 0.85 \pm 0.03$ \\
\hline $5-46$ & 136 & $0.92 \pm 0.04$ & ${ }^{8} 0.92 \pm 0.04$ & $0.85 \pm 0.04$ \\
\hline $46-120$ & 137 & $0.75 \pm 0.04$ & $0.71 \pm 0.05$ & $0.65 \pm 0.06$ \\
\hline
\end{tabular}

"Hours post-insemination.

${ }^{D}$ Means \pm SEM (no. at embryonic stage / no. of 2-cell embryos) are based on 16 females; within a column means with different superscripts ${ }^{\text {d.e }}$ were significantly different (ANOVA, Tukey, $P<0.05$ ).

cDays post-insemination, day of insemination is day 1.

In the second experimental series, in which after insemination oocytes from three females were pooled, divided over 10 treatment groups and cultured with or without ouabain on different days during the culture period of 5 days, 23 replicate experiments were performed. From the 69 females, a total of 2394 oocytes was obtained. The mean fertilization frequency per group of three females was $0.79 \pm 0.17$ (SD); no significant differences between the 10 groups were observed (data not shown). Results are summarized in Table 2. The mean rate of embryos reaching the 4-cell stage at $50 \mathrm{~h}$ post-insemination did not differ significantly between the 10 groups, although the mean rate of embryos reaching the morula stage at $74 \mathrm{~h}$ post-insemination, the early blastocyst stage at $98 \mathrm{~h}$ post-insemination, and the late blastocyst stage at $120 \mathrm{~h}$ post-insemination did differ significantly between the 10 groups (ANOVA, $P<0.05$ ). Significant differences between groups exposed to ouabain and their control groups not exposed to ouabain during the same experimental period are shown in Table 2. 
Table 2. Temporal effect of ouabain on preimplantation development of mouse zygotes from a hybrid strain cullured in vitro

\begin{tabular}{|c|c|c|c|c|c|}
\hline \multirow{3}{*}{$\begin{array}{l}\text { Treatment } \\
\text { period } \\
\text { (hi post- } \\
\text { insemination) }\end{array}$} & \multirow{3}{*}{$\begin{array}{l}\text { Embryönic } \\
\text { stage }^{a}\end{array}$} & \multicolumn{4}{|c|}{ Treatment condition } \\
\hline & & \multicolumn{2}{|c|}{ Without ouabain } & \multicolumn{2}{|c|}{ With $50 \mu M$ ouabain } \\
\hline & & $\begin{array}{l}\text { No. of } \\
\text { embryos }\end{array}$ & $\begin{array}{l}\text { Mean development } \\
\pm \text { SEM }\end{array}$ & $\begin{array}{l}\text { No. of } \\
\text { embryos }\end{array}$ & $\begin{array}{l}\text { Mean development } \\
\pm \text { SEM }\end{array}$ \\
\hline \multirow[t]{5}{*}{$5-22$} & 2 -cell & 189 & 1.00 & 188 & 1.00 \\
\hline & 4-cell & 136 & $0.73 \pm 0.04$ & 141 & $0.80 \pm 0.04$ \\
\hline & morula & 124 & $0.68 \pm 0.04$ & 135 & $0.77 \pm 0.03$ \\
\hline & e. blast. & 86 & $0.47 \pm 0.04$ & 95 & $0.53 \pm 0.05$ \\
\hline & 1. blast. & 111 & $0.60 \pm 0.04$ & 125 & $0.70 \pm 0.04$ \\
\hline \multirow[t]{5}{*}{$22-46$} & 2-cell & 189 & 1.00 & 182 & 1.00 \\
\hline & 4-cell & 132 & $0.74 \pm 0.05$ & 154 & $0.88 \pm 0.03$ \\
\hline & morula & 122 & $0.67 \pm 0.05$ & 145 & $0.84 \pm 0.03$ \\
\hline & e. blast. & 85 & $0.48 \pm 0.05$ & 111 & $0.64 \pm 0.05$ \\
\hline & 1. blast & 104 & $0.58 \pm 0.05$ & 137 & $0.79 \pm 0.04$ \\
\hline \multirow[t]{5}{*}{$46-70$} & 2-cell & 193 & 1.00 & 176 & 1.00 \\
\hline & 4-cell & 138 & $0.75 \pm 0.04$ & 135 & $0.78 \pm 0.04$ \\
\hline & morula & 129 & $0.70 \pm 0.04$ & 132 & $0.75 \pm 0.05$ \\
\hline & e blast. & 85 & $0.47 \pm 0.04$ & 109 & $0.62 \pm 0.06$ \\
\hline & 1. blast & 114 & $0.62 \pm 0.04$ & 124 & $0.71 \pm 0.06$ \\
\hline \multirow[t]{5}{*}{$70-94$} & 2-cell & 191 & 1.00 & $18: 8$ & 1.00 \\
\hline & 4-cell & 139 & $0.76 \pm 0.05$ & 146 & $0.78 \pm 0.05$ \\
\hline & morula & 131 & $0.72 \pm 0.05$ & 131 & $0.73 \pm 0.04$ \\
\hline & e. blast. & 102 & $0.55 \pm 0.05$ & 99 & $0.57 \pm 0.05$ \\
\hline & I. blast. & 125 & $0.66 \pm 0.05$ & 120 & $0.67 \pm 0.05$ \\
\hline \multirow[t]{5}{*}{$5-120$} & 2-cell & 189 & 1.00 & 194 & 1.00 \\
\hline & 4-cell & 145 & $0.78 \pm 0.05$ & 170 & $0.89 \pm 0.03$ \\
\hline & morula & 134 & $0.71 \pm 0.05$ & 158 & $0.85 \pm 0.03$ \\
\hline & e. blast. & 102 & $0.55 \pm 0.06$ & 128 & $0.70 \div 0.04$ \\
\hline & \#. Blast. & 122 & $0.65 \pm 0.05$ & 150 & $* 0.80 \pm 0.04$ \\
\hline
\end{tabular}

Embryonic stages were scored at the following times (h post-insemination): 2 -cell: $26 ; 4$-cell: 50 ; morulae: 74 ; blastocysts: 98 (early); and 120 (late); e. blast = early blastocyst; 1 . blast. = late blastocyst.

"Means \pm SEM (no. at embryonic stage/no. of 2 -cell embryos) are based on 23 replicate experiments: within each line, means of groups indicated with an asterisk are significantly different (ANOVA, Bonferroni, $P<0.05$ ) from the control group not treated with ouabain during the same period.

\section{Effect of ouabain on the 2-cell block in-vitro}

In the third experimental series, oocytes from each of 35 randomly bred Swiss females were fertilized in vitro and divided over a set of four treatment groups. The results from eight females could not be used because of insufficient numbers of 2-cell embryos in one or more treatment groups. From the remaining 27 females, a total of 1036 oocytes was obtained [mean number of oocytes per female: $38.4 \pm 13.1$ (SD)]. The fertilization frequency per female was $0.82 \pm 0.16$ (SD); no significant differences between the four groups were 
observed (data not shown). The results presented in Table 3 clearly showed that the embryos from the used randomly bred strain exhibit a 2-cell block, and that significantly more of them developed into 4-cell embryos, morulae and blastocysts when cultured in the presence of either EDTA or ouabain, as compared to the control group cultured without supplements. Culture under $5 \% \mathrm{O}_{2}$ resulted in significantly more 4-cell embryos than in the control, but not significantly more morulae and blastocysts.

Table 3. Effect of ouabain on the 2-cell block of mouse zygotes from a random-bred strain cultured in vitro

\begin{tabular}{|c|c|c|c|c|}
\hline \multirow[b]{2}{*}{$\begin{array}{l}\text { Experimental } \\
\text { conditions }\end{array}$} & \multirow{2}{*}{$\begin{array}{l}\text { No. of } \\
2 \text {-cell } \\
\text { embiyos }\end{array}$} & \multicolumn{3}{|c|}{ Mean embryanic development \pm SEM $^{a}$} \\
\hline & & $\begin{array}{l}\text { Day } 3^{\circ} \\
\text { 4-cell embryos }\end{array}$ & $\begin{array}{l}\text { Day } 4^{b} \\
\text { morulae }\end{array}$ & $\begin{array}{l}\text { Day } 5^{\circ} \\
\text { blastocysts }\end{array}$ \\
\hline Standard culture & 219 & $c_{0.24} \pm 0.02$ & ${ }^{c} 0.07 \pm 0.02$ & $0.06 \pm 0.02$ \\
\hline$+0.1 \mathrm{mM}$ EDTA & 210 & ${ }^{d} 0.53 \pm 0.05$ & $0.39 \pm 0.05$ & $0.39 \pm 0.05$ \\
\hline + 50 . $M$ ouabain & 196 & ${ }^{\circ} 0.71 \pm 0.04$ & ${ }^{d} 0.52 \pm 0.06$ & ${ }^{d} 0.50 \neq 0.06$ \\
\hline Culture under $5 \% \mathrm{O}_{2}$ & 220 & $0.42 \pm 0.03$ & $0.19 \pm 0.02$ & $0.18 \pm 0.02$ \\
\hline
\end{tabular}

${ }^{a}$ Means \pm SEM (no. at embryonic stage/no. of 2-cell embryos) are based on 27 females; within a column, means with different superscripts ${ }^{\mathrm{c}, \mathrm{d}, \mathrm{e} e}$ are significantly different (ANOVA, Tukey, $P<0.05$ ). Days post-insemination, day of insemination is day 1.

\section{Discussion}

Culturing mouse embryos in the presence of $50 \mu \mathrm{M}$ ouabain during the early preimplantation period resulted in all experiments in a higher incidence of blastocyst formation. This finding confirms our previous observations (Dumoulin et al., 1992c, 1993).

In a first exploratory series of experiments to determine the time interval of the preimplantation period during which ouabain benefits mouse embryo development " ouabain was shown to exert its beneficial effect exclusively when present during the first 2 days post-insemination.

In the second series of experiments, the temporal effect of ouabain was examined in more detail. Only embryos exposed to ouabain either in the period of $22-46 \mathrm{~h}$ postinsemination , or during the whole preimplantation period benefited from its presence. This positive effect of ouabain on subsequent embryonic development was noticeable from the morula stage onward. The time period of $22-46 \mathrm{~h}$ post-insemination coincides roughly with the 2-cell stage. In the mouse, the first cleavage division takes place at $18-22 \mathrm{~h}$ postinsemination in vitro (Howlett and Bolton, 1985), whereas by $48 \mathrm{~h}$ post-insemination most embryos will be at the early 4-cell stage (Flach et al., 1982). When embryos were exposed to ouabain between 46 and $70 \mathrm{~h}$ post-insemination, blastocyst formation was accelerated; however, this did not result in a higher incidence of blastocysts at $120 \mathrm{~h}$ post-insemination. Wiley (1984) also found an accelerated embryonic development when morula-stage embryos were exposed to low concentrations $(10 \mu \mathrm{M})$ of ouabain. 
It is not unlikely that a compound which exerts such a marked effect on mouse embryo development during the 2-cell stage should aiso influence the 2-cell block exhibited by mouse embryos from randomly bred strains when cultured in vitro (Goddard and Pratt, 1983). Therefore, the effect of ouabain on the preimplantation development of embryos from a randomly bred mouse strain was compared with the effect of EDTA, and with the effect of culturing under low oxygen conditions, as these two conditions have been shown partially to obviate the 2-cell block. Abramczuk et al. (1977) showed that $>70 \%$ of 1-cell embryos from a randomly bred strain developed into blastocysts in medium supplemented with $11 \mu \mathrm{M}$ of the chelating agent EDTA, while without EDTA only $15-30 \%$ of embryos reached the blastocyst stage. The finding that EDTA can overcome the 2-cell block was later confirmed by others (Fissore et al., 1989; Toyoda et al., 1989; Mehta and Kiessling, 1990). Nasr-Esfahani (1990) found that 0.1 mM EDTA gave optimal development rates: $58 \%$ blastocysts as compared to $0 \%$ when no EDTA was present. Recently, it has been shown that the culture of zygotes from randomly bred mice under reduced oxygen concentrations allowed some embryos to overcome the 2-cell block in vitro. Umaoka et al. (1992) found that $29 \%$ of zygotes of randomly bred mice developed to the blastocyst stage when cultured under $5 \% \mathrm{O}_{2,}$ compared to only $2 \%$ of blastocysts when the embryos were cultured under ambient $\mathrm{O}_{2}$ concentration. Our experiments show that ouabain is at least as effective as EDTA, and more effective than the culture under $5 \% \mathrm{O}_{2}$, in allowing the embryos from randomly bred mice to develop beyond the 2-cell stage.

As the only known action of ouabain is the inhibition of the enzyme $\mathrm{Na}^{+}-\mathrm{K}^{+}$-ATPase (Anmer, 1985; Sweadner, 1989), our results confirm the findings of Powers and Tupper (1977) in demonstrating indirectly the presence of this enzyme in the 2-cell mouse embryo. By immunocytochemical methods, Gardiner et al. (1990) were able to detect low levels of $\mathrm{Na}^{*}-\mathrm{K}^{+}$-ATPase in 2-cell mouse embryos. The low expression of this enzyme during early mouse preimplantation development is suddenly increased in the late morula and blastocyst stages, and is accompanied by an abrupt change of the intracellular distribution of the enzyme (Watson and Kidder, 1988; Gardiner et al., 1990; Watson et al., 1990). In the morula, $\mathrm{Na}^{+}-\mathrm{K}^{+}$-ATPase is found throughout the cytoplasm of each blastomere, while in the blastocyst, the enzyme is found localized to the basolateral cell surfaces of the trophectoderm encircling the blastocoelic cavity (Watson and Kidder, 1988). It has been hypothesized that $\mathrm{Na}^{+}-\mathrm{K}^{+}-$ATPase is involved in the process of cavitation in mammalian embryos, by pumping $\mathrm{Na}^{+}$into the blastocoel against its concentration gradient, thus resulting in an osmotic flow of water into the cavity (Wiley, 1984; Watson and Kidder, 1988; Biggers et al., 1988). The effects of ouabain demonstrated on later preimplantation development and blastocyst formation would be consistent with that hypothesis. Indeed, the presence of $1 \mathrm{mM}$ (DiZio and Tasca, 1977), $0.1 \mathrm{mM}$ (Wiley, 1984), or $0.5 \mathrm{mM}$ ouabain (Manejwala et al., 1989) during the morula and blastocyst stages resulted in impaired blastocyst formation in the mouse. Also in the rabbit, blastocyst fluid accumulation is inhibited by ouabain (Biggers et al., 1988). In our experiments, we did not find any effect of ouabain when present during the late preimplantation period. Possibly, the ouabain concentration we used $(50 \mu \mathrm{M})$ was too low to result in the expected lower incidence of blastocyst formation. 
It is as yet unclear why the transient inhibition of $\mathrm{Na}^{*}-\mathrm{K}^{+}-\mathrm{ATPase}$ by ouabain during the 2-cell stage, when only low housekeeping' levels of $\mathrm{Na}^{+}-\mathrm{K}^{+}-\mathrm{ATPase}$ activity are present in the mouse embryo (Gardiner et al., 1990), leads to such a marked pasitive effect on subsequent embryonic development in vitro. $\mathrm{Na}^{*}-\mathrm{K}^{*}$-ATPase is the most important regulator of intracellular electrolyte concentrations in mammalian cells: It directly controls the intracellular $\mathrm{Na}^{*}$ and $\mathrm{K}^{*}$ concentrations by actively transporting three $\mathrm{Na}^{*}$ ions out of the cell and two $\mathrm{K}^{+}$ions into the cell, thus producing ionic gradients. As a result, under normal steady-state conditions the cytoplasm of most cells, including mouse preimplantation embryos, has a high (100-160 mM) $\mathrm{K}^{+}$concentration and a low $(3-30 \mathrm{mM}) \mathrm{Na}$ concentration, this in contrast to the extracellular fluid (Schuurmans Stekhoven and Bonting. 1981; Lee; 1987). $\mathrm{Na}^{*}-\mathrm{K}^{*}$ ATPase, in combination with several secondary transport systems and ion channels, controls indirectly many other essential cellular functions, such as cell volume, membrane potential and the intracellular concentrations of many other substances by maintaining the steep $\mathrm{Na}^{*}$ and $\mathrm{K}^{*}$ concentration gradients (Sweadner and Goldin, 1980; Rossier et al., 1987). For example, $\mathrm{Na}^{+}-\mathrm{Ca}^{2+}$-exchange and $\mathrm{Na}^{*} \mathrm{co}$-transport systems such as amino acid transport all depend on the $\mathrm{Na}^{+}$gradient (Scott, 1987). When the active transport of $\mathrm{Na}^{*}$ and $\mathrm{K}^{+}$ ians by $\mathrm{Na}^{+}-\mathrm{K}^{+}$-ATPase is inhibited by ouabain. $\mathrm{Na}^{+}$tends to flow into the cell, the $\mathrm{K}^{+}$ out of the cell, by passive ion channels because of their steep concentration gradients. This will result in slowing down the $\mathrm{Na}^{+}$co-transport systems (Scott, 1987), in an elevation of the intracellular $\mathrm{Ca}^{2+}$ concentration (Sweadner and Goldin, 1980), and in a membrane depolarisation (Stahl, 1986), which in turn will activate voltage-sensitive ion-channels like $\mathrm{Ca}^{2+}$ channels (Miller, 1992).

As inhibition of $\mathrm{Na}^{*}-\mathrm{K}^{*}$-ATPase clearly has a positive effect on mouse embryonic development, this could mean that this enzyme is also inhibited in vivo. There is good evidence for the existence of an endogenous inhibitor of $\mathrm{Na}^{+}-\mathrm{K}^{+}-\mathrm{ATPase}$ with a role in blood volume regulation (Wilkins, 1985). We have found recently that culture of mouse embryos in the presence of the $B$-amino acid taurine results in a higher incidence of blastocyst formation (Dumoulin et al., 1992a). In the hamster, it has been found that the in-vitro development of IVF embryos beyond the 8-cell stage was absolutely dependent on hypotaurine, a precursor of taurine (Barnett and Bavister, 1992). Both taurine and hypotaurine have been shown to have an inhibitory effect on $\mathrm{Na}^{+}-\mathrm{K}^{+}$-ATPase (Mrsny and Meizel, 1985), although this was not confirmed in other studies (Akera et al., 1976). Interestingly, taurine is also present at high concentrations in female reproductive tract fluids of several mammalian species (Meizell et al., 1980; Casslén, 1987; Miller and Schultz, 1987; Dumoulin et al., 1992a).

A second possible explanation for the positive effect of inhibition of $\mathrm{Na}^{+}-\mathrm{K}^{+}-\mathrm{AT}$ Pase on mouse embryonic development could be that the culture conditions used are not optimal, leading to an intracellular electrolyte imbalance that can be ameliorated by this inhibition. That the conditions usualy used to culture mammalian embryos are not optimal is illustrated firstly by the fact that embryos of randomly bred mouse strains, as well as embryos of many other mammalian species, exhibit a developmental block in vitro (Bavister, 1988), secondly by the fact that the rate of mouse preimplantation embryo development in vitro is retarded as compared with that in vivo (Harlow and Quinn, 1982; Caro and Trounson. 1987), and lastly by the fact that in-vitro-fertilized and cultured mouse embryos lead to lower implantation rates and lower birth weights when tranferred to pseudopregnant recipients, as compared to in-vivo-developed embryos transferred directly after retrieval (Han and Kiressling, 1988). Although the succesful culture of mouse zygotes to the blastocyst stage was reported by Whitten and Biggers as early as 1968 , much effort is still made to determine more optimal electrolyte composition of the culture media (Quinn et al., 1985; McKiernan and Bavister, 
1990, Lawitts and Biggers, 1991a,b). The electrolyte composition of the cuture media usually used to culture mammalian preimplantation embryos is similar to that of serum, and different from the oviductal fluid in which embryonic development in vivo takes place (Roblero et al., 1976, Borland et al., 1977; Bavister, 1981; Quinn et al., 1985). It is still an unsolved paradox as to why the in-vitro development of mouse 1-cell embryos to the blastocyst stage is optimal in media with low $K^{*}$ concentrations (Lawitts and Biggers, $1991 \mathrm{~b}$; Dumoulin et al. 1993 ), whereas the $K^{*}$ concentration in oviductal fluid is very high, e.g. between 18 $\mathrm{mM}$ and $30 \mathrm{mM}$ (Roblero et al., 1976, Borland et al. 1977). Studies from Lawitts and Biggers $(1991 \mathrm{a}, \mathrm{b} ; 1992)$ indicate that a high concentration of inorganic salt in the culture medium may be a possible cause for the 2-cell block of randomly bred mouse embryos. They hypothesize that, when cells are placed in hypertonic medium and no organic solutes such as glutamine are present, cells caln only accumulate inorganic salts as a respons to the osmotic stress (Lawitts and Biggers, 1992). This may raise the intracellular concentration of these salts to values that are detrimental to the cell. However, when cells are placed in hypo-osmotic medium as used by these authors, they react by losing their major internal ion, $K^{*}$, by a number of different mechanisms, followed by an osmotic flow of water, in an attempt to maintain their cell volume (Hoffmann and Simonsen, 1989). The lowering of the $\mathrm{K}^{*}$ concentration in the cell occurs also when $\mathrm{Na}^{+}-\mathrm{K}^{+}$-ATPase is inhibited by ouabain, as in our experiments.

More experiments are needed to understand the intricate interactions of the different ion-transporting mechanisms and ion channels the embryo uses to maintain the correct balance between the intra- and extracellular inorganic salt concentrations.

\section{References}

Abramczuk,J., Solter,D. and Koprowski,H. (1977) The beneficial effect of EDTA on development of mouse one-cell embryos in chemically defined medium. Dev. Biol., 61, 378-383.

Akera, T., Ku, D. and Brody, T.M. (1976) Allerations of ion movements as a mechanism of drug-induced arrhythmias and inotropic responses. In Huxtable, R. and Barbeau, A. (eds), Taurine Raven Press, New York, pp. $121-134$

Anner, B.M. (1985) The receptor function of the $\mathrm{Na}^{*}, \mathrm{~K}^{+}$-activated adenosine triphosphatase system. Biochem. J. 227, 1-11.

Barnet, D.K. and Bavister,B.D. (1992) Hypotaurine requirement for in vitro development of golden Mamster one-cell embyos into morulae and blastocysts, and production of tem offspring from in vitro-fertilized ova. Biol. Reprod. 47, 297-304

Bavister,B.D. (1981) Analysis of culture media for in vitro fertilization and criteria for succes. In Mastroianni.L. and Biggers ${ }_{2}$.D. (eds). Fertilization and embryonic development in vitro. Plenum Press, New York, pp. 41-60.

Bavister, B.D. (1988) Role of oviductal secretions in embryonic growth in vivo and in vitro. Theriogenology, 29, 143-154.

Biggers, J.D., Bell,J E. and Benos, D.J. (1988) Mammalian blastocysts: transport functions in a developing epithelium. Am. J. Physiol, 255, C419-C432.

Borland,R.M. Hazra.S. Biggers,J.D and Lechene, C.P. (1977) The elemental composition of the environments of the gametes and preimplantation embryo during the initiation of pregnancy. Biol. Reprod., $16,147-157$

Caro, C.M., Trounson, A and Kirby, C. (1987) Effect of growth factors in culture medium on the rate of mouse embryo development and viability in vitro. J. in Vitro Fent. Embryo Transfer , 4, $265-268$.

Casslen, B. G. (1987) Free amino acids in human uterine fluid J. Reprod. Med. 32, 181-184.

DiZio. 5.M. and Tasca, R.J. (1977) Sodium-dependent amino acid transport in preimplantation mouse embryos. Dev. Biol. 59, 198-205. 
Dumoulin, J.C.M., Evers, J.L.H. Bras,M., Pieters,M.H.E.C. and Geraedts, J P.M. (1992a) Positive effect of taurine on preimplantation development of mowse embryos in vitro. J. Reprod Fertil. 94, 373-380.

Dumoulin,J.C.M. Ewers, J.L.H., Bakker,J.A, Bras,M.,Pieters, M.H.E.C and Geraedts, J.P.M. (1992b) Temporal effects of taurine on mouse embryo development in vitro. Hum. Reprod:, $7_{3} 403-407$.

Dumoullin, J.C.M., Pieters,M.H.E.C., Bras,M, Michiels,A.H.J.C., Land,J.A, Geraedts,J.P.M. and Evers,J.L.H. (1992C) Inhibition of $\mathrm{Na}^{*}-\mathrm{K}^{*}$-ATPase is beneficial for preimplantation mouse development in vitro. Abstracts of the 8th ESHRE Meeting. The Hague. Hum. Reprod., T (Suppl.), p. 128.

Dumoulin,J.C.M., Evers, J.L.H. Michiels,A.H.J.C., Pieters, M.H.E.C.,Bras,M., Land,J.A and Geraedts, J.P.M. (1993) Modulation of embryonic $\mathrm{Na}^{*}-\mathrm{K}^{*}$-ATPase activity and mouse preimplantation development in vitro in media containing high concentrations of potassium. Mol. Reprod. Devel., in press.

Fissore, R.A., Jackson,K.V. and Kiessling,A.A. (1989) Mouse zygote development in culture medium without protein in the presence of ethylenediaminetetraacetic acid. Biol. Reprod., 41, 835-841.

Flach, G. Johnson, M.H., Braude,P.R. "Taylor ${ }_{v}$.A.S. and Bolton, V.N. (1982) The transition from maternal to embryonic control in the 2-cell mouse embryo. EMBO J., 1,681-686.

Fleiss,J.L. (1986) The design and analysis of clinical experiments. Wiley \& Sons, New York

Gardiner,C.S., Williams, J.S. and Menino,A.R. (1990) Sodium/potassium adenosine triphosphatase a- and $B$-subunit and $\alpha$-subunit mRNA levels during mouse embryo development in vitro. Biol. Reprod. 43, 788-794.

Goddard,M.J. and Pratt H.P.M. (1983) Control of events during early cleavage of the mouse embryo: an analysis of the '2-cell block'. J.Embryol.exp.Morph., 73, 111-133.

$\mathrm{Han}{ }_{s} \mathrm{H}$-D. and Kiessling, A.A. (1988) In vivo development of transferred mouse embryos conceived in vitro in simple and complex media. Fertil. Steril., 50, 159-163.

Harlow,G.M. and Quinn, P. (1982) Development of preimplantation mouse embryos in vivo and in vitro. Aust. J.Biol Sci., 35, 187-193.

Hoffmann,E.K. and Simonsen,L.O. (1989) Membrane mechanisms in volume and pH regulation in vertebrate cells. Physiol. Rev, 69, 315-382.

Howlett,S.K. and Bolton, V.N. (1985) Sequence and regulation of morphological and molecular events during the first cell cycle of mouse embryogenesis. J. Embryol. exp. Morph., 87, 175-206.

Huxtable, R.J. (1992) Physiological actions of taurine. Physiol. Rew., 72, 101-163.

Jacobsen, J.G and Smith,L.H. (1968) Biochemistry and physiology of taurine and taurine derivatives. Physiol. Rev., 48, 424-511.

Lawitts,J.A. and Biggers, J.D. (1991a) Optimization of mouse embryo culture media using simplex methods. J. Reprod. Fert., 91, 543-556.

Lawitts,J.A. and Biggers,J.D. (1991b) Overcoming the 2-cell block by modifying standard components in a mouse embryo culture medium. Biol. Reprod. 45, 245-251.

Lawitts,J.A. and Biggers,J.D. (1992) Joint effects of sodium chloride, glutamine, and glucose in mouse preimplantation embryo culture media. Mol. Reprod. Devel., 31, 189-194.

Lee,S. (1987) Membrane properties in preimplantation mouse embryos. J. In Vitro Fert. Embryo Transfer. $4,331-333$

Manejwala,F.M., Cragoe, E.J. and Schultz,R.M. (1989) Blastocoel expansion in the preimplantation mouse embrya: role of extracellular sodium and chloride and possible routes of their entry. Dev. Biol. 133, 210-220.

McKiernan,S.H. and Bavister,B.D. (1990) Environmental variables influencing in vitra development of hamster 2-cell embryos to the blastocyst stage. Biol. Reprodl., 43, 404-413.

Mehta, T.S and Kiessling,A.A. (1990) Developmental potential of mouse embryos conceived in vitro and cultured in ethylenediaminetetraacetic acid with or without amino acids or serum. Biol. Reprodi, 43, 600-606.

Meizel,S., Lui ,C.W., Working,P.K. and Mrsny.R.J. (1980) Taurine and hypotaurine: their effects on motility, capacitation and the acrosome reaction of hamster sperm in vitro and their presence in sperm and reproductive tract fluids of several mammals. Develop. Growth and Differ., 22, 483-494.

Miller,J.G.D. and Schultz,G.A. (1987) Amino acid content of preimplantation rabbit embryos and fluids of the reproductive tract. Biol. Reprod., 36, 125-129.

Miller,R.J. (1992) Voltage-sensitive Ca ${ }^{2 *}$ channels. ل. Biol. Chem., 267, 1403-1406.

Mrsny,R.J. and Meizel, S. (1985) Inhibition of hamster sperm Na ${ }^{+}, K^{*}$-ATPase activity by taurine and hypotaurine. Life Sci, 36, 271-275

Nasr-Esfahani,M. Johnson, M.H. and Aitken, R.J. (1990) The effect of iron and iron chelators on the in-vitro block to development of the mouse preimplantation embryo: BAT6 a new medium for improved culture of mouse embryos in vitro. Hum. Reprod, 5,997-1003

Powers, R.D. and Tupper,J.T. (1977) Developmentall changes in membrane transport and permeability in the early mouse embryo. Dev. Biol, , 56, 306-315. 
Quinn, $P$, Kerin,J.F, and Warnes, G.M. (1985) Improved pregnancy rate in human in vitro fertilization w the use of a medtum based on the composition of human tubal fiuid. Fertil. Sterit. 44, 493 498 .

Roblero, L. Biggers, J.D. and Lechene,C.P. (1976) Electron probe analysis of the elemental microenvironment of oviducal mouse embryos. J. Reprod. Fert. 61, 387-393.

Rossier, $B . C_{1}$, Geering, $K$ and Kraehenbuhl, J.P. (1987) Regullation of the sodium pump: how and why? Trends Biochem. Sci. 12, 483-487.

Schuurmans Stekhoven, $F$, and Bonting, S L (1981) Transport adenosine triphosphates: properties and functions. Physiol Rew, 61, 1-76:

Scott, D.M. (1987) Sodium cotransport systemis. cellular, molecular and regulatory aspects. BioEssays $71-78$.

Stahi, W.S, (1986) The Na,K, ATPase of nenous tissue. Neurochem. Int. 8, 449-476.

Sweadner, KJ. and Goldin, S.M. (1980) Active transport of sodium and potassium ions. New Engl.J.Med $302,777-783$.

Sweadrier,KJ. (1989) Isozymes of the Nat/K*-ATPase. Biochim. Biophys. Acta, 988, 185-220.

royoda, Y. Azuma, S and Takeda, S. (1989) Effects of chelating agents on preimplantation developmen of mouse embryos fertilized in vitro. In Yoshinaga, $K$ and Moni $T$. (eds). Development of preimplantatio embryos and their enviromment. Alan R. Liss, New York, pp. 171-179.

Umaoka, Y., Noda, Y., Narimoto, K. and Mori, T. (1992) Effects of oxygen toxicity on early development of mouse embryos. Mol. Reprod. Devel, 31, 28-33.

Watson, A.J. and Kidder, G.M. (1988) Immunofluorescence assessment of the timing of appearance and cellular distribution of Na/K-ATPase during mouse embryogenesis. Dev. Biol. 126, 80-90.

Watson,A.J., Pape,C., Emanuel,J.R., Levenson,R. and Kidder, G.M. (1990) Expression of Na,K-ATPase $\alpha$ and $B$ subunit genes during preimplantation development of the mouse. Dev. Genet, $11,41-48$.

Wiley L.M. (1984) Cavitation in the mouse preimplantation embryo: Na/K-ATPase and the origin of nascent blastocoele fluid. Dev. Biol., 105, 330-342.

Whitten, W.K. and Biggers, J.D. (1968) Complete development in vitro of the preimplantation stages of the mause in a simple chemically defined medium. J. Reprod. Fert. 17, 399-401.

Wilkins, M.R. (1985) Endogenous digitalis: a review of the evidence. Trends Pharmacol. Sci, ,6, 286-288. 


\section{Chapter 6}

\section{Taurine acts as an osmolyte in human and mouse oocytes and embryos.}

John C.M. Dumoulin', Lucie C.P. van Wissen', Paul P.C.A. Menheere ${ }^{2}$, Anton H.J.C. Michiels ${ }^{3}$, Joep P.M. Geraedts ${ }^{3}$ and Johannes L.H. Evers

Departments of ${ }^{1}$ Obstetrics \& Gynaecology, ${ }^{2}$ Clinical Chemistry, and ${ }^{3}$ Molecular Cell Biology \& Genetics, Academic Hospital, University of Limburg, Maastricht, The Netherlands.

Published in:

Biology of Reproduction, 56, 739-744 (1997) 


\section{Summary}

Taurine transport in mouse embryos has been shown to be osmotically regulated. We studied release of taurine from mouse and human oocytes and embryos when exposed to conditions that created osmotic imbalances, either by incubation in anisosmotic media or by inhibition of $\mathrm{Na}^{+} \mathrm{K}$-ATPase with ouabain. Furthermore, we studied the effect of cleavage in mouse embryos on release of taurine.

When human oocytes that remained unfertilized after in vitro fertilization, human embryos (2- to 8-cell), and mouse 2-cell embryos were loaded with [ $\left.{ }^{3} \mathrm{H}\right]$ taurine and subsequently incubated for $4 \mathrm{~h}$ in hyposmotic media ( 200 and $240 \mathrm{mOsm} / \mathrm{kg}$ ), they showed significantly lower radioactivity as compared to those incubated in media of 280,320 , and $360 \mathrm{mOsm} / \mathrm{kg}$ and higher radioactivity of the incubation media. Incubation with $1.5 \mathrm{mM}$ ouabain resulted in decreased radioactivity of mouse embryos and increased radioactivity of incubation medium. When mouse 2-cell embryos were cultured for $24 \mathrm{~h}$ after loading with [ ${ }^{3} \mathrm{H}$ ]laurine, radioactivity of embryos that cleaved to the 4-cell stage was significantly lower than that of uncleaved embryos. This finding is in accordance with the theory that cell division induces cell volume-regulatory mechanisms. In contrast, when 1-cell embryos were cultured for $24 \mathrm{~h}$, radioactivity of embryos developing to the 2-cell stage was significantly higher than that of uncleaved embryos.

These data support the theory that taurine is released by embryos when they have to adjust their cell volume because of either extracellularty induced or intracellularly occurring osmotic imbalances. When culture is performed without taurine, the resultant taurine depletion of embryos may be disadvantageous, either because the embryo has to rely more on its inorganic osmolytes for volume regulation or because taurine can no longer provide its other protective functions.

\section{Introduction}

Taurine is a $\beta$-amino acid that is present in millimolar concentrations in many tissues of the mammalian body, with highest concentrations found in the brain and heart (e.g., 40 $m M$ in the rat heart) $[1,2]$. High levels of taurine are also found in mouse preimplantation embryas $[3,4]$. In contrast, most body fluids, such as plasma and extracellular fluid, contain much lower concentrations, typically in the range of 10-100 $\mathrm{M}$ [1]. Remarkably, however, in female reproductive tract fluids of several mammals, including the mouse, taurine is found in high concentrations [5-7]. In the human, a concentration of up to $11.7 \mathrm{mM}$ taurine has been found in uterine fluid of the luteal phase [8]. The actions of taurine on tissues and cells are manifold, and vary widely (see extensive review in [1]). It has been shown that taurine exerts a positive effect on preimplantation embryonic development in vitro in the mouse [3,7,9], pig [10], cow [11], and rabbit [12]. However, the precise nature of this action of taurine is as yet unknown. The best-studied function of taurine in several cell types is that of osmoregulation [1]. Mammalian cells confronted by either changing extracellular osmolality or changing concentrations of intracellular osmolytes maintain a constant cell volume by the release and uptake of solutes, followed by the release or uptake of water $[13,14]$. The principal solutes involved in osmotic regulation are the inorganic ions $\mathrm{K}^{+}$and $\mathrm{Cl}^{-}$[13]. Low molecular weight organic compounds, which contribute 10-20\% to the total intracellular osmolarity in mammals, can also be used as osmoregulators [1, 
15]. The low molecular weight organic compound taurine has been shown to be an important osmoregulator in many cell types [16-18]. Also in mouse preimplantation embryos, taurine transport has been shown to be stimulated under anisosmotic conditions [19]. It has been demonstrated in mouse embryos that taurine release takes place via $\mathrm{Na}^{*}$-independent channels and taurine uptake via the $\mathrm{Na}^{*}$-dependent system $\beta[$ [19].

In the present study, the role of taurine as an osmolyte in preimplantation embryos was studied more precisely. First; to establish our experimental methodology, the release of radioactive-labeled taurine from mouse oocytes and embryos was studied under experimental conditions known to result in osmotic imbalances, i.e., incubation in hyposmotic media and inhibition of the cellular enzyme $\mathrm{Na}^{*}-\mathrm{K}^{+}-\mathrm{ATP}$ ase with ouabain. To test whether the different experimental conditions resulted in any immediate damage to the embryos, their viability was assessed using the fluorescein diacetate (FDA) test [20] in a separate experiment. Second, the release of taurine from human oocytes and embryos under anisosmotic conditions was examined to investigate whether taurine release was also hyposmotically stimulated in the human. Third, the release of taurine from mouse embryos was measured under semiphysiological conditions in which they are routinely cultured in vitro, in order to study the effect of cleavage divisions on the efflux of taurine.

\section{Materials and methods}

\section{Zygotes and embryos}

Mouse oocytes and 2-cell embryos were obtained after fertilization in vitro (IVF) of oocytes from (C57BI x CBA)F1 hybrid females with spermatozoa from random-bred Swiss males. Oocytes were used for labeling with radioactive taurine at $4 \mathrm{hr}$ postinsemination (hpi), and 2-cell embryos were used at $22 \mathrm{hpi}$. The IVF and embryo culture methods used were as described previous:y [7]. T6 medium [21] was used in all experiments. Osmolality of the medium was $280 \mathrm{mOsm} / \mathrm{kg}$. For IVF, the medium contained $30 \mathrm{mg} / \mathrm{ml}$ BSA. Four hours after insemination, oocytes were transferred to fresh medium containing $5 \mathrm{mg} / \mathrm{ml} \mathrm{BSA}$.

Human oocytes that showed no signs of fertilization at Day 2 after insemination (IVF fallures), and surplus embryos from IVF treatments, were used for our experiments provided that the couple had given consent. The surplus embryos used were embryos that had been judged unsuitable for cryopreservation at Day 3 after insemination because of either poor morphology, slow development, or both. Human IVF and embryo culture methods were as described previously [22].

\section{Radiolabeled taurine efflux experiments}

Oocytes and embryos were incubated in a 50- $\mu$ d drop of T6 medium containing $10 \mu \mathrm{M}$ $\left[{ }^{3} \mathrm{H}\right]$ taurine $(9.6 \mathrm{Ci} / \mathrm{mmol}$, Amersham/Life Science, Buckinghamshire, UK) under mineral oil for $2 \mathrm{~h}$ in an atmosphere of $5 \% \mathrm{CO}_{2}$ in air at $37^{\circ} \mathrm{C}$. After this, embryos or zygotes were washed four times in $1 \mathrm{ml}$ medium without label to remove radiolabel not taken up. Of the final wash medium, an aliquot of $50 \mu \mathrm{l}$ was taken and the radioactivity was measured in order to check whether the washing procedure was sufficient. Some oocytes or embryos were used immediately for measurement of radioactivity after the 2 -h labeling period. Remaining oocytes or embryos were distributed at random among different experimental groups for measurement of the efflux of taurine. They were cultured for $4 h$, and in some 
experiments, for $24 \mathrm{~h}$, in 50 - $\mu l$ drops of $\mathrm{T} 6$ containing no taurine. This medium was either standard T6 $(280 \mathrm{mOsm} / \mathrm{kg})$, supplemented in one experimental series with ouabain, or T6 with various osmolalities. Media with different osmolalities were prepared by dilution of a stock solution of concentrated T6 $(360 \mathrm{mOsm} / \mathrm{kg})$ with appropriate volumes of water. After the incubation period, oocytes or embryos were washed two times in fresh medium of the same composition and were processed as described below for radicactivity assessment.

For measurement of radioactivity, oocytes or embryos were transferred, either in groups of 5 (in the mouse) or individually (in the human), with a minimum of medium, to glass vials containing $50 \mathrm{pl}$ of a hypotonic lysis buffer $(\mathrm{pH} 2.0,100 \mathrm{mOsm} / \mathrm{kg}$ ) in order to lyse the cells and dissolve their zona pellucida. In most experimental series, the complete volume of medium $(50 \mu \mathrm{l})$ in which the oocytes or embryos had been incubated was taken for measurement of radioactivity as well. To all samples, $10 \mathrm{ml}$ of Rialuma liquid scintillation counting cocktail (Perstorp Analytical, Oud Beijerland, The Netherlands) was added. This cocktail is based on pseudo cumene and has a high sample-holding capacity linked to a high counting efficiency and a high quench resistance. Nevertheless, counting efficiency and quenching were verified; each measurement used external standard spectral quench ratios with a ${ }^{226} \mathrm{Ra}$ source. No correction due to (color or volume) quenching proved to be necessary. Radioactivity (in cpm) was measured using a Wallac 1219 Rackbeta liquid scintillation counter (Wallac Oy, Turku, Finland). Counting time was fixed for all samples at 10 minutes. Background level of the Rialuma cocktail was measured as $17.7 \pm 1.2(\mathrm{cpm}$ $\pm S D)$.

\section{FDA viability test}

Groups of five 2-cell mouse embryos were subjected to the same experimental conditions as described above, i.e., loading with radioactive taurine for $2 \mathrm{~h}$ followed by incubation for $4 \mathrm{~h}$ in media with different osmolalities or in medium with the highest ouabain concentration tested. After this, embryos were incubated for exactly $1 \mathrm{~min}$ at room temperature in Hepesbuffered T6 containing $2.5 \mu \mathrm{g} / \mathrm{ml}$ FDA [20]. FDA solutions were prepared just before use from a stock solution. Embryos were washed several times in T6 without FDA and observed with a Bio-Rad MRC-600 confocal scanning laser microscope (Bio-Rad Laboratories, Richmond, CA). Care was taken that each group of embryos was examined at exactly the same time period $(10 \mathrm{~min})$ after incubation in $\mathrm{FDA}_{\mathrm{v}}$ as it has been shown that intracellular accumulated fluorescein is quickly lost from cells. The mean fluorescence intensity of the scanned area of each embryo was, after subtraction of background fluorescence, expressed in arbitrary units on a scale of $0-256$. 


\section{Statistical methods}

In each experimental series, several replicate experiments were performed on different days. For each replicate experiment, a mean uptake value of [ $\left.{ }^{3} \mathrm{H}\right]$ taurine was determined by averaging the cpm of 3-5 groups of oocytes or embryos measured immediately after the 2-h labeling periad. Radioactivity of each group of 5 (mouse) or of single (human) oocytes or embryos, after an incubation of 4 or $24 \mathrm{~h}$ in medium without label, was expressed as percentage of the mean uptake value of the corresponding experiment. This procedure was repeated in each independent replica experiment. The mean percentages \pm SEM of radioactivity were calculated for every experimental group cultured in different efflux media and were examined statistically with an ANOVA or Student's $t$-test " where appropriate [23]. When the ANOVA test showed significant differences $(p<0.05)$, differences between individual experimental groups were evaluated using the multiple-comparisons test according to Tukey [23]. In the experimental series in which the radioactivity of the various efflux media was measured, the amount of labeled taurine released per embryo in the $50-\mu$ d drop of medium was calculated by dividing the radioactivity by the number of embryos incubated in the drop of medium. These data were analyzed statistically as indicated above.

\section{Results}

Mean radioactivity values (in cpm $\pm \mathrm{SD}$ ) of the oocytes and embryos after the 2-th labeling periad were, respectively, $971 \pm 343$ in 32 measurements of groups of five 1-cell mouse embryas at 6 hpi, $2361 \pm 886$ in 79 measurements of groups of five 2-cell mouse embryos at $24 \mathrm{hpi}, 927 \pm 765$ in 29 measurements of single human IVF failures on the third day after insemination and $812 \pm 333$ in 17 measurements of single human spare embryos on the third day after insemination. Since for unknown reasons the uptake of labeled taurine varied considerably between replica experiments, radioactivity of oocytes or embryos after incubation of 4 or $24 \mathrm{~h}$ in medium without label was expressed as percentage of the mean uptake value of the corresponding experiment. Mean radioactivity of the last washing medium, before the embryos were distributed over the various efflux media, in a total of 46 experiments, was $34.8 \pm 15.2$ (cpm \pm SD), indicating that radiolabel not taken up by the embryos can be successfully removed in the washing procedure.

In the first experimental series, mouse 2-cell embryos labeled for $2 \mathrm{~h}$ with [ ${ }^{3} \mathrm{H}$ ]taurine were subsequently cultured for $4 \mathrm{~h}$ in media with different osmolalities. During this period: embryos do not release a significant amount of $\left[{ }^{3} \mathrm{H}\right]$ taurine when cultured in media of 280 $\mathrm{mOsm} / \mathrm{kg}$ or higher (Table 1). However, incubation in hyposmotic media results in decreased radioactivity of embryos, accompanied by an increase in radioactivity of the incubation media, indicating a release of $\left[{ }^{3} \mathrm{H}\right]$ taurine in the medium by the embryos. 
Table 1. Effect of osmolality on [ 3 H]taurine release from mouse 2-cell embryos

\begin{tabular}{|c|c|c|}
\hline $\begin{array}{l}\text { Osmolality } \\
\text { (mosm/kg) }\end{array}$ & $\begin{array}{c}\text { Radioactivity } \\
\text { of embryos } \\
(0 \% \text { of uptake })^{a}\end{array}$ & $\begin{array}{c}\text { Radioactivity } \\
\text { of efflux medium } \\
\text { (cpm/embryo/50 } \mathrm{ul})^{\mathrm{b}}\end{array}$ \\
\hline $\begin{array}{l}\text { Uptake } \\
360 \\
320 \\
280 \\
240 \\
200\end{array}$ & $\begin{array}{r}900 \pm 3 \\
995 \pm 4 \\
93 \pm 4 \\
98 \pm 3 \\
74 \pm \pm 4 \\
93 \pm 2\end{array}$ & $\begin{array}{c}\cdot \\
c_{33} \pm 3 \\
c_{36} \pm 5 \\
c_{29} \pm 4 \\
d_{129} \pm 23 \\
e_{312} \pm 37\end{array}$ \\
\hline
\end{tabular}

"Means + SEM, based on 18 measurements of groups of five 2-cell embryos "obtained in 7 replicate experiments.

Means \pm SEM, based on measurements of the incubation media used in the 7 replicate experiments, divided by the number of embryos cultured in the media.

cdie In a column, means with different superscripts are significantly different (ANOVA, Tukey, $p<0,001$ ).

In the second experimental series, labeled mouse 2-cell embryos were cultured for 4 h in media with various ouabain concentrations. Incubation in $1500 \mu \mathrm{M}$ ouabain resulted in significantly decreased radioactivity of embryos and an increase in radioactivity of the incubation media (Table 2).

Table 2. Effect of ouabain on [3] $\mathrm{H}]$ taurine release from mouse 2-cell embryos

\begin{tabular}{|c|c|c|}
\hline $\begin{array}{l}\text { Ouabain } \\
\text { concentration } \\
(\mu \mathrm{M})\end{array}$ & $\begin{array}{l}\text { Radioactivity } \\
\text { of embryos } \\
(\% \text { of uptake })^{a}\end{array}$ & $\begin{array}{c}\text { Radioactivity } \\
\text { of efflux medium } \\
(\mathrm{cpm} / \mathrm{embryo} / 50 \mu \mathrm{l})^{\mathrm{b}}\end{array}$ \\
\hline $\begin{array}{l}\text { Uptake } \\
0 \\
50 \\
500 \\
1500\end{array}$ & $\begin{array}{r}100 \pm 2 \\
89 \pm 2 \\
c_{90} \pm 3 \\
c_{81} 87 \pm 3 \\
81 \pm 4\end{array}$ & $\begin{array}{c}- \\
c_{47} \pm 2 \\
c_{n} d_{28} \pm 4 \\
c_{2} d_{27} \pm 4 \\
d_{36} \pm 5\end{array}$ \\
\hline
\end{tabular}

"Means \pm SEM, based on 25 measurements of groups of five 2-cell embryos, obtained in 5 replicate experiments.

"Means \pm SEM, based on measurements of the incubation media used in the 5 replicate experiments, divided by the number of embryos cultured in the media.

${ }^{e d}$ In a column, means with different superscripts are significantly different (ANOVA, Tukey, $p<0.05$ ). 
In the third experimental series, viability of mouse 2-cell embryos was tested after they were subjected to several of the experimental conditions used in the first and second series. All embryos examined showed a bright fluorescence. As can be seen in Table 3, no differences in fluorescent light intensity was noted in any of the treatment groups.

Table 3. Effect of osmolality and ouabain on fluorescent light intensity of 2-cell mouse embryas after exposure to FDA

\begin{tabular}{|c|c|}
\hline Experimental condition ${ }^{a}$ & $\begin{array}{l}\text { Fluarescent intensity } \\
\text { (units/embryo) }\end{array}$ \\
\hline $360 \mathrm{mOsm} / \mathrm{kg}$ & $157 \pm 8$ \\
\hline $320 \mathrm{mosm} / \mathrm{kg}$ & $162 \pm 9$ \\
\hline $280 \mathrm{mOsm} / \mathrm{kg}$ & $165 \pm 8$ \\
\hline $240 \mathrm{mOsm} / \mathrm{kg}$ & $152 \pm 10$ \\
\hline $200 \mathrm{mOsm} / \mathrm{kg}$ & $155 \pm 9$ \\
\hline 1500 uM ouabain & $151 \pm 8$ \\
\hline
\end{tabular}

aEmbryos were incubated for $2 \mathrm{~h}$ in radioactive taurine and subsequently for $4 \mathrm{~h}$ in the various experimental conditions before exposure to FDA.

Means + SEM of arbitrary intensity units, based on 30 measurements of single 2-cell embryos, obtained in 6 replicate experiments; no significant differences were observed (ANOVA).

In the fourth and fifth experimental series, human IVF failures (fourth series) or spare embryos (fifth series) at the third day after insemination (2- to 8-cell embryos) were labeled for $2 \mathrm{~h}$ with $\left[{ }^{3} \mathrm{H}\right]$ taurine and subsequently cultured for $4 \mathrm{~h}$ in media with various osmolalities. Both for the IVF failures, as for the 2- to 8-cell spare embryos, incubation in hyposmotic medium of $200 \mathrm{mOsm} / \mathrm{kg}$ resulted in decreased radioactivity of embryos, matched with an increase in radioactivity of the incubation media, indicating a release of $\left[{ }^{3} \mathrm{H}\right]$ taurine into the medium (Tables 4 and 5).

Table 4. Effect of osmolality on $\left[{ }^{3} \mathrm{H}\right] \mathrm{tau}$ tane release from human IVF fallures at Day 3 post-insemination

\begin{tabular}{|c|c|c|}
\hline $\begin{array}{l}\text { Osmollality } \\
\text { (mOsm/kg) }\end{array}$ & $\begin{array}{l}\text { Radioactivity } \\
\text { of embryos } \\
(\% \text { of uptake })^{a}\end{array}$ & $\begin{array}{c}\text { Radioactivity } \\
\text { of effiux medium } \\
\text { (cpm/embryo/50 } \mathrm{wl})^{\mathrm{b}}\end{array}$ \\
\hline Uptake & $100 \pm 10$ & $m$ \\
\hline 360 & $96 \pm 11$ & $c_{37} \pm 6$ \\
\hline 280 & ${ }^{6} 90 \pm 12$ & $58 \pm 17$ \\
\hline 200 & $31 \pm 7$ & $d_{298 \pm 59}$ \\
\hline
\end{tabular}

\footnotetext{
${ }^{2}$ Means \pm SEM, based on 29 measurements of single IVF failures, obtained in 10 replicate experiments.

"Means \pm SEM , based on measurements of the incubation media used in the 10 replicate experiments, divided by the number of embryos cultured in the media.

ed In a column, means with different superscripts are significantly different (ANOVA, Tukey, $p<0.01$ )
} 
Tabile 5. Effect of osmolality on [HItaunine release from human spare embryos (2- to 8-cell) at Day 3 postinsemination

\begin{tabular}{|c|c|c|}
\hline $\begin{array}{l}\text { Osmolaity } \\
\text { (mosmkg) }\end{array}$ & $\begin{array}{c}\text { Radioactivity } \\
\text { of embryos } \\
(\% \text { of uptake })^{a}\end{array}$ & $\begin{array}{c}\text { Radioactivity } \\
\text { of efflux medium } \\
\text { (cpm/embryol50 wly }\end{array}$ \\
\hline $\begin{array}{l}\text { Uptake } \\
280 \\
200\end{array}$ & $\begin{array}{l}{ }^{0} 100 \pm 7 \\
{ }^{d} 68 \pm 10 \\
e_{36 \pm 4}=4\end{array}$ & $\begin{array}{c}34 \pm 7 \\
9307 \pm 33\end{array}$ \\
\hline
\end{tabular}

Means \pm SEM, based on 17 measurements of single human embryos, obtained in 6 replicate experiments.

${ }^{5}$ Means \pm SEM, based on measurements of the incubation media used in the 6 replicate experiments, divided by the number of embryos cultured in the media.

cide Means with different superscripts are significantly different (ANOVA, Tukey, $p<0.001$ ).

"Means with different superscripts are significantly different ( $t$-test, $p<0.001$ ).

In the sixth and seventh experimental series, mouse oocytes (sixth series) or 2-cell embryos (seventh series) were labeled for $2 \mathrm{~h}$ with [ $\left.{ }^{3} \mathrm{H}\right]$ taurine, washed, and cultured in fresh medium without label for a further $24 \mathrm{~h}$. After this time, embryos that showed no cleavage were separated from embryos that did cleave to the next developmental stage, and radioactivity of groups of 5 embryos was measured. As can be seen in Table 6, the mean radioactivity of oocytes that cleaved to the 2-cell stage was significantly higher than the radioactivity of those that remained at the 1-cell stage. In contrast, radioactivity of 2-cell embryos that cleaved to the 4-cell stage was significantly lower than that of embryos that remained at the 2-cell stage (Table 7).

Table 6. Relationship between the first cleavage division in the mouse and release of [ $\left.{ }^{3} \mathrm{H}\right] \mathrm{taurine}$

\begin{tabular}{lcc}
\hline Cleavage stage & $\begin{array}{c}\text { No. of } \\
\text { measurements }\end{array}$ & $\begin{array}{c}\text { Radioactivity } \\
\text { of embryos } \\
(\% \text { of uptake) }\end{array}$ \\
\hline Uptake & 32 & $100 \pm 4$ \\
Remained at the 1-cell stage & 33 & $62 \pm 2$ \\
Cleaved to the 2-cell stage & 32 & $77 \pm 4$ \\
\hline
\end{tabular}

"Means \pm SEM, based on the indicated number of measurements of groups of five embryos, obtained in 8 replicate experiments.

bed Means with different superscripts are significantly different (ANOVA, Tukey, $p<0.001$ ). 
Table 7. Relationship between the second cleavage division in the mouse and release of [

\begin{tabular}{lcc}
\hline Cleavage stage & $\begin{array}{c}\text { No. of } \\
\text { measurements }\end{array}$ & $\begin{array}{c}\text { Radioactivity } \\
\text { of embryos } \\
(\%) \text { of uptake }\end{array}$ \\
\hline Uptake & 36 & $b_{100 \pm 2}$ \\
Remained at the 2-cell stage & 31 & $87 \pm 3$ \\
Cleaved to the 4-cell stage & 44 & $975 \pm 2$ \\
\hline
\end{tabular}

Means \pm SEM, based on the indicated number of measurements of groups of five embryos, obtained in 10 replicate experiments.

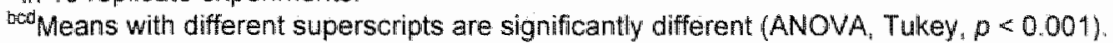

\section{Discussion}

The results obtained in the first experimental series, in which the release of taurine was studied in anisosmotic media (Table 1), are in agreement with an earlier report in which it was shown that taurine transport in mouse embryos is dependent on the osmolality of the incubation medium [19]. In human IVF failures and surplus embryos we found comparable results (Tables 4 and 5), showing that taurine transport in human embryos is also hyposmotically stimulated.

Our second series of experiments show that the presence of $1.5 \mathrm{mM}$ ouabain results in slightly decreased radioactivity of embryos and an increase in radioactivity of the incubation media (Table 2). Ouabain is a specific inhibitor of the enzym $\mathrm{Na}^{*}-\mathrm{K}^{*}-\mathrm{ATPase}$, which is the most important regulator of intracellular electrolyte concentrations in mammalian cells. $\mathrm{Na}^{+}-\mathrm{K}^{+}$-ATPase directly controls the intracellular $\mathrm{Na}^{+}$and $\mathrm{K}^{+}$concentrations and indirectly, in concert with many secondary transport systems and ion channels, other essential cellular functions including cell volume $[2,24,25]$. Inhibition of $\mathrm{Na}^{*}-\mathrm{K}^{*}$ ATPase will force cells to use their other volume-regulating mechanisms in order to counteract cell swelling [2]. Activation of $\mathrm{Na}^{*}-\mathrm{K}^{+}-2 \mathrm{Cl}^{-"}$ and $\mathrm{Na}^{*}{ }^{*} \mathrm{Cl}^{-}$cotransport $[14,25]$ and $\mathrm{K}^{*}$ and $\mathrm{Cl}^{-}$channels [25-27], but also a release of taurine and other amino acids $[2,28]$, was detected in different cell types exposed to ouabain. The quantitatively small taurine efflux abserved at high ouabain concentrations in our experiments is comparable to findings of Smith et al. [28] using chick cardiac myocytes

We did not found any differences in fluorescence intensity in embryos exposed to FDA after being subjected to the different experimental conditions (Table 3). FDA can be used to assess cell viability because only viable cells are able to produce and retain intracellular fluorescein when exposed to FDA [20]. FDA, being non-polar, readily enters the cell, where it is hydrolysed by esterases to yield fluorescein which, being polar, cannot readily cross an intact cell membrane and is thus accumulated in the cell. Our results indicate that the exposure of mouse embryos for $4 \mathrm{~h}$ to extreme conditions such as hyposmotic and hyperosmotic media ( 200 and $360 \mathrm{mOsm} / \mathrm{kg}$ ), or $1.5 \mathrm{mM}$ ouabain, does not result in immediate cellular damage, which could possibly have been an alternative explanation for the observed taurine efflux.

Our data regarding the hyposmotic- and ouabain-induced release of taurine in embryos are in accordance with the theory that taurine functions as an osmolyte in cells when they have to adjust their cell volume because of either extracellularly induced or intracellularly 


\section{References}

1. Huxtable RJ. Physiological actions of taurine. Phys Rev 1992; 72:101-163.

2. Hoffrnann EK $K_{i n}$ Dunham $\mathrm{PB}$. Membrane mechanisms and intracellular signalling in cell volume regulation. Int Rev Cytol 1995; 161:173-262.

3. Van Winkle LJ, Dickinson HR. Differences in amino acid content of preimplantation mouse embryos that develop in vitro versus in vivo in vitro effects of five amino acids that are abundant in oviductal secretions Biol Reprod 1995; $5296-104$

4. Schultz GA, Kaye PL, McKay DJ, Johnson MH Endogenous amino acid pool sizes in mouse eggs and preimplantation embryos. J Reprod Fert 1981; 61:387-393.

5. Meizel S, Lui CW: Working PK, Mrsny RJ. Taurine and hypotaurine: their effects on motility, capacitation and the acrosome reaction of hamster sperm in vitro and their presence in sperm and reproductive tract fluids of several mammals. Develop Growth and Differ 1980; 22:483-494.

6. Miller JGO, Schuitz GA. Amino acid content of preimplantation rabbit embryos and fluids of the reproductive tract. Biol Reprod 1987; 36:125-129.

7. Dumoulin JCM, Evers JLH, Bras Mite Piets MHEC, Geraedts $\mathbb{U P M}$. Positive effect of taurine on preimplantation development of mouse embryos in vitro. J Reprod Fertill 1992; 94:373-380.

8. Casslen BG. Free amino acids in human uterine fluid. J Reprod Med 1987; 32:181-184.

9. Spindte A. Beneficial effects of taurine on mouse zygotes developing in protein-free culture medium. Theriogenology 1995; 44:761-772.

10. Petters RM. Wells KD. Cutture of pig embryos. J Reprod Fertil Suppl 1993; $48: 61.73$

11. Liu Z, Foote RH. Development of bovine embryos in KSOM with added superoxide dismutase and taurine and with five and twenty percent $\mathrm{O}_{2}$. Biol Reprod 1995; 53:786-790.

12. Li J, Foote $\mathrm{RH}$, Simkin M. Development of rabbit zygotes cultured in protein-free medium with catalase taurine, or superoxide dismutase. Biol Reprod 1993; 48:33-37.

13. Hoffmann EK, Simonsen LO. Membrane mechanisms in volume and $\mathrm{pH}$ regulation in vertebrate cells. Phys Rev 1989; 69:315-382.

14. Macknight ADC. Volume maintenance in isosmotic conditions. Curr Top Membr Transp 1987: 30:3-43.

15. McManus ML, Churchwell KB. Strange K. Regulation of cell volume in health and disease. New Engl $J$ Med 1995; 333: 1260-1266.

16. Pasantes-Morales $H$, Schousboe A. Volume regulation in astrocytes: a role for taurine as an osmoeffector. J Neurosci Res 1988; 20:505-509.

17. Rasmusson RL, Davis DG, Lieberman M. Amino acid loss during volume regulatory decrease in cultured chick heart cells. Am J Physial 1993; 264:C136-C145.

18. Sanchez-Olea $R$, Pasantes-Morales $H$, Lazaro $A_{1}$ Cerejijido $M$. Osmolarity-sensitive release af free amino acids from cultured kidney cell (MDCK). J Membr Bial 1991; 121:1-9.

19. Van Winkle $L J$ Patel M. Wasserlauf HG, Dickinson HR, Campione AL. Osmotic regulation of taurine transport via system $B$ and novel processes in mouse preimplantation conceptuses. Biochim Biophys Acta 1994; 1191:244-255.

20. Mohr LR, Trounson AO. The use of flucrescein diacetate to assess embryo viability in the mouse. J Reprod Fert 1980; $58: 189$-196

21. Quinn $P$, Kerin JF. Warnes GM. Improved pregnancy rate in human in vitro fertilization with the use of a medium based on the composition of human tubal fluid. Fertil Steril $1985 ; 44: 493-498$.

22. Dumoulin JCM, Vanwuchelen RCM, Land JA, Pieters MHEC, Geraedts JPM, Evers JLH. Effect of oxygen concentration on in vitro fertilization and embryo culture in the human and the mouse. Fertil Steril 1995; 63:115-119.

23. Fleiss JL. The Design and Analysis of Clinical Experiments. New York: John Wiley \& Sons: 1986.

24. Sweadner KJ, Goldin SM. Active transport of sodium and potassium ions. N Engl d Med 1980. $302: 777-783$.

25. Rossier BC, Geering $K$, Kraehenbuhl JP. Regulation of the sodium pump: how and why? Trends Biochem Sci 1987; 12:483-587.

26. Strange $\mathrm{K}$. Ouabain-induced cell swelling in rabbit cortical collecting tubule: $\mathrm{NaCl}$ transport by principal cells. I Membr Biol 1989; 107:249-261.

27. Strange $\mathrm{K}$, Volume regulatory $\mathrm{Cl}$ loss after $\mathrm{Na}^{*}$ pump inhibition in $\mathrm{CCT}$ principal cells. Am J Physiol 1991: 260: F225-F234 
28. Drewnowska $\mathrm{K}$, Baumgarten $\mathrm{CM}$. Regulation of cellular volume in rabbit ventricular myocytes: bumetanide, chlorothiazide, and ouabain. Am J Physiol 1991; 260:C122-C131.

29. Smith TW. Rasmusson RL, Lobaugh LA, Lieberman $M . N^{*} / K^{*}$ pump inhibition induces cell shrinkage in cultured chick cardiac myocytes. Basic Res Cardiol 1993; 88:411-420.

30. Yancey $\mathrm{PH}_{4}$ Clark ME , Hand SC, Bowlus RD, Somero GN. Living with water stress: evolution of asmolyte system. Science 1982; 217:1214-1222.

31. Van Winkle L.J, Haghighat N. Campione AL. Glycine protects preimplantation mouse conceptuses from a detrimental effect on development of the organic ions in oviductal fluid. J Exp Zool 1990; 253:215219.

32. Biggers JD, Lawitts JA, Lechene CP. The protective action of betaine on the deleterious effects of $\mathrm{NaCl}$ on preimplantation mouse embryos in witro. Mol Reprod Dev 1993; $34: 380-390$.

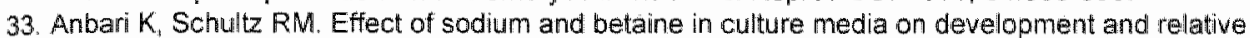
rates of protein synthesis in preimplantation mouse embryos in vitro. Mol Reprod Dev 1993; 35;24-28.

34. Kempski O, von Rosen S, Weigt H, Staub F, Peters J. Baethmann A. Glial ion transport and volume control. Annals NY Acad Sci 1994; 633:306-317.

35. Gardner DK, Leese $H J$. The role of glucose and pyruvate transport in regulating nutrient utilization by preimplantation mouse embryos. Development 1988; 104:423-429.

36. Gardner DK, Leese $\mathrm{HJ}$. Concentrations of nutrients in mouse oviduct filuid and their effect on embryo development and metabolism in vitro. J Reprod Fert 1990; 88:361-368.

37. Conaghan ل, Handyside AH, Winston RML, Leese HJ. Effects of pyruvate and glucose on the development of human preimplantation embryos in vitro. J Reprod Fert 1993; 99:87-95.

38. Dumoulin JCM, Evers JLH, Bakker JA, Bras M, Pieters MHEC, Geraedts JPM. Temporal effects of taurine on mouse preimplantation development in vitro. Hurn Reprod 1992; 7:403-407.

39. Dartsch $\mathrm{PC}_{1}$. Ritter $\mathrm{M}_{1}$ Haussinger D. Lang F. Cytoskeletal reorganization in $\mathrm{NIH} 3$ T3 fibroblasts expressing the ras oncogene. Eur J Cell Biol 1994; 63:316-325.

40. Jansson B. Rask-Andersen H. Correlations between serum osmolality and endolymphatic sac response using hypertonic glycerol. ORL 1993; 55:185-192.

41. Puka $M$, Sundell $K$, Lazarewicz JW, Lehmann $A$. Species differences in cerebral taurine concentrations correlate with brain water content. Brain Res 1991:548:267-272.

42. Hay-Schmidt $A$. The influence of asmolality on mouse two-cell development. $J$ Ass Reprod Genet 1993; 10:95-98.

43. Davidson $A_{e}$ Vermesh $M$, Lobo RA, Paulson RJ. Mouse embryo culture as quality control for human in vitro fertilization: the one-cell versus the two-cell model. Fertil Steril 1988; 49:516-521.

44. Timbrell JA, Seabra V, Waterfield CJ. The in vivo and in vitro protective properties of taurine. Gen Pharmac $1995 ; 26: 453-462$. 

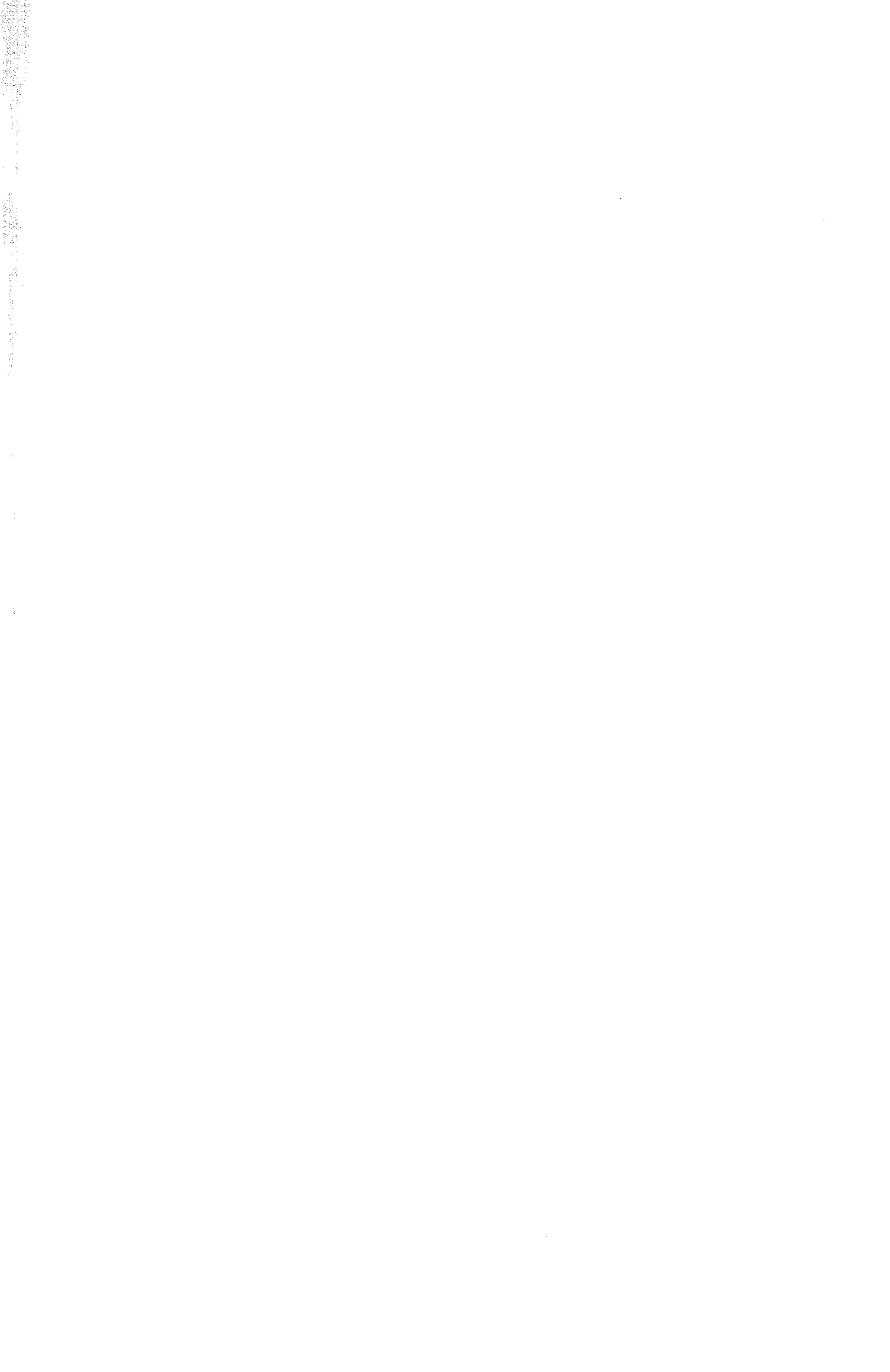
Chapter 7

General discussion 


\subsection{Effect of taurine on embryonic development in vitro}

Our studies on the effect of taurine on preimplantation embryonic development in the mouse indicate that at concentrations of $1,5,10$ and $20 \mathrm{mM}$ taurine, significantly more two-cell embryos reach the blastocyst stage compared with medium without taurine. Furthermore, culture in the presence of $5 \mathrm{mM}$ or $10 \mathrm{mM}$ taurine resulted in blastocysts with the highest mean number of cells. Taurine exerts none of these beneficial effects on mouse embryonic development after the second day of development in vitro. The effect of taurine on blastocyst formation appears to be restricted mostly to the period $20-48 \mathrm{~h}$ after fertilization, during which time mouse embryos are at the two-cell stage. This beneficial effect of taurine was found in various $\mathrm{K}^{*}$ concentrations tested, including the high concentration of about 20 $\mathrm{mM}$ present in the oviduct. It was expected that a compound which exerts such a marked effect on mouse embryo development during the two-cell stage, should also influence the two-cell block in vitro of mouse embryos from random-bred strains. However, no effect of taurine on this developmental block was observed.

Beneficial effects of taurine on preimplantation embryonic development in vitro were also found by other authors. Eppig and co-workers described in 1990 a beneficial effect of $7 \mathrm{mM}$ taurine on mouse oocyte maturation in vitro [98]. Positive effects of taurine on embryonic development were published for the first time in 1991, simultaneously, in the mouse, by our laboratory $[84,85,86]$, and in the pig by Petters and co-workers $[293,294]$. In the pig, the presence of $7 \mathrm{mM}$ of taurine resulted in a significantly higher number of blastocysts as compared to control medium without taurine ( $67 \%$ vs $45 \%$ ), and significantly more cells per blastocyst ( $33 \mathrm{vs} 23$ ) [293]. The positive effect of taurine in the mouse was later confirmed by other authors [353,399]. Spindle [353] demonstrated in 1995 that addition of $24 \mathrm{mM}$ taurine to the culture medium of mouse embryos resulted not only in better preimplantation development, but also had a positive effect on postimplantation development, as embryos cultured in the presence of taurine resulted in more fetuses, and a higher mean weight of the fetuses. Also in the rabbit, hamster, and cow, taurine was found to be beneficial for embryo development in vitro. Li and Foote reported in 1993 that $2.5-10 \mathrm{mM}$ taurine significantly increased the proportion of rabbit zygotes developing into expanding blastocysts $(70-78 \%$ vs $40 \%$ for controls) and that it increased the cell number per embryo from an average of 100 to 154-159 [205]. In a study from McKiernan and Bavister in 1995 [236], in which the effect of adding single amino acids to the medium on embryonic development was studied in the hamster, taurine $(0.5 \mathrm{mM})$ produced the highest percentage of blastocysts and the highest mean number of cells per blastocyst of all 21 amino acids studied. When combinations of amino acids were used, a combination of taurine with glutamine and glycine improved development best [236]. In the cow, studies by Foote and co-workers published in $1995[213,214]$, indicate that significantly more embryos developed to the blastocyst stage in three different media (KSOM TCM-199, and Ménézo's B2) when $7 \mathrm{mM}$ or $14 \mathrm{mM}$ taurine was added. In contrast with the above mentioned studies in which taurine was found to have a positive effect on embryo development in vitro, in a recent study by Gardner and Lane [126], it was found that addition of both taurine and glycine to medium containing a mixture of other amino acids resulted in a dose-dependent reduced percentage of zygotes derived from a random bred mouse strain that developed to the blastocyst stage, as well as on blastocyst cell number. This is the first study reporting a negative effect of taurine on preimplantation embryonic development. However, it can be concluded from all studies using several animal species and different culture media, that taurine, at least when present as the sole amino acid, has indeed a beneficial effect on embryonic development in vitro. 


\subsection{Effects of taurine on cells and tissues in general}

The effects of taurine on cells, tissues, and organisms have been described in almost all studies on this subject as being beneficial for cell viability; and any adverse effect of faurine in whichever way on whichever cell or tissue type is hard to find (although some reports exist; e.g. the above mentioned combined effect of glycine and taurine on development to the blastocyst stage in random bred mice [126], and the as yet unexplained finding that taurine appears to be toxic to cat neurons in culture [381]). Examples of a dose-dependent increase in viability when taurine is supplied to cells cultured in vitro can be found in many different cell types (e.g. human lymphoblastoid cells [424], mouse cerebellar cells [359], neurites from goldfish retinas [359], and hamster spermatozoa [203, 241, 260]). In whole organisms, in a species like the cat, which misses the enzymes to produce taurine itself, a dietary deficiency of taurine results in malfunctioning of several systems, including the visual system (e.g. degeneration of the retina), the reproductive system (e.g. more frequent abortions), the immune system, and cardiovascular system [359]. More information about the biological actions of taurine can be found in several recent reviews $[161,162,359$, $378,424]$.

In general, the diverse effects of taurine on different cell types and tissues can be summarized as being "protective" in one way or the other $[162,378,424]$. Protection against arrhythmogenesis of the heart and $\mathrm{Ca}^{24}$-overload cardiomyopathy [162]; protection against damage caused by toxic compounds in lung, heart, and liver [378]; protection against DNA damage caused by aromatic amino compounds in vitro [189]; protection of mouse cerebellar neurons cultured in vitro against excitotoxins [380]; protection of macrophages against the effects of ozone exposure $[20,21]$; protection of lymphoblastoid cells against retinol [284], and iron-ascorbate induced damage [286]; protection against radiation damage [162]; protection of rabbit spermatozoa against lipid peroxidation [11]; protection of bovine embryos against high oxygen concentrations [213]; protection of bovine [88a] and mouse [227] embryos against heat shock; protection against cryoinjury of certain turtle species living in the Arctic seas [77a]; the list is seemingly endless.

Although taurine has been a subject of much research, the mechanisms underlying these diverse protective effects of taurine are still not clear but may include modulation of intracellular calcium levels, membrane stabilization, protection against free radical damage. modulation of ionic balance in the cell in general, and osmoregulation [162, 378]. The difficulty in explaining the functions of taurine is not hard to imagine, considering the facts that taurine 1) is ubiqitously present in high amounts in cells; 2) does not seem to undergo significant reactions or interactions with any other substance in the cell; and 3) has so many diverse effects on different cell types. 


\subsection{Possible functions of taurine in cells}

As it is far too early to attempt to understand the mechanisms by which taurine may be beneficial for preimplantation embryonic development, one has to look for similarities and comparisons with observations in other cell types. A cautionary remark has to be made about such a comparison of preimplantation stage embryos with other cell types. Different cell types have different characteristics and conclusions based on observations of one cell type may not be applicable to another. Much of the data on taurine and ion transport; for instance, are obtained in electrically excitable cells such as astrocytes and heart cells. Membrane transport systems and other characteristics of such cells may be very different from those in embryos. However, also similarities exist, for instance oocytes and embryos from many species possess voltage-gated ion channels and other transport mechanisms comparable to those in excitable cells [255]. Despite the obvious difficulties in comparing the different cell types, the diverse possible functions of taurine are discussed and compared with our findings on the effect of taurine in embryos.

\section{Taurine as a modulator of $\mathrm{Na}^{+}-\mathrm{K}^{+}$-ATPase activity}

Our findings of more or less comparable positive effects of taurine ouabain and low- $\mathrm{K}^{*}$ media on mouse embryonic development suggest a common underlying mechanism. Also in other cell types, similar effects of taurine and ouabain [80], and of taurine and low- $K^{*}$ [261] have been found. As both ouabain and low- $K^{*}$ media are well known inhibitors of $\mathrm{Na}^{+}-\mathrm{K}^{+}$-ATPase, it could be speculated that taurine would exert its effect via the inhibition of this enzyme. Indeed, it has been shown that taurine, in concentrations of $0.1-10 \mathrm{mM}$, inhibited the activity of isolated sperm $\mathrm{Na}^{+}-\mathrm{K}^{+}$-ATPase in a dose-dependent manner [261]. However, such an inhibitory effect of taurine has not been found in other studies (using taurine concentrations ranging from $5 \mathrm{mM}$ to $40 \mathrm{mM}$ ) [3, 181, 409]. It has been speculated that the differences between these studies could be explained by a hypothetical indirect effect of taurine on the membrane $\mathrm{Na}^{*}-\mathrm{K}^{*}$-ATPase involving a soluble factor as an intermediate [261].

The $\mathrm{Na}^{*}-\mathrm{K}^{*}-\mathrm{A}$.TPase, through its control of the intracellular $\mathrm{Na}^{*}$ and $\mathrm{K}^{*}$ levels, controls indirectly many cellular functions. Inhibition of the $\mathrm{Na}^{+}-\mathrm{K}^{+}-\mathrm{ATPase}$ results in increased intracellular $\mathrm{Na}^{*}$ levels and decreased $\mathrm{K}^{*}$ levels, as has been demonstrated in many cell types and also in mouse embryos [395]. Consequently, many $\mathrm{Na}^{*}$-cotransport systems, such as amino acid transport and ion transport will be inhibited [342]. Also membrane depolarization occurs (as has been demonstrated in Xenopus oocytes [74]), and such a depolarization is followed by activation of several voltage-dependent ion channels such as calcium channels in many cell types, including those of mouse and hamster embryos [252]. Furthermore, inhibition of the $\mathrm{Na}^{*}-\mathrm{K}^{*}$.ATPase is followed by a sustained increase in intracellular calcium level in several cell types, with its many possible implications [364]. However, too less is known about the ionic and other transport systems of preimplantation embryos to understand the consequences of the intibition of the $\mathrm{Na}^{*}-\mathrm{K}^{*}-\mathrm{ATPase}$ for such cells. Evidence gathered from mouse embryos indicates that they differ considerably from those of many other cells. Some examples are: embryos apparently contain a different form of $\mathrm{Na}^{*}-\mathrm{K}^{+}-\mathrm{ATPase}$ [395]; embryos at the 2-cell stage lack the $\mathrm{Na}^{*} / \mathrm{H}^{*}$ antiport system which other cell types use for intracellular $\mathrm{pH}$ control [19]; embryos contain unique $\mathrm{K}^{+}$transport systems, other than the $\mathrm{Na}^{*}-\mathrm{K}^{*}$-ATPase for $\mathrm{K}^{+}$-uptake [396]. 
It could be speculated that; if the action of taurine on mouse embryos would indeed be the inhilition of $\mathrm{Na}^{+}-\mathrm{K}^{+}$-ATPase, the intracellular taurine concentration would gradually decrease, because of the resultant higher intracellular $\mathrm{Na}^{*}$ concentration, which in turn would inhibit uptake of taurine via the $\mathrm{Na}^{+}$-taurine cotransporter. Indeed it has been found that ouabain prevents taurine uptake in human retinal epithelial cells [428]. However, as will be discussed later, it seems much more likely that a lower intracellular concentration of taurine would result in a decreased viability of embryos which would not be in accordance with the observed positive effect of ouabain.

An additional factor that hampers the interpretation of our experiments using ouabain in order to inhibit the $\mathrm{Na}^{*}-\mathrm{K}^{*}$-ATPase is that the optimal ouabain concentration of $50 \mu \mathrm{M}$ that promoted embryo development was shown to result in only about $50 \%$ of maximum inhibition of the $\mathrm{Na}^{+}-\mathrm{K}^{+}$-ATPase in mouse 2-cell embryos [395]. Furthermore, it has been demonstrated that chronic exposure ( 3 days) of chick heart cells and human erythrocytes results in an increased number of $\mathrm{Na}^{+}-\mathrm{K}^{*}-$ ATPase molecules per cell and restoration of the high intracellular $\mathrm{K}^{+}$-level [410]. Thus, the inhibition of the $\mathrm{Na}^{*}-\mathrm{K}^{+}$-ATPase by $50 \mu \mathrm{M}$ ouabain in our experiments must be considered to be only partial, and possibly only temporary.

To conclude, considering the facts that 1 ), it remains unclear whether or not taurine indeed inhibits the $\mathrm{Na}^{+}-\mathrm{K}^{+}-\mathrm{ATPase}$, and 2), $\mathrm{Na}^{+}-\mathrm{K}^{+}-$ATPase is a central player in a bewildering web of intracellular relationships, and 3), it is unclear what happens intracellularly in the mouse embryos under our experimental conditions using ouabain, we decided that it will be difficult to elucidate any role of taurine through the study of this enzyme. Consequently, we did not pursue this line of research any further.

\section{Taurine as an antioxidant}

Both taurine as well as hypotaurine have been proposed to have a protective function against oxidative damage [162]. Hypotaurine, which oxidizes spontaneously to taurine, is a powerful scavenger of hydroxyl radical and hypochlorite, but is not particularly reactive to superoxide $[162,374]$, although one report claims that hypotaurine does scavenge superoxide in rabbit spermatozoa [11]. Taurine, too, has also often been suggested to act as an antioxidant and as such to protect cells against damage by reactive oxygen species (ROS) [141, 162, 424]. However, taurine reacts poorly with superoxide, peroxide, and the hydroxyl radical $[15,162]$. Taurine does react with the highly reactive oxidant hypochlorous acid $(\mathrm{HOCl})$ to form $\mathrm{N}$-chlorotaurine $[162,374,378,424]$. The resultant chlorotaurine is a somewhat more stable and less toxic oxidant, and can subsequently be reduced to $\mathrm{Cl}^{-}$and taurine $[162,374,378,424]$. HOCl is a very potent oxidising agent implicated in causing DNA damage $[16,189]$. A well known source of $\mathrm{HOCl}$ are human white blood cells which generate it from peroxide and $\mathrm{Cl}^{-}$catalyzed by the enzyme myeloperoxidase [16]. However, whether the positive effect of taurine on embryonic development in vitro can be attributed to its $\mathrm{HOCl}$ scavenging capacity seems doubtful. Although nothing is known about the possible production of $\mathrm{HOCl}$ by embryos, it seems unlikely that they will produce significant amounts. 


\section{Taurine as a membrane stabilizer}

Another possible mechanism of taurine involung cellular protection against ROS can be found in its membrane protective properties. The mechanism of this membrane protection has been speculated to be either directly by decreasing the rate of lipid peroxidation [11], or indirectly by its regulator function of long-chain fatty acid metabolism in cells [335].

Unsaturated bonds in membrane lipids are prime targets for ROS [222]. The ensuing lipid peroxidation results in a loss of membrane fluidity, an increase of the 'leakiness' of the membrane to molecules that do not normally cross it (such as $\mathrm{Ca}^{2+4}$ ions), and inactivate and aggregate membrane-bound enzymes $[140,222]$. In several cell types, addition of taurine has been shown to result in increased viability, accompanied by decreased rates of lipid peroxidation (as measured by malondialdehyde formation). Taurine (5-20 mM) protects human lymphoblastoid cells exposed to retinol and retinoic acid, both well known membrane destabilizers [284]. Taurine protects rod outer segments in the eye against light-induced lipid peroxidation [285]. Taurine (1-10 mM) protects ymphoblastoid cells against iron-ascorbate-induced lipid peroxidation [286]. Taurine $(>0.1 \mathrm{mM})$ partially prevents a decline of membrane integrity as a result of ozone-induced lipid peroxidation, as illustrated by lower levels of lipid peroxidation, and a lower leakage of glutathione, $K^{*}$, and proteins from rat alveolar macrophages [21]. Taurine $(0.5 \mathrm{mM})$ partially protects rabbit spermatozoa against loss of motility, and reduces the rate of lipid peroxidation [11]. Mammalian spermatozoa are especially susceptible to oxidative damage, as their membranes are rich in highly unsaturated fatty acids which are vulnerable to peroxidative damage, while they lack catalase and GSH reductase as enzymatic protection mechanisms [11, 162].

However, as pointed out by Halliwell [139], the finding of increased concentrations of end products of lipid peroxidation, such as malondialdehyde, provides no evidence that lipid peroxidation is the first and direct cause of cell damage. Oxidant injury by any source can lead to GSH depletion and metal ion release, which in turn lead to lipid peroxidation [139]. Thus, taurine can increase the viability of cells by mechanisms reducing ROS stress, but not implicating lipid peroxidation in the first place, and as a secondary consequence, reduce the rate of lipid peroxidation [286]. This indirect mechanism of the membrane protective action of taurine involves possibly its effect on long-chain fatty acid metabolism [335]. Low levels of intracellular taurine lead to an accumulation of long-chain fatty acylcamitine. Acylcarnitine will be incorporated into the cell membranes, causing changes in membrane structure and alterations in ion channel and transport systems, resulting in increased intracellular ion accumulation. This ultimately leads to decreased cell viability and increased lipid peroxidation [286,335]. Especially calcium has been shown to accumulate in lymphoblastoids under these conditions [286]. Such an increased ion accumulation might be more damaging than lipid peroxidation as such. Indeed, when lipid peroxidation is induced in cells cultured in either ion-free, sodium-free, chloride-free, or calcium-free medium, far less damage is inflicted [286].

Taurine has been shown to have a synergistic action with zinc in protecting cells from the consequences of membrane damage, especially in cells of the retinal layer of the eye [285], in which zinc and taurine levels are extremely high [162]. Also human lymphoblastoid cells exposed to retinol, are protected by taurine $(5-20 \mathrm{mM})$ as well as zinc $(50-100 \mu \mathrm{M})$ alone, but a combined addition of zinc and taurine offered the best protection [284]. 
Results from our laboratory indicate that also in mouse embryonic development. a supple. mentation of the culture medium with taurine together with micromolar levels of zinc is more beneficial than both taurine and zinc alone [249]. This synergistic action of taurine and zinc is unlikely to be a consequence of a taurine-zinc complex, since a complex like this is not very stable $[162,424]$.

\section{Taurine as an osmolyte}

Regulatory volume decrease (RVD) and increase (RVI) are fundamental properties of all mammalian cells [155]. Under physiological conditions, in which the osmolality of the environment (e.g. blood plasma) is kept constant, changes in cell volume are mainly caused by changes in intracellular solute content [ 155 ]. Uptake of sugars and amino acids by the cell, activation of membrane transport systems by hormones (e.g. activation of $\mathrm{Na}^{+} / \mathrm{H}^{+}$ exchange and $\mathrm{Na}^{+} / \mathrm{K}^{+} / 2 \mathrm{Cl}^{-}$cotransport by insulin in liver cells, and activation of $\mathrm{K}^{+}$and $\mathrm{Cl}^{-}$channels by glucagon), and metabolic events (e.g. lactate production), have all been shown to affect volume homeostasis [155]. In many different cell types, RVD is accomplished mainly by the opening of volume-sensitive $\mathrm{K}^{*}$ and $\mathrm{Cl}^{-}$channels, activation of $\mathrm{Cl}^{-} / \mathrm{HCO}_{3}^{-}$ exchanger, and certain organic molecules, resulting in a loss of osmolytes followed by the loss of cell water [155]. RV/ results predominantly from activation of $\mathrm{Na}^{+} / \mathrm{H}^{+}$exchange (which is absent in mouse 2-cell embryos [19]) and $\mathrm{Na}^{+} / \mathrm{K}^{+} / 2 \mathrm{Cl}-$ cotransport, followed by an uptake of water [155].

Besides inorganic ions, low-molecular-weight organic compounds, which contribute $10-20 \%$ to the total intracellular osmolarity in an average mammallian cell, can be used as osmoregulators $[162,237]$. Examples of such low-molecular-weight organic compounds used by cells are: taurine, betaine, sarcosine, mannitol, sucrose, sorbitol, glycerophosphorylcholine, and myoinositol [162, 425, 426, 428]. Taurine has been shown to be quantitatively the most important organic osmoregulator in many cell types [162,

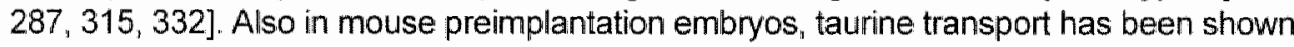
to be stimulated under anisosmotic conditions and thus to function as an osmoregulator. In hyperosmotic media, taurine uptake is stimullated [398], whille in hyposmotic media taurine release is stimulated (this thesis). It could be hypothesized that because of the high glucose concentrations which are used in many culture media, embryos would release taurine at a high rate under in vitro conditions. High extracellular glucose concentrations will in some cell types result in an increased intracellular glucose concentration, which in turn will force the cell to respond to this osmotic stress by releasing osmolytes [128]. However, we noted no differences in radioactive taurine effiux when mouse 2-cell embryos were cultured for 5 hours in media containing 5 or $0 \mathrm{mM}$ glucose (unpublished observations). 


\subsection{Possible functions of taurine in embryos}

From the above it can be concluded that the mechanism responsible for the beneficial effect of taurine on cells in general, as well as on mouse embryonic development is still unclear. At the end of this thesis an attempt is made to a synthesis of the existing knowledge.

The one thing that seems to be certain is that mouse embryos ([399], and this thesis). human embryos (this thesis), as well as other cell types [424], loose most of their intracellular taurine within days when cultured in medium without taurine. Such a taurine depletion would force the embryo to rely more on its inorganic osmolytes for its volume regulation. However, when used as the sole source of osmoregulators, inorganic osmolytes have distinct disadvantages compared to low-molecular-weight organic osmolytes such as taurine $[162$. 195]. High intracellular concentrations of electrolytes have destabilizing effects on macromolecules and can inhibit enzymatic activity $[425,426]$. Furthermore, major changes of electrolyte concentrations can alter membrane potential and membrane transport mechanisms coupled to lon gradients [237]. Especially changes in the intracellular $K^{*}$ concentration could be of relevance in this respect, since this ion is quantitatively one of the most important inorganic osmolytes [155], and a decrease in intracellular $\mathrm{K}^{+}$seems to be a common factor in experimental conditions shown to be beneficial to embryonic development:

1) inhibition of the $\mathrm{Na}^{+}-\mathrm{K}^{*}$-ATPase with ouabain both leads to lower intracellular $\mathrm{K}^{+}$levels in mouse embryos [395], and is beneficial to mouse embryonic development (this thesis);

2) a lower osmolality of the culture medium has been shown to result both in lower intracellular $K^{*}$-levels in many cell types (as a consequence of regulatory volume decrease) [155], and is beneficial to embryonic development in several species $[31,194,234$, $393,413 \pi$

3) a low $\mathrm{K}^{+}$concentration itself of the culture medium both results in lower intracellular $\mathrm{K}^{+}$-levels in several cell types [411], and is beneficial to embryonic development in several species (this thesis, and $[87,193,405,416]$ ):

Interestingly , the intracellular $\mathrm{K}^{+}$concentration of mouse 1-cell to 8 -cell embryos developed in vivo indeed seems to be relatively low (90-105 mM) [196] compared to that of the average mammalian cell (140 mM) [4].

To conclude, taurine has a clearly positive effect on development in vitro of mouse embryos. The observed effect of taurine supplementation of the culture medium could be the result of the replenishment of intracellular taurine concentrations. When no taurine is added tho the medium, the resultant taurine depletion may be harmful to embryos, either because the embryo has to rely more on its inorganic osmolytes for its volume regulation, or because taurine can no longer provide its other protective functions, such as membrane stabilization. 


\subsection{Future aspects}

Does taurine play the same role in preimplantation embryonic development in the human? In view of the beneficial effect that taurine has on embryonic development in several mammalian species, and since human uterine fluid contains high concentrations of taurine [60], it seems a logical next step to investigate whether the beneficial effect of taurine applies also to human embryos. Preliminary data on the culture of a small series of human spare embryos from the third untill the sixth day after insemination in medium containing $10 \mathrm{mM}$ taurine performed in our laboratory did not show a higher rate of blastocyst formation than culture of embryos in control medium without taurine. However, these results need to be confirmed in a larger series. Also, the effect of taurine on human embryo development should be studied during the first few days after insemination, as, in the mouse, the effect of taurine was only noticeable during the first two days of development. Effects of taurine on pregnancy and implantation rates in the human have not been investigated so far. Several reasons exist why the investigation of the effect of taurine on human embryo development has a low priority. First, studies using human embryos for culture experiments during their early stages of development, when embryo transfer still has to take place, are not acceptable because of obvious ethical and practical objections. Second, IVF results in terms of pregnancy rates approach the rates of natural conception, and therefore in vitro culture of human embryos is considered by many to be at least adequate. And third, research into improved in vitro culture conditions of human embryos has been relatively unsuccessful so far. Even when comparing very different types of medium, no significant differences were found in pregnancy and implantation rates $[73,164,356]$, although initial studies in small series did show differences between media $[310,312]$. The studies reporting the results of large series indicate that either the human embryo is relatively insensitive to widely varying culture conditions, or that other factors (genetic composition of gametes and embryos, patient-related factors, hormonal stimulation, the simultaneous replacement of more than one embryo, etc.) are more significant than the contribution of culture conditions to the success of IVF treatment. However, it should not be ignored that human IVF results, in terms of implantation rate per embryo transferred, are still well below the implantation rate in natural conception cycles.

Does taurine play the same role on preimplantation embryonic development in vivo or does the observed positive effect of taurine only apply to embryos cultured in vitro? The taurine concentrations of 1 to $20 \mathrm{mM}$ that were shown to be beneficial to mouse embryonic development are in the range of concentrations found in uterine fluids of several mammalian species (see Table 4, General introduction). However, oviductal fluids of some species studied contain taurine concentrations in the micromolar range, i.e. lower than the concentrations of taurine being effective on mouse embryo growth. The concentration of taurine being higher in the uterus than in the oviduct would suggest a physiological role of taurine during late preimplantation development. Contrary to this, our findings on mouse embryonic development in vitro indicate a beneficial role of taurine during the early preimplantation period, whereas no effect was found during the late preimplantation period. Possibly, the mouse is different from other species studied with respect to the taurine content of the oviduct, as we have shown that taurine comprised a much higher proportion of the total free amino acid present in oviductal fluid as compared to serum (Chapter 2). Also in human oviductal fluid we have found indications of high levels of taurine (Bakker and Dumoulin, unpublished observations). 
To answer the question of whether taurine plays the same role on preimplantation embryonic development in vivo as in vitro, too little information is available at this point in time. Temporal studies on the effect of taurine on in vitro development of species other than the mouse, as well as studies to determine the absolute concentrations of taurine in mouse uterine fluid, and oviductal fluid in the mouse and human should give more insight in this question.

What are the mechanisms responsible for the beneficial effect of taurine on mouse embryonic development? As has been discussed above, these mechanisms are still unclear. As taurine exhibits many effects on cells that are directly or indirectly $\mathrm{Ca}^{2+}$ related, and has profound effects on cell calcium regulation [162] a possible relationship between taurine and intracellular calcium homeostasis in cleavage stage embryos could be of significance. Calcium signals have been shown to be implicated in cell division and cell cycle control in somatic cells [66, 152]. Sperm-induced calcium oscillations, which occur during the first few hours after fertilization, trigger the activation of the oocyte and the embryonic developmental program [362,363]. Calcium signals also seem to play an important role in early embryonic development in non-mammalian species [180,358], as well as in mammalian species (in the human [351, 352], in the mouse [187]). Therefore, efforts are presently undertaken to study the possible relationship between taurine and intracellular calcium homeostasis in cleavage stage embryos at the single cell level using fluorescence imaging techniques. 
References 


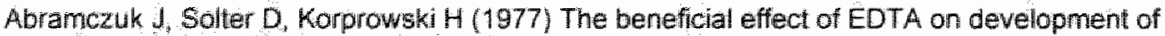
mouse one-cel embryos in chemically defined medium. Dev Bol, 61, $378-383$.

Aghayan $M$, Rao LV, Smith RM. Jarett L, Charron MJ. Thorens B. Heyner S (1992) Developmental expression and cellular localization of glucose transporter molecules during mouse preimplantation development Dewelopment, $115,305-312$

3. Akera T. Ku D, Brody TM (1976) Atterations of lon movements as a mechanism of drug-induced

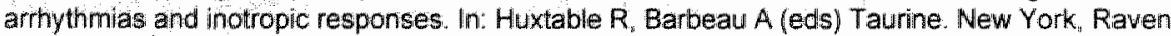
Press, pp 121-134.

4. Alberts B, Bray D, Lewis J, Raff M, Roberts K, Watson JD (1994) Molecular Biology of the cell. Thitrd Edition, Carland Publishing, lnc, New York.

5. Ali J, Whitten WK, Shelton JN (1993) Effect of culture systems on mouse early embryo development. Hun Reprod, $8,1110-1114$.

6. Allen RL Wright RW (1984) lin witro development of porcine embryos in coculture with endometrial cell monolayers or cuiture supernatants. J Anim Sci, 59, 1657-1661.

7. Almagor $M$, Dejar $C$, Kafka I. Yaffe $H(1996)$ Pregnancy rates after communal growth of preimplantation human embryos in vitro. Fertil Steril, 66, 394-397.

Alsalili M, Yuzpe A. Tummon I, Parker J, Martin J, Daniel S, Rebel M, Nisker J (1995) Cumulative pregnancy rates and pregnancy outcome after in-vitro fertilizalion: $>5000$ cycles at one centre Hum Reprod, $10,470-474$.

Altman PL, Dittmer DS (1961) Blood and other body fluids. Biological Handbooks, Fed Am Soc Exp Biol, Washington DC

10. Altman PL, Dittmer DS (1974) Biology Data Book. Second Edition, Volume lll Fed Am Soc Exp Biol, Bethesda, USA.

11. Alvarez JG, Storey BT (1983) Taurine, hypotaurine, epinephrine and albumin inhibit lipid peroxidalion in rabbit spermatozoa and protect against loss of motility. Biol Reprod, 29, 548-555.

12. Amso NN, Shaw RW (1993) A critical appraisal of assisted reproduction techmiques. Hum Reprod, 8. $168-174$

13. Anbari K, Schultz RM (1993) Effect of sodium and betaine in culture media on development and relative rates of protein synthesis in preimplantation mouse embryos. Moll Reprod Dev, 35, $24-28$

14. Artley JK, Braude PR, Johnson MH (1992) Gene activity and cleavage arrest in human pre-embryos Hum Reprod, 7, 1014-102\%.

15. Aruoma OI, Halliwell B, Hoey BM, Butler J (1988) The antioxidant action of taurine, hypotaurine and their metabolic precursors. Biochem J, 256, 251-255.

16. Aruoma OI (1994) Nutrition and health aspects of free radicals and antioxidants. Fo Chem Toxic. $32,671-683$.

17. Ball GD. Leibfried ML. Lenz RL, Ax RL, Bavister BD, First NL (1983) Factors affecting successful in witro fertilization of bovine follicular oocyles. Biol Reprod, 28, 717-725.

Ballatori $N_{*}$ Boyer J. (1992) Taurine transport in skate hepatocytes. II. Volume activation, energy and sulfhydry dependence. Am J Physiol, 262, G451-6460.

19. Baltz JM Biggers JD, Lechene C (1990) Apparent absence of $\mathrm{Na}^{+} / \mathrm{H}^{+}$antiport activity in the twocell mouse embryo. Dev Biol, $138,421-429$.

20. Banks MA, Porter DW, Martin WG, Castranova W (1990) Effecis of in vitro ozone exposure on peroxidative damage, membrane leakage, and taurine content of rat alveolar macrophages. Toxicol Appl Phamacol $105,55=65$

21. Banks MA, Porter DW, Martin WG, Castranova W (1991) Ozone-induced lipid peroxidation and membrane leakage in isolated rat alveolar macrophages: protective effects of taurine. J Nutr Biochemn 2. $308-313$

22. Batnett DK, Bavister BD (1996) What is the relationship between the metabolism of preimplantation embryos and their developmental competence. Mol Reprod Dev, 43, 105-133.

23. Barnet: DK, Bavister BD (1996) Inhibitory effect of glucose and phosphate on the second cleavage division of hamster embryos: is it linked to metabolism? Hum Reprod, 11, 177-183.

24. Bastias MC. McGee-Belser ST. Bryan SH, Vasquez JM (1993) in vitro deleterious effect of hypoxanthine in Ham's nutrient mixture F-10 culture medium on human oocyle fertilization and early embryonic development. Fertil Steril, 60, 876-880.

25. Batt PA, Gardner DK, Cameron AWN (1991) Oxygen concentration: and protein source affect the devellopment of preimplantation goat embryos in vitro. Reprod Fertil Dev, 3, 601-607. 
Bavister BD (1981) Analysis of optimal conditions for in vitro fertilization and criteria for success: In: Mastroianni L "Biggers JD, Sadler WA (eds) Fertilization and embryonic development in vitro. Plenum Press, New York, pp 41-60.

27. Bavister BD (1988) Role of oviductal secretions in embryonic growth in wivo and in vitro. Theriogenollogy, 29, 143-154.

28. Bavister BD (1992) Co-culture for embryo development: is it really necessary? Hum Reprod, 7 . 1339.1341

29. Bavister BD (1995) Culture of preimplantation embryos; facts and artifacts. Hum Reprod Update " $1,91-1.48$.

30. Bavister $\mathrm{BD}$, Goldem $\mathrm{M}$ (1989) Alteration of extracellular cation concentrations and ratios in culture medium does not affect first cleavage division of hamster zygotes in vitro nor overcome the "two-cell block". Reprod Fertil Dev, 1, 231-236.

31. Beckmann LS, Day BN (1991) Culture of the one- and two-cell porcine embryo: effects of varied osmolarity in Whitten's and Kreb's Ringer bicarbonate media. Theriogenology 35, 184.

32. Beckmann LS, Day BN (1993) Effects of media NaCl concentration and osmolarity on the culture of early-stage porcine embryos and the viability of embryos cultured in a selected superior medium. Theriagenology. 39, 611-622.

33. Bennett TL, Rose JC (1992) Cortisol effect on atrial natriuretic factor response to hypertonic saline in fetal sheep. J Dev Physial, 17, 251-255

34. Bensaude $O$, Babinet $C$, Morange $M$, Jacob F (1983) Heat shock proteins, first major products of zygotic gene activity in mouse embryos. Nature, 305, 331-333

35. Beral V, Doyle $\mathrm{P}$. Tan SL, Mason BA, Campbell S (1990) Outcome of pregnancies iresulting fram assisted conception. Bril Med Bull $46,753-768$.

36. Betterbed B, Wright RW (1985) Development of one-cell ovine embryos in two culture media under two gas atmospheres. Theriogenology. 23, 547-553

37. Bhatnagar P. Papaioannou VE, Biggers JD (1995) CSF-1 and mouse preimplantation development in vitro. Development, 121, 1333-1339.

38. Biggers JD (1987) Pioneering mammalian embryo culture. In: Bavister BD (ed) The mammalian preimplantation embryo. Plenum Press, New York, pg 1-22,

39. Biggers JD, Bell JE, Benos D.J (1988) Mammalian blastocyst: transport functions in a developing epithelium. Am J Physiol, 255, C419-C432.

40. Biggers JD, Lawitts JA, Lechene CP (1993) The protective action of betaine on the deleterious effects of $\mathrm{NaCl}$ on preimplantation mouse embryos in vitro. Mol Reprod Dev, 34, 380-390.

41. Blanco J, Egozcue J, Vidal F (1996) Incidence of chromosome 21 disomy in human spermatozoa as determined by fluorescent in-silu hybridisation. Hum Reprod, 11, 722-726.

42. Bleau $G$, St-Jacques S (1988) Transfer of oviductal proteins to the zona pellucida. In: Dielt J (ed) Structure and function of the mammalian egg coat. Springer Verlag.

43. Boland $M(1984)$ Use of the rabbit oviduct as a screening tool for the viability of mammalian eggs. Theriogenology, 21, 126-137.

44. Bolton VN, Oades PJ, Johnson MH (1984) The relationship between cleavage, DNA replication, and gene expression in the mouse 2-cell embryo. J Embryol exp Morph 79, 139-163.

45. Bongso $\mathrm{A}$, Fong $\mathrm{CY}, \mathrm{Ng} \mathrm{SC}$, Ratnam $\mathrm{S}$ (1993) The search for improved in-vilto systems should not be ignored: embryo co-culture may be one of them. Hum Reprod $8,1155-1160$.

46. Borland RM, Hazra S, Biggers JD, Lechene CP (1977) The elemental composition of the environments of the gametes and preimplantation embryo during the initiation of pregnancy. Biol Reprod, 16, 147-157.

47. Borland RM, Biggers JD. Lechene CP, Taymor ML (1980) Elemental composition of fluid in the human Fallopian tube. J Reprod Fert, 58, 479-482.

48. Boue A, Boué J, Gropp A (1985) Cytogenetics of pregnancy wastage. Adv Hum Genet, 14, 1-57

49. Bowman $P$, McLaren A (1970) Cleawage rate of mouse embryos in vivo and in vitro. J Embryol Exp Morphol, 24, 203-207.

50. Bowman P. McLaren A (1970) Viability and growth of mouse embryos after in vitro culture and fusion. J Embryol Exper Morphol, 23, 693-704.

51. Brackett BG, Mastroianni L (1974) Composition of oviducal fluid. In: Johnson AD, Foley CW (eds) The oviduct and its functions. Acad Press inc, New York, pg 133-159.

52. Braude $P$, Bolton $V$, Moore $S$ (1988) Human gene expression first occurs between the four and eight-cell stages of preimplantation development. Nature ${ }_{3} 332,459-461$ 
53. Brinster FL (1965) Studies on the development of mouse embryos in vitro. I. Effect of osmolarity and hydrogen ion concentration. J Exp Zool, 158,49-58.

54. Brinster RL (1965) Studies on the development of mouse embryos in vitro. II. The effect of energy source. J Exp Zool, $158,59-68$.

55. Brinster RL (197) Uptake and incorporation of amino acids by the preimplantation mouse embryo. SReprod Fertil $27,329-338$

56. Brown JJG, Whittingham DG (1992) The dynamic provision af different energy substrates improves development of one-cell randombred mouse embryos in vitro. J Reprod Fert, 95, 503-511.

57. Buster JE, Bustillo M Rodi IA, Cohen SW, Hamilton M, Simon JA. Thorneycroft IH, Marshall JR (1985) Biologic and morphologic development of donated human ova recovered by nonsurgical uterine lavage. Am J Obstet Gynecol 153, 211-217.

Camous $S$, Heyman $Y$, Meziou $W_{1}$ Menézo $Y$ (1984) Cleavage beyond the block stage and after transfer of early bovine embryos cultured with trophoblastic wesicles. J Reprad Fert, 72, 479-485

Canseco RS, Sparks AET, Pearson RE, Gwazdauskas FC (1992) Embryo density and medium volume effects on early murine embryo development. J Ass Reprod Genet, 9, 454-457.

60. Casslèn BG (1987) Free amino acids in human uterine fluid. Possible role of high taurine concentration J Reprod Med, 32, 181-184.

61. Casslén B. Nilsson B (1984) Human uterine fluid, examined in undiluted samples for osmolarity and the concentrations of inorganic ions, albumin, glucose, and urea. Am J Obstet Gynecol, 150, 877.881

62. Chan SYW (1985) Taurine and human spermatozoal capacitation. Cell Biol Internat Rep, 9, 127-130.

63. Chatot $\mathrm{CL}$, Ziomek: CA, Bavister BD, Lewis JL, Torres I (1989) An improved culture medium supports development of random-bred 1-cell mouse embryos in vitro. J Reprod Fert. 86, 679-688.

64. Chatot $\mathrm{Cl}_{\text {, }}$, Tasca $\mathrm{Ru}$, Ziomek $\mathrm{CA}$ (1990) Glutamine uptake and utilization by preimplantation mouse embryos in CZB medium. J Reprod Fert, 89, 335-346.

65. Chia CM, Winston RML, Handyside AH (1995) EGF, TGF- $\alpha$ and EGFR expression in human preimplantation embryos. Development, 121, 299-307

66. Ciapa B, Pesando D, Wilding $M$, Whitaker $M(1994)$ Cell-cycle calcium transient driwen by cyclic changes in inositol triphosphate levels. Nature. 368, 8.75-878.

Cillier M, ONNeill C, Ammit AJ, Saunders DM (1988) Biochemical and pharmacological characterization of human embryo-derived platelet activating factor. Hum Reprod, 3, 993-998.

Claman P, Armant DR, Seibel MM, Wang T-A, Oskowitz SP, Taymor ML (1987) The impact of embryo quality and quantity on implantation and the establishment of viable pregnancies. J In Vitro Fert Embryo Transfer, 4, 218-222.

69. Clegg KB, Piko L (1982) RNA synthesis and cytoplasmic polyadenylation in the one-cell mouse embryo. Nature, 295, 342-345.

70. Conaghan J, Handyside AH, Winston RML, Leese HJ (1993) Effects of pyruvate and glucose on the development of human preimplantation embryos in vitro. J Reprod Fertil, 99, 87-95.

71. Coonen E, Pieters MHEC, Dumoulin JCM, Meyer H Evers JLH, Rameakers FCS, Geraedis JPM (1991) Nonisotopic in siltu try bridisation as a method for mondisjunction studies in human spermatozoa Mol Reprod Dev, 28, 18-22.

72. Cummins $J M$, Breen TM, Harrison KL, Shaw JM, Wilson LM, Hennessey JF (1986) A formula for scoring humian embryo growth rates in in vitro fertilization: its value in predicting pregnancy and in comparison with visual estimates of embryo quality. J In Vitro Fert Embryo Transfer, 3, 284-295

Cuminins JM, Breen TM, Fuller SM, Harrison KL, Wilson KL, Hennessey JF, Shaw JM, Shaw $G$ (1986) Comparison of two media in a human in vitro fertilization program: lack of significant differences in pregnancy rate. J In Vitro Fertil Embryo Transf: 3, 326-330.

Dascal N, Landau EM, Lass $Y$ (1984) Xenopus oocyte resting potential, muscarinic responses and the role of calcium and guanosine $3^{3}, 5^{4}$-cyclic monophosphate. J Physiol, $352,551-574$.

75. David A, Serr DM, Czennobilsky B (1973) Chemical composition of human oviduct fluid. Fertil Steril, $24,435-439$.

76. Delhanty JDA, Handyside AH (1995) The origin of genetic defects in the human and their detection in the preimplantation embryo. Hum Reprod Update, 1, 201-215.

77. Deutz NEP, Reijven PLM, Athanasas G, Soeters PB (1992) Post-operative changes in hepatic, intestinal, splenic and muscle fluxes of amino acids and ammonia in pigs. Clin Sci, 83, 607-614.

$77 a$.

Diamond JM (1989) Resurrection of frozen animals. Nature, 339, 509-5.10.

78. Dickens Cu. Leese HJ (1994) The regulation of rabbit oviduct fluid formation. J Reprod Fert, 100, $577-581$. 
Dickens CJ, Maguiness SD, Comer MT. Palmer A, Rutherford AJ, Leese HJ (1995) Human tubal fluid: formation and composition during vascular perfusion of the Fallopian tube: Hum Reprod, 10, 505-508.

80. Dietrich J. Diacono J (1971) Comparison between ouabain and taurine effects on isolated rat and guinea-pig hearts in low calcium medium: Life Sci, 10,499-507.

81. Dorfmann $A D$, Bender $S$, Robinson $P$, Fugger $E$, Bustillo M, Schulman JD (1987) Effects of reduced oxygen concentration on in vitro fertilization and cleavage of human oocytes. Abstracts of the 43 rol American Fertility Society Meeting, Reno, Nevada, pg 46.

82. Downs SM, Dow MPD (1991) Hypoxanthine-maintained two-cell block in mouse embryos: dependence on glucase and effect of hypoxanthine phosphoribosyltransferase inhibitors. Bial Reprod, 44, 1025 1039.

83. Drewes PA, McKee RW (1967) Amino-acid composition of ascitic fluid and blood plasma from mice bearing Ehrich-Lettre tumour. Nature, 213, 411-412.

84. Dumoulin JCM Evers JLH, Land JA, Bras M; Pieters MHEC, Geraedts JPM (1991) Taurine stimulates mouse embryonic devlopment in vitro. Abstract no 154, ip 52; Abstracts from the 7th meeting of the European Society of Human Reproduction (ESHRE) and the 7 th World Congress on IVF and Assisted Procreation.

85. Dumoulin JCM, Evers JLH, Bras M, Pieters MHEC, Geraedts JPM (1992) Positive effect of taurine on preimplantation development of mouse embryos in vitro. J Reprod Fert, 94, 373-380.

86. Dumoulin JCM, Evers JLH, Bakker JA, Bras M, Pieters MHEC, Geraedts JPM (1992) Temporal effects of taurine on mouse preimplantation development in vitro. Hum Reprod, 7, 403-407.

87. Dumoulin JCM, Evers JLH, Michiels AHJC, Pieters MHEC, Bras M, Land JA, Geraedts JPM (1993) Modulation of embryonic $\mathrm{Na}^{*}-K^{k}$-ATPase activity and mouse preimplantation development in vitro in media containing high concentrations of potassium. Mol Reprod Dev, 36, 320-327.

88. Dumoulin JCM, Vanvuchelen RCM, Land JA, Pieters. MHEC, Geraedts JPM, Evers JLH (1995) Effect of oxygen concentration on in vitro fertilization and embryo culture in the human and the mouse. Fertil Steril, 63, 115 119 .

88a. Ealy AD, Drost $M$, Barros CM, Hansen PJ (1992) Thermoprotection of preimplantation bovine embryos from heat shock by glutathione and taurine. Cell Biol Int Rep. 16, 125-131.

89. Ebert KM, Paynton BV, Moknight GS, Brinster RL (1984) Translation and stability of ovalbumin messenger RNA injected into growing oocytes and fertilized ova of mice. J Embryol Exp Morph, $84,91-99$.

90. Edirisinghe WR, Wales RG (1985) Influence of environmental factors on the metabalism of glucose by preimplantation mouse embryos in vitro. Aust $J$ Biol Sci, 38, 411-420.

91. Edmands KD, Lindsay KS, Miller JF, Williamson E, Wood PJ (1982) Early embryonic mortality in women. Fertil Steril, 38, 447-453.

92. Edwards RG, Brody SA (eds) (1995) Principles and practice of assisted human reproduction. Chapter 1. Human fecundity and Assisted Conception. Salunders Co, Philadelphia. pp 1-10.

93. Edwards RG, Brody SA (eds) (1995) Principles and practice of assisted human reproduction. Chapter 11. Implantation rates during IVF, GIFT, and other forms of Assisted Conception. Saundiers Co, Philadelphia. pp 475-518

94. Edwards RG (1996) Human conception in vitro 1995, a summing-up. Hum Reprod, 11, Suppl 1. 199-2 1 it.

95. Eldadah ZA, Grifo JA, Dietz HC (1995) Marfan syndirome as a paradigm for transcript-targeted preimplantation diagnosis of heterozygous mutations. Nature Medicine, 1,798-803.

Ellington JE, Carney EW, Farrell PB. Simkin ME, Foote RH (1990) Bowine 1-2-cell embryo development using a simple medium in three oviduct epithelial cell coculture systems. Bial Reprod, 43,97-104

97. Englert $Y$, Puissant $F$, Camus $M$, Van Hoeck J, Leroy $F(1986)$ Clinical study on embryo transfer after human in vitro fertilization. J In Vitro Fert Embryo Transfer, 3, 243-246.

98. Eppig Jل, Schroeder AC, VandeSandt JJM, Ziomek CA, Bavister BD (1990) Developmental capacity of mouse 00 cytes that grow and mature in culture: the effect of modification of protocol. Theriogenology. $33,89-100$.

99. Erbach GT, Lawitts JA. Papaioannou VE, Biggers JD (1994) Differential growth of the mouse preimplantation embryo in chemically defined media. Biol Reprod, $50,1027-1033$.

100. Eyestone WH, Northey DL, Leibfried-Rutledge ML (1985) Culture of one-cell bovine embryos in the sheep oviduct. Biol Reprod, 32 (Suppl.1), 100a.

101. Eyestone WH, Lawyer ML, Critser ES, Leibfried-Rutledge ML (1986) Cell cycle stage of early porcine embryos during developmental arrest in vitro. Biol Reprod, 34, (Suppl). 98. 
102. Eyestone WH. Vignien J. First ML (1987) Co-culture of early bovine embryos with oviductal epithelium Theriogenology, 27,228

103. Eyestone WWH. First NL (1989) Co-culture of early cattle embryos to the blastocy st stage with oviductal tissue of in conditioned medium, If Reprod Fert, 85, 715-720.

104. Fahning ML, Schultz RH, Graham EF (1967) The free amino acid content of uterine fluids and blood serum in the cow I Reprod Fert 13,229-236.

105. Farin PW, Fanin CE (1995) Tranisfer of bovine embryos produced in vivo or in witro: survival and fetal development. Biol Reprod: 52, 676-682.

106. Fazleabas AT, Verhage HG (1986) The detection of oviduct-speciffic proteins in the baboon (Papio anubis): Biol Reprod, 35, 455-462.

107. Fischer $B_{v}$ Jung $T$, Hegele-Hartung $C$. Beier HM (1990) Development of preimplantation rabbit embryos in uterine flushing-supplemented culture media. Mol Reprod Dev, 27, 216-223.

108. Fischer $\mathrm{B}$, Bavister $\mathrm{BD}$ (1993) Oxygen tension in the oviduct and uterus of thesus monkeys, hamsters and rabbits. I Reprod Fert, 99,673-679

109. Fissore RA, Jackson KV, Kiessiling AA (1989) Mouse zygote development in culture medium without protein in the presence of ethylenediaminetetraacetic acid. Biol Reprod, 41, 835-841.

110. FitzGerald L, DiMattina M (1992) An improved medium for long-term culture of human embryos overcomes the in vitro developmental block and increases blastocyst formation. Fertil Steril, 57, $641-647$

111. FIVNAT (French In Vitro National) (1993) French national IVF registry: analysis of 1986 to 1990 data. Fertil Steril, 59, 587-595.

112. FIVNAT (French In Vitro National) (1995) Pregnancies and birth resulting from in vitro fertilization: French national registry, analysis of data 1986 to 1990 . Fertil Steril 64, 746-756.

113. Fleming TP, Johnson MH (1988) From egg to epithelium. Annu Rev Cell Biol, 4, 459-458.

114. Fraser LR (1986) Both taurine and albumin support mouse sperm motility and fertilizing ability in witro but there is no obligatory requirement for taurime. J Reprod Fert, 77, 271-280.

115. Fukui Y, McGowan LT, James RW, Pugh PA, Tervit HR (1991) Factors affecting the in-vitro development to blastocysts of bovine oocytes matured and fertilized in vitro. J Reprod Fert, 92, 125-131.

116. Funahashi $H$, Kim N-H, Stumpf TT, Cantley TC, Day BN (1996) Presence of organic osmolytes in maturation medium enhances cytoplasmic maturation of porcine ooc/tes. Biol Reprod, 54, 1412-1419.

117. Gandolfi F, Moor RM (1987) Stimulation of early embryonic develapment in the sheep by co-culture with oviduct epithelial cells. J Reprod Fertil, 81, 23-28.

118. Gandolfi F, Brevini TAL, Richardson L, Brown CR, Moor RM (1989) Characterization of proteins secreted by sheep oviduct epithelial cells and their function in embryanic development. Development. $106,303-312$.

119. Gardiner CS, Williams JS, Menino AR (1990) Sodium/potassium adenosine triphosphatase $\alpha$-and $\beta$-subunit and $\alpha$-subunit mRNA levels during mouse embryo development in vitro. Biol Reprod, $43,788-794$.

120. Gardiner CS, Grobner MA, Menino AR (4990) Sodium/potassium adenosine triphosphatase $a$-subunit and a-subunit mRNA tevels in early rabbit embryos. Biol Reprod, 42, 539-544.

121. Gardner DK, Leese HJ (1990) Concentration of nutrients in mouse oviduct ftuid and their effects on embryo development and metabolism in vitro. J Reprod Fert, 88, 361-368.

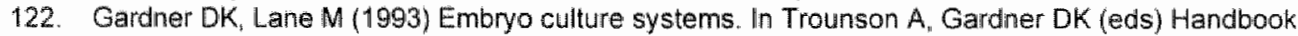
of in Vitro Fertilization. CRC Press, Boca Raton, pg 85-114.

123. Gardner DK, Sakkas D (1993) Mouse embryo cleavage, metabolism and viability: role of medium composition. Hum Reprod, 8, 288-295.

124. Gardner DK, Lane M (1993) Amino acids and ammonium regulate mouse embryo development in vitro. Biol Reprod, 48, 377-385.

125. Gardner DK, Lane M, Spitzer A, Batt P (1994) Enhanced rates of cleavage and development for sheep zygotes cultured to the blastocyst stage in vitro in the absence of serum and somatic cells: amino acids, vitamins, and culturing embryos in groups stimulate development. Biol Reprod, 50, $390-400$.

126. Gardner DK, Lane M (1996) Alleviation of the '2-cell block' and development to the blastocyst of CF1 mouse embryos: role of amino acids, EDTA and physical parameters. Hum Reprod, 11, 2703-2712.

127. Gardner DK, Lane $\mathrm{M}_{\mathrm{v}}$ Calderon I Leeton J (1996) Environment of the preimplantation human embryo in vivo: metabolite analysis of oviduct and uterine fluids and metabolism of cumulus cells. Fertil Steril, 65, 349-353. 
128. Geldervan NM (1989) Brain taurine content as a function of cerebral metabolic rate osmotic regulation of glucose derived water production. Neurochem Res, 14, 495-497.

129. Gid ley-Baird AA, O'Neill C. Sinosich MJ, Porter RN, Pike IL, Saunders DM (1986) Failure of implantation in human in vitro fertilization and embryo transfer patients: the effects of altered progesterone/estrogen ratios in humans and mice. Fertil Steril, 45, 69-74.

430. Goddard JM, Pratt HPM (1983) Control of events during early cleavage of the mouse embryo: an analysis of the "2-cell block". J Embryol Exp Morphol, 73, 111-133.

131. Gonen Y, Dirnfeld M, Goldman S, Koifman M, Abramovici H (1991) Does the choice of catheter for embryo transfer influence the success rate of in-vitro fertilization? Hum Reprod, 6, 1092-1094.

132. Goto $Y$, Noda Y. Mori T, Nakano M (1993) Increased generation of reactive oxygen species in embryos cultured in vitro. Free Radic Biol Med, 15, 69-75.

133. Green TR, Fellman JH, Eicher AL, Pratt KL (1991) Antioxidant role and subcellular location of hypotaurine and taurine in human neutrophils. Biochim Biophys Acta, 1073, 91-97.

134. Grippo AA, Henault MA, Anderson SH, Killian GJ (1992) Cation concentrations in fluid from the oviduct ampulla and isthmus of cows during the estrous cycle. J Dairy Sci, 75, $58-65$.

135. Guerin P, Guillaud J, Ménézo Y (1995) Hypotaurine in spermatozoa and genital secretions and its production by oviduct epithelial cells in vitro. Hum Reprod ${ }_{n} 10,866-872$.

136. Guillomot M, Fléchon J-E, Leroy $F$ (1993) Blastocyst development and implantation. In: Thibault C. Levasseur MC, Hunter RHF (eds) Reproduction in mammals and man. Ellipses, Paris, pg 387-410.

137. Gulyas BJ, Wood M, Whittingham DG (1984) Fusion of oocytes and development of oocyte fusion products in the mouse. Dev Bioll, 101, 246-250.

138. Gutteridge JMC (1995) Lipid peroxidation and antioxidants as biomarkers of tissue damage. Clin Chem, 41, 1819-1828.

139. Halliwell B (1987) Oxidants and human disease: some new concepts. FASEB $\mathbb{\Downarrow}, 1,358-364$.

140. Halliwell B, Gutteridge JMC (1989) Free radicals in biology and medicine. Second edition, Clarendon Press, Oxford.

141. Halliwell $B$, Aeschbach $R$, Löliger J, Aruoma Ol (1995) The characterization of antioxidants. Fd Chem Toxilc, 33, 601-617.

142. Hamner CE, Williams WL (1965) Composition of rabbit oviduct secretions. Fertil Steril, 16, 170-176.

143. Han HD, Kiessling AA (1988) in vivo development of transferred mouse embryos conceived in witro in simple and complex media. Fertil Siteril, $50,159-163$.

144. Handyside $A H$ (1992) Abnormalities of human preimplantation development in vitro. Reprod Fertil Dev, 4, 481-495.

145. Harada T. Tanikawa M, Iwabe $T$, Onohara $Y$, Mio $Y$, Terakawa $N$ (1992) Measurement of uptake and incorporation of nucleic acid precursors by preimplantation mouse embryos after development in vivo and in vitro. J Ass Reprod Genet, 9, 551-556.

146. Harlow $\mathrm{GM}_{4}$ Quinn $\mathrm{P}$ (1982) Development of preimplantation mouse embryos in vivo and in vitro. Aust J Biol Sci, 35, 187-193.

147. Harper $ل \mathrm{JC}$, Coonen $\mathrm{E}$, Handyside AH, Winston RML, Hopman AHN, Delhanty JDA (1995) Moseicism of autosomes and sex chromosomes in morphologically normal, monospermic preimplantation human embryos. Prenatal Diagnosis, 15, 41-49.

148. Harper M.JK (1994) Gamete and zygote transport. In: Knobil E, Neill ID (eds) The physialogy of reproduction, Second Edition, Raven Press, Ltd, New York, pg 123-187.

149. Hassold T, Chen N. Funkhauser J, Jooss T, Manuel B, Matsuura J, Wilson C. Yamane JA, Jacobs PA (1980) A cytogenetic study of 1000 spontaneous abortions. Ann Hum Genet, 44; 151-178.

150. Hassold $T J$ (1986) Chromosome abnormalities in human reproductive wastage. Trends in Genetics, $2,105-110$.

151. Hay-Schmidt A (1993) The influence of asmolality on mouse two-cell development. J Assis Reprod Genet, 10, 95-98.

152. Hepler PK (1994) The role of calcium in cell division. Cell Calcium, 16, 322-330.

153. Hernvann A, Gonzales $\mathrm{J}$, Troupel $\mathrm{S}$, Galli A, (1986) Amino acid content of human semen in normal and infertility cases. Andrologia, 18, 461-469.

154. Ho Y, Doherty AS, Schultz RM (1994) Mouse preimplantation embryo development in vitro: effect of sodium concentration in culture media on RNA synthesis and accumulation and gene expression. Mol Reprod Dev, 38, 131-141.

155. Hoffmann EK, Dunham PB (1995) Membrane mechanisms and intracellular signalling in cell volume regulation. Int Rev Cytol, 161, 173-262. 
156: Hoim P. Walker SK, Seamark RF (1996) Embryo viability, duration of gestation and bith weight in sheep after transfer of in vitro matured and in vitro fertilized zygotes cultured in vitro or in vivo. $J$ Reprod Ferti. $107,175-181$

157. Holmdaht TH, Mastroianni I. Jr (1965) Continuous collection of rabbit oviduct secretions at low temperature. Fertil Steril, $16,587-595$

158. Homes $\mathrm{RP}$, Goodman $\mathrm{HO}$, Shihabi $Z \mathrm{~K}$, Jarow JP (1992) The taurine and hypotaurine content of hurvan semen. $J$ Aridrol, 13, 289-292.

159. Howlet $S K$, Bolton V (1985) Sequence and regulation of morphological and molecular events during the first cell cycle of mouse embryogenesis: J Embryal exp Morph, 87, 175-206.

160. Hut MGR, Fleming CF. Hughes AO, MCDermott A (1996) The age-related decline in female fecundity. a quantitative controlled study of implanting capacity and survival of individual embryos after in vitro fertifization, Fertil Steril, $65,783-790$.

161. Huxtable RJ (1989) Taurine in the central nervous system and the mammalian actions of taurine Prog Neurobiol, 32, 471-533.

162. Huxtable RJ (1992) Physiological actions of taurine. Phys Rev.72, 101-163.

163. lannaccone $\mathrm{PM}_{i}$ Bossert NL, Connelly CS (1987) Disruption of embryonic development due to preimplantation chemical insults: a critical review. Am J Obstet Gynecol, 157, 476-484.

ignoul-Vanvuchelen R. Dumoulin JCM, Bergers-Janssen JM, Bras M, van Wissen LCP. Geraedts JPM, Evers JLH (1996) Comparison of IVF-50 commercial medium with 'in-house' prepared human tubal fluid medium for human IVF. Human Reprod, 11, Abstract book 1, abstract 36, pg 17.

165. Iritani $A_{\mathrm{r}}$ Gomes WR, VanDemark NL (1969) Secretion rates and chemical composition of oviduct and uterine fluids in ewes. Biol Reprod, 1, 72-76.

166. Iritani $A$, Nishikawa $Y$, Gomes WR, VanDemark NL (1971) Secretion rates and chemical composition of oviduct and uterine fluids in rabbits. J Anim Sci, 33,829-835.

167. Uritari A, Sato E, Nishikawa $Y$, (1974) Secretion rates and chemical composition of oviduct and uterine fluids in sows. J Anim Sci, 39, 582-588.

168. Jacobs PA (1992) The chromosome complement of human gametes. Oxford Rev Reprod Biol, $14,47-72$

169. Jamieson ME, Coutts JRT, Connor JM (1994) The chromosome constitution of human preimplantation embryos fertilized in vitro. Hum Reprod, 9, 709-715.

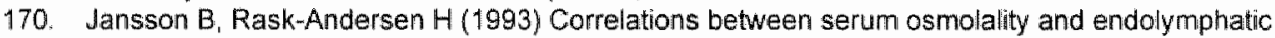
sac response using hypertonic glycerol. ORL (J Otorhinolaryngology), 55, $185-192$.

171. Jarrell VL, Day BN. Prather RS (1991) The transition from maternall to zygotic control of development occurs during the 4-cell stage in the domestic pig. Sus scrofa: quantitative and qualitative aspects of protein synthesis. Biol Reprod, 44, 62-68.

172. Jaszczak S, Hafez ESE, Moghissi KS, Kurrie DA (1972) Concentration gradients of amino acids between the uterine and blastocoelic fluid in the rabbit. Fertil Steril, $23,405-409$.

173. Johnson MH, Nast-Esfahani MH (1994) Radical solutions and cultural problems: could free oxygen radicals be responsible for the impaired development of preimplantation mammalian embryos in vitro? BioEssays, 16, 31-38.

174. Johnston LA, Donoghue AM, O'Brien SJ, Wildt DE (1991) Influence of temperature and gas atmosphere on inmwitro fertilization and embryo development in domestic cats. J Reprod Fert, 92, 377-382.

175. Johnston LA, Donoghue AM, O'Brien SJ, Wildt DE (1991) Culture medium and protein supplementation influence in vitro fertilization and embryo development in the domestic cat. J Exp Zool, 257, 350-359.

176. Jones HW. Rogers PAW (1988) Results from in vitro fertilization. In: Wood $C$. Trounson $A O$ (eds) Clinical in vitro fertilization and embryo transfer, 2nd ed, Springer-Verlag, Berlin. pg. 51.

177. Jung T, Fischer B, Beier HM (1987) Quantitative aspects of protein synthesis in non-cultured and cultured rabbil blastocysts. Hum Reprod, 2, 23-27.

178. Kapur RP, Jolinson LV (1985) An oviductal fluid glycoprotein associated with ovulated mouse ova and early embryos. Dev Biol, 112, 89-93.

179. Kapur RP, Jahnson LV (1986) Selective sequestration of an oviductal fluid glycoprotein in the perivitelline space of mouse oocytes and embryos. J Exp Zool, 238, 249-260.

180. Keating $T J$, Cork RJ, Robinson KR (1994) Intracellular free calcium oscillations in normal and cleavageblocked embryos and artificially activated eggs of Xenopus lavis. J Cell Sci. 107, 2229-2237.

181. Khatter JC, Soni PL, Hoeschen RJ Alto LE Dhalla NS (1981) Subcellular effects of taurine on guinea pig heart. In: Schaffier SN, Baskin SI, Kocsis JJ (eds) The effects of taurine on excitable tissues New York, Spectrum publications, pp 281-294. 
182. Kiessling AA, Davis HW, Wiliams CS, Sauter RW, Harrison LW (1994) Development and DNA polymerase activities in culture of preimplantation mouse embryos: comparison with embryos developed in vivo. $J$ Exp Zool, 258, 34-4T.

183. Kim JH, Funahashi $H_{y}$ Niwa K, Okuda K (1993) Glucose requirement at different developmental stages of in vitro fertilized bowine embryas cultured in semi-defined medium. Theriogenology, $39_{3}$ 875-886.

184. Kishi J, Noda $Y$, Narimoto K, Uimaoka Y, Mori T (1991) Block to development in cultured rat 1 -cell embryos is overcome using medium HECM-1. Hum Reprod, 6, 1445-1448.

185. Knutzen V, Stratton CJ, Sher G, McNamee PI, Huang TT, Soto-Albors C (1992) Mock embryo transfer in early luteal phase, the cycle before in vitro fertilization and embryo transfer: a descriptive study. Fertil Steril, 57, 156-162.

186. Kola I Sathananthan AH, Gras L (1993) Chromosomal analysis of preimplantation mammalian embiryos. In: Trounson A, Gardner DK (eds) Handbook of In Vitro Fertilization, CRC Press, Boca Raton, pg $173-193$.

187. Kono $T$, Jones $K T$, Bos-Mikich $A$, Whittingham DG, Carroll $\downarrow$ (1996) A cell cycle-associated change in $\mathrm{Ca}^{2+}$ releasing activity leads to the generation of $\mathrm{Ca}^{2+}$ transients in mouse embryos during the first mitotic division. لl Cell Biol, 132, 915-923.

188. Kozma C, Macklin W, Cummins LM, Mauer R (1974) Anatomy, physiology, and biochemistry of the rabbit. In: Weisbroth SH, Flatt RE, Kraus AL (eds) The biology of the laboratory rabbit Acad Press, New York, pp 55-72.

189. Kozumbo WJ, Agarwal S, Koren HS (1992) Breakage and binding of DNA by reaction products of hypochlorous acid with aniline, 1-naphthylamine or 1-naphthol. Toxic Appl Pharmaci 115, 107-115.

190. Lane M, Gardner DK (1992) Effect of incubation volume and embryo density on the development and viability of mouse embryos in vitro. Hum Reprod, 7, 558-562.

191. Lane $M$, Gardner DK (1994) Increase in postimplantation development of cultured mouse embryos by amino acids and induction of fetal retardation and exencephaly by ammonium ions. J Reprod Fertil ${ }_{1}$ 102, 305-312.

192. Lane M, Gardiner DK (1997) Differential regulation of mouse embryo development and viability by amino acids. J Reprod Fertil, 109, 153-164.

193. Lawitts JA, Biggers JD (1991) Overcoming the 2-cell block by modifying standard components in a mouse embryo culture medium. Biol Reprod, 45, 245-251.

194. Lawitts JA Biggers JD (1991) Optimization of mouse embrya culture media using simple methods. J Reprod Fert, 91, 543-556.

195. Lawitts JA, Biggers JD (1992) Joint effects of sodium chloride, glutamine, and glucose in mouse preimplantation embryo culture media. Mol Reprod Dev, 31, 189-194.

196. Lee $S$ (1987) Membrane properties in preimplantation mouse embryos. I In Vitro Fert Embryo Transf. $4,331-333$.

197. Lee JD, Kamiguchi $Y$, Yanagimachi R (1996) Analysis of chromosome constitution of human spermatozioa with normal and aberrant head morphologies after injection into mouse oocytes. Hum Reprod, 11, $1942-1946$.

198. Leese $H_{J}$ (1983) Studies on the movement of glucose, pyruvate and lactate into the ampulla and isthmus of the rabbit oviduct. Quart J Exp Physiol, 68, 89-96.

199. Leese HJ. Aldridge S (1979) The movement of pyruvate, lactate and lactate dehydrogenase into rabbit oviductal fluid. J Reprod Fert, 56, 619-622.

200. Leese HJ, Barton AM (1984) Pyruvate and glucose uptake by mouse ova and preimplantation embryos. J Reprod Fert, 72, 9-13,

201. Leese HJ (1988) The formation and function of aviduct fluid. J Reprod Fert, 82, 843-856.

202. Legge $M$, Sellens MH (1991) Free radical scavengers ameliarate the 2-cell block in mouse embryo culture. Hum Reprod, 6, 867-871.

203. Leibfried ML, Bavister BD (1981) The effects of taurine and hypotaurime on in vitro fertilization in the golden hamster. Gam Res, 4, 57-63.

204. Leibfried ML, Bavister BD (1982) Effects of epinephrine and hypotaurine on in-vitro fertilization in the golden hamster. J Reprod Fert $66,87-93$.

205. Li J, Foote $\mathrm{RH}_{v}$ Simkin $\mathrm{M}$ (1993) Development of rabbit zygotes cullured in protein-free medium with catalase, taurine, or superoxide dismutase. Bial Reprod, $48,33.37$

206. Li J, Foote RH (1993) Culture of rabbit zygotes into blastocysts in protein-free medium with one to twenty per cent oxygen. J Reprod Fert, 98, 163-167. 
207. LI J, Foote RH (1995) Effect of inositol and glycine with increasing sodium chloride and constant osmolality on development of rabbit embryos. J Ass Reprod Genet, 12, 141-146.

208. Li J, Foote RH (1996) Differential sensitivity of ane-cell and two-cell rabbit embryos to sodium chlibride and total osmolarity during culture into blastocysts. I Reprad Fertil. 108, 307-312.

209. Lippes J, Enders RG, Pragay DA, Bartholomew WR (1972) The collection and analysis of human Fallopian tubal fluid. Contraception, 5, 85-95.

210. Lippes $\mathrm{J}$, Ktasner $J_{4}$ Alfonso LA, Dacalos ED, Lucero R (1981) Human oviductal fluid proteins. Fertil Steril, $36,623-629$.

211. Little W, Sansom BF, Mainston R, Allen WM (1984) Importance of water for the health and productivity of the dairy cow. Res Vet Sci, 37, $283-289$.

212. Liu LPS, Chan STH, Ho PC, Yeung WSB (1995) Human oviductal cells produce high molecular weight factor(s) that improves the development of mouse embryo. Hum Reprod, 10, 2781-2786

213. Liu Z, Foote RH (1995) Development of bovine embryos in KSOM with added superoxide dismulase and taurine and with five and twenty percent $\mathrm{O}_{2}$. Biol Reprod, 53, 786-790.

214. Liu Z, Foote $\mathrm{RH}$, Yang $\times(1995)$ Development of early bovine embryos in co-culture with $\mathrm{KSOM}$ and taurine, superoxide dismutase or insulin. Theriogenology, 44, 741-750.

215. Liu Z, Foote RH (1995) Etfects of aminc acids on the development of in-vitro matured / in-vitro fertilization bovine embryos in a simple protein-free medium. Hum Reprod "10, 2985-2991.

216. Liu Z, Foote RH (1996) Sodium chloride, osmolyte, and asmolarity effects an blastocyst formation in bovine embryos produced by in vitro fertilization (IVF) and cultured in simple serum-free media. J Assist Reprod Genet, 13,562-568.

217. Lopata $A$, Patullo MJ, Chang A, James B (1976) A method for collecting motile spermatozoa from human semen. Fertil Steril, 27, 677-684.

218. Lopata A, Jolnnston IWH, Hoult IJ, Speirs Al (1980) Pregnancy following intrauterine implantation of an embryo obtained by in vitro fertilization of a preovulatory egg. Fertil Sterill, 33, 117-120.

219. Lopata $A_{\text {, Hay }} \mathrm{DL}$ (1989) The surplus human embryo: its potential for growth, blastulation, hatching. and human chorionic gonadotrpin production in culture. Fertil Steril, 51, 984-991.

220. Loutradis D, John D, Kiessling AA (1987) Hypoxanthine causes a 2-cell block in random-bred mouse embryos. Biol Reprod, 37, 311-316.

221. Maas DHA, Storey BT. Mastroianni L (1976) Oxygen tension in the oviduct of the Rhesus monkey (Macaca mulatta). Ferti Steril, 27, 1312-1317.

222. Machlin $L J$, Bendich $A$ (1987) Free radical tissue damage: protective role of antioxidant nutrients. FASEB $\downarrow$, 1, 441-445.

223. Magienis RE (1988) On the origin of chromosome anomaly. Am J Hum Genet, 42, 529-533.

224. Maguiness SD, Shrimanker $K$, Djahanbakhch $O$, Grudzinskas JG (1992) Oviductal proteins. Contemp Rev Obstet Gynaecol, 4, 42-50.

225. Mahadevan MM, Trounson AO, Leeton JF (1983) The relationship of tubal blockage, infertility of unknown cause, suspected male infertility and endometriosis to success of in vitro fertilization and embryo transfer. Fertil Steril, 40, 755-762.

226. Mahadevan MM, Trounson AO (1985) Removal of the cumulus oophorus from the human oocyte for in vitro fertilization. Fertil Steril $43,263-267$.

227. Malayer JR, Pollard JW, Hansen PJ (1992) Modulation of thermal killing of bovine lymphocytes and preimplantation mouse embryos by alanine and taurine. A J Vet Res, 53, 689-694.

228. Manejwala FM, Cragoe EJ, Schullz RM (1989) Blastocoel expansion in the preimplantation mouse embryo: role of extracellular sodium and chloride and possible apical routes of their entry. Dev Biol. $133,210-220$.

229. Marsh RF (1994) Symposium on risk assessment of the possible occurrence of bovine spongiform encephalopathy in the United States. J Am Vet Med Assoc, 204, 70-73.

230. Martin RH, Ko E, Rademaker A (1991) Distribution of aneuploidy in human gametes: comparison between human sperm and oocytes. Am J Med Genet, 39, 321-331.

231. Martin RH, Ko E, Chan K (1993) Detection of aneuploidy in human interphase spermatozoa by fluorescence in situ hybridization (FISH). Cytogenet Cell Genet, 64, 23-26.

232. Mastroianni L, Wallach RC (1961) Effect of ovulation and early gestation on owiduct secretions in the rabbit. Am J Physiol, 200, 815-818.

233. Mastroianni $\mathrm{L}$. Jones $\mathrm{R}$ (1965) Oxygen tension within the rabbit fallopian tube $J$ Reprod Fert, 9, 99-102.

234. MoKiernan SH، Bavister BD (1990) Environmental variables influencing in vitro development of hamster 2-cell embryos to the blastocyst stage. Biol Reprod, 43, 404-413. 
McKieman SH. Bavister BD. Tasca RJ (1991) Energy substrate requirements for th vitro development of hamster 1 - and 2-cell embryos to the blastocyst stage. Hum Reprod, 6, 64-75.

236. McKieman SH, Clayton MK. Bavister BD (1995) Analysis of stimulatory and tinhibitory amino acids for development of hamster one-cell embryos in vitro. Mol Reprod Dev, $\mathbf{4 2}, 188199$.

237. McMamus ML, Churchwell KB, Strange $\mathrm{K}$ (1995) Regulation of cell volume in health and disease: New Engl J Med, 333, 1260-1266.

238. Medical Research International and the Society for Assisted Reproductive Technology (1990) In vitro fertilization-embryo transfer in the United States: 1988 results from the IVF-ET Registry. Fertil Steril ${ }_{1}$ 53, 13-20.

239. Medical Research International, Society for Assisted Reproductive Technology, The American Fertility Society (1991) In witro fertilization-embryo transfer (IVF-ET) in the United States: 1989 results from the IVF-ET Registry. Fertil Steril, 55, 14-22.

240. Mehta TS, Kiessling AA (1990) Develapment potential of mouse embryos conceived in vitro and: cultured in ethylenediaminetetraacetic acid with or without amino acids or serum. Biol Reprod, 43, $600-606$

241. Meizel S, Lui CW. Working PK, Mrsny RJ (1980) Taurine and hypotaurine: their effects on motility, capacitation and acrosome reaction of hamster sperm in vitro and their presence in sperm and reproductive tract fluid of several mammals. Dev Growth Differ, 22, 483-494.

242. Melby EC, Altman NH (1974) CRC Handbook of Laboratory Animal Science, volume II CRC Press. Cleveland, Onio, pp 397-405.

243. Ménézo $Y$, Laviolette P (1972) Les constituants aminés des sécrettions tubaires chez la lapine. Anin Biol anim Bioch Biophys, 12, 383-396.

244. Ménézo $Y$ (1975) Amino constituents of tubal and uterine fluids of the estrous ewe: comparison with blood serum and ram seminal fluid. In: The biology of spermatozoa. INSERM Int Symp, Nouzilly, 1973, pp 174-181, Karger, Basel.

245. Ménézo $Y$, Wintenberger-Torres S (1976) Free amino acid content of ewe uterine fluid under various harmonal treatments during early pregnancy. Ann Biol anim Bioch Biophys, 16, 537-543.

246. Ménézo $Y$. Testart $J_{\text {"Perrone }} \mathrm{D}$ (1984) Serum is not necessary in human in vitro fertilization, early embryo culture, and transfer. Fertil Steril $42,750-755$.

247. Ménézo Y, Guerin JF, Czyba JC (1990) Improvement of human early embryo development in vitro by coculture on monolayers of Vero cells. Biol Reprod, 42, 301-306.

248. Menézo $Y$, Renard $J-P(1993)$ The life of the egg before implantation. In: Thibault $C$, Levasseur MC. Hunter RHF (eds) Reproduction in mammals and man. Ellipses, Paris, pg 349-367.

249. Michiels AHJJ. Dumoulin JCM, Bras M, Wissen van LCP. Evers JLH, Geraedts JPM (1996). The combined effect of taurine and zinc on mouse preimplantation embrya development in vitro. Hum Reprod, 11, Abstract Book 1, p 31 (Abstract).

250. Miller JF, Williams E, Glue J, Gordon YB, Grudzinskas JG, Sykes A (1980) Fetal loss after implentation. Lancel. 1, 554-556.

251. Miller $J$ GO, Schultz GA (1987) Amino acid content of preimplantation rabbit embryos and fluids of the reproductive tract. Biol Reprod, 36, $125 \mathrm{~m} 129$

252. Mitani $S(1985)$ The reduction of calcium current associated with eally differentiation of the murine embryo. J Physiol, 363, 71-86.

253. Moessner J, Dodson WC (1994) The quality of human embryo growth is improved when cultured in groups rather than separately. Proceedings of the 50 th Annual Meeting of the American Fertility Society, abstract P-182

254. Monis $H_{4}$ Bavister BD (1990) Analysis of the inhibitory effect of inorganic phosphate on development of four-cell hamster embryos in vitro. J Exp Zool, 256, 75-83.

255. Moody WJ, Simoncini L, Coombs JL, Spruce AE, Villaz M (1991) Development af tan channels in early embryos. J Neurobiol, 22, 674-684

256. Moore $K_{,}$Bondiali KR (1993) Glycine and alanine supplementation of culture medium enhances development of in vitro matured and fertilized cattle embryos. Bial Reprod, 48, 833-840.

257. Mortimer D (1984) Elaboration of a new culture medium for physiological sludies on human sperm motility and capacitation. Hum Reprod, 1, 247-250.

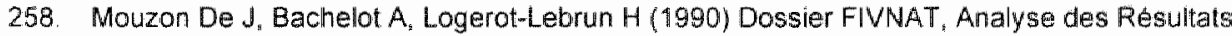
1986 -1990. Association FIVNAT, Hôpital de Bicêtre "Paris, France.

259. Mouzon De J, Lancaster $P$ (1995) World Collaborative Report prepared on behalf of the International Working group for Registers on Assisted Reproduction. Report presented during the XVth World Congress on Fertility and Sterility, Montpeliser, september 17-22, 1995. 
260. Mrsny RJ, Waxuran L; Meizel $S$ (1979) Taurine maintains and stimulates motility of hamster sperm during capacitation in vitro. J exp Zool, 210, 123-128.

261. Mrsiny R., Meizel S (1985) Inithibition of hamster sperm Na*, K*-ATPase activity by taurine and hypotaurine. Life $\mathrm{Sc}_{i} 36_{i}, 271 \cdot 275$.

262. Muggleton-Harris $A$, Whittingham DG, Wisson $L$ (1982) Cytoplasmic control of premplantation development in witro in the mouse. Nature, $299,460-462$

263. Munne $S$; Lee A, Rosenwaks $Z$, Grifo $J_{3}$ Cohen $J$ (1993) Diagnosis of major aneuploidles in human preimplantation embryos: Hurn Reprod, 8 2 2185-2191.

264. Naglee DL, Maurer RR, Foote RH (1969) Effect of osmolarity on in vitro development of rabbit embryos in a chemically defined medium. Exp Cell Res, 58; 331-333.

265. Nasr-Esfahani MH, Aitken JR, Johnson MH (1990) Hydrogen peroxide levels in mouse oocytes and early cleavage stage embryos developed in vitro or in wivo. Development, 109, 501-507.

266. Nasr-Esfahani $M_{i}$ Johnson $M H$; Aitken $R d,(1990)$ The effect of iron and iron chelators on the in-vitro block to development of the mouse preimplantation embryo: BAT6 a new medium for improved culture of mouse embryos in vitro. Hum Reprod, 5,997-1003.

267. Nasr-Esfahani MH, Johnson MH (1991) The origin of reactive oxygen species in mouse cultured in vitro. Development, 113,551-560.

268. Nasr-Esfahani MH, Johnson MH (1992) How does transferrin overcome the in vitro block to development of the mouse preimplantation embryo? I Reprod Fert: 96, 41-48.

269. Nasr-Esfahani $\mathrm{M}_{i}$. Winston $\mathrm{Nu}$, Johnson MH (1992) Effects of glucose, ethylenediaminetetraacetic acid and oxygen tension on the concentration of reactive oxygen species and on development of the mouse preimplantation embryo in witro. J Reprod Fert 96, 219-231

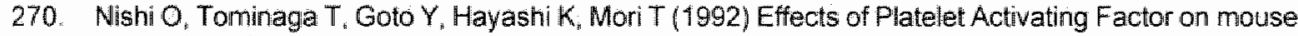
embryo implantation in vitro. $J$ Assis Reprod Genet $12,330-334$.

271. Noda $Y$, Narimoto $K$, Umaoka $Y$, Takakura K, Kanzaki H, Taii S, Mori T (1991) Improved blastulation rate in human embryo culture with $\alpha-M E M$ under a low oxygen. Abstracts of the 47th American Fertility Society Meeting, Orlando Florida S68.

272. Noda Y, Goto Y, Umaoka $Y$, Shiotani M, Nakayama T, Mori T (1994) Culture of human embryos in alpha modification of Eagle's medium under low oxygen tension and low illumination. Fertil Steril, 62, $1022-1027$

273. Nonogaki T, Noda $Y$, Narimoto K, Umaoka $Y$, Mori $T$ (1992) Effects of superoxide dismutase on mouse in vitro fertilization and embryo culture system. J Ass Reprod Genet, 9, 274-280.

274. Nureddin A, Epsaro E, Kiessling AA (1990) Purines inhibit the development of mouse embryos in vitro. J Reprod fert, 90, 455-464.

275. Olds D, VanDemark NL (1957) Composition of luminal fluids in bovine female genitalia. Fertil Steril, 8, 345-354.

276. Oliphant $G$. Ross PR (1982) Demonstration of production and isolation of three sulfated glycoproteins from the rabbit oviduct. Biol Reprod, 26, 537-544.

277. O'Neill C (1997) Evidence for the requirement of autocrine growth factors for development of mouse preimplantation embryos in vitro. Biol Reprod, 56, 229-237.

278. Ouhibi N, Hamidi J Guillaud J, Ménézo Y (1990) Co-culture of 1-cell mouse embryos on different cell supports. Hum Reprod, 5, 737-743.

279. Overstrom EW, Benos DJ, Biggers JD (1989) Synthesis of $\mathrm{Na}^{*} / \mathrm{K}^{*}$-ATPase by the preimplantation rabbit blastocyst. J Reprod Fert, 85, 283-295.

280. Ozias $\mathrm{CB}_{i}$ Stern $\mathrm{S}$ (1973) Glycogen tevels of preimplantation mouse embryos developing in vitro Biol Reprod, 8, 467-472.

281. Pabon JE, Findley WE, Gibbons WE (1989) The toxic effect of short exposures to the atmospheric oxygen concentration on early mouse embryonic development. Fertil Steril, 51, 896-900.

282. Papaioannou VE, Ebert KM (1986) Development of fertilized embryos transferred to oviducts of immature mice. J Reprod Fertil, 76, 603-608.

283. Paria BC, Dey SK (1990) Preimplantation embryo development in vitro cooperative interactions among embryos and role of growth factors. Proc Natl Acad Sci USA, 87, 4756-4760.

284. Pasantes-Morales H, Wright CE, Gaull GE (1984) Protective effect of taurine, zinc and tocopherol on retinol-induced damage in thuman lymphoblastoid. cells J Nutr, 114, 2256-2261.

285. Pasantes-Morales $\mathrm{H}, \mathrm{Cruz} \mathrm{C}$ (1985) Taurine and hypotaurine inhibit light-induced lipid peroxidation and protect rod outer segment structure. Brain Res, 330, 154-157.

286. Pasantes-Morales H, Wright CE, Gaull GE (1985) Taurine protection of lymphoblastoid cells from iron-ascorbate induced damage. Biochem Pharmacol, 34, 2205-2207. 
287. Pasantes-Morales H. Schousboe A (1988) Volume regulation in astrocyles: a iole for taune as an osmoeffector. I Neurosci Res, 20,505-509.

288. Patients guide to Donor Insemination and IVF clinics 1995$)$ Published by: The Human Fattisation and Embryology Authority, London, UK.

289. Paulson RJ, Sauer MV, Lobo RA (1990) Factors affecting embryo implantation after human ing witro fertilizaltion: a hypothesis. Am $\mathbb{J}$ Obstet Gynecol, 163, 2020-2023.

290. Petersen $K$, Hornnes PJ, Ellingsen $S$, Jensen F, Brocks W, Sterup J, Jacobsen JR. Andersen AN (1995) Perinatal outcome after in vitro fertilisalion. Acta Obstet Gynecol Scand, 74, $129-131$.

291. Petters RM (1992) In vitro culture of early stages embiyos from livestock. Tissue Cult Res Commun. $11,305-313$

292. Petters $\mathrm{RM}$, Johnson $\mathrm{BH}_{4}$ Reed ML. Archibong AE (1990) Glwcose, glutamine and inorganic phosphate in early development of the pig embryo in vitro. JReptod Fert, 89, 269-275.

293. Petters RM, Reed ML (1991) Addition of taurine or hypotaurine to culture medium improves development of one and two-cell pig embryos in vitro. Theriogenology, 35, 253 (Abstract).

294. Pelters RM. Wells KD (1993) Culture of pig embryas. $₫$ Reprod Fertil Suppl, 48, 6.1-73.

295. Pieters MHEC, Geraedts JPM, Dumoulin JCM, Evers JLH, Bras M, Kornips FHAC, Menheere PPCA (1989) Cytogenetic analysis of in vitro fertilization (IVF) failures. Hum Genet, 81, 367-370.

296. Pieters MHEC, Dumoulin JCM, Engehart CM, Bras M. Evers JLH "Geraedts JPM (1991) limmaturity and aneuploidy in human oocy tes after different stimulation protocols. Fertil Steril, 56, 306-310.

297. Plachot Mandelbaum J, Junca A-M, de Grouchy J, Salat-Baroux J, Cohen J ( 1989 ) Cytogenetic analysis and developmental capacity of normal and abnormal embryos after IVF. Hum Reprod. 4, Supplement $99-103$.

298. Plachot M (1992) Viability of preimplantation embryos. Balliere's Clin Obstet Gynaecol, 6, $327 \times 338$.

299. Poindexter AN, Thompson DJ, Gibbons WE, Findley WE, Dodson MG, Young RL (1986) Residual embryos in failed embryo transfer. Fertil Steril, 46, $262-267$.

300. Poueymirou WT, Conover JC, Schulz RM (1989) Regulation of mouse preimplantation development: differential effects of CZB medium and Whitten's medium on rates and patterns of protein synthesis in 2-cell embryos. Biol Reprod, 41, 317-322.

301. Powers RD. Tupper JT (1977) Developmental changes in membrane transport and permeability in the early mouse embryo. Dev Biol, 56, 306-315

302. Prather RS (1993) Nuclear control of early embryonic development in domestic pigs. J Reprod Fertil Suppl, 48, 17-29.

303. Prather RS, Peters MS, Van Winkle LJ (1993) Alanirie and leucine transport in unfiertilized pig aocytes and early blastocysts. Mol Reprod Dev, 34, 250-254.

304. Prather RS, Peters MS, Van Winkle LJ (1993) Aspartate and glutamate transport in unfertilized pig oocytes and early blastocysts. Mol Reprod Dev, 36, 49-52.

305. Pratt HPM (1987) Isolation, culture and manipulation of pre implantation mouse embryos In: Monk M (ed) Mammalian development, a practical approach, IRL Press, Oxford, 13942

306. Pratt HPM, Bolton VN, Gudgeon KA (1983) The legacy from the oocyle and its role in controlling early development of the mouse embryo. In: Molecular biology of egg maturation. Pitman Books, London (Ciba Foundation symposium 98), pg 197-227.

307. Pratt HPM, Muggleton-Harris AL (1988) Cycling cytoplasmic factors that promote mitosis in the cultured 2-cell mouse embryo. Dewelopment, 104, 115-120.

308. Puissant $F$, Van Rysselberghe M, Barlow P. Deweze $J_{5}$ Leroy $F$ (1987) Embryo scoring as a prognostic tool in WV treatment. Hum Reprod, 2, 705-708.

309. Puka . Sundell K. Lazarewicz JW. Lehmann A (1991) Species differences in cerebral taurine concentrations correlate with brain water content. Brain Res, 548, 267-272.

310. Quim P (1995) Enhanced resuls in mouse and human embryo culture using a modified muman tubal fluid medium lacking glucose and phosphate. I Ass Reprod Genet, 12, 9r-105.

311. Quinn P. Harlow GM (1978). The effect of axygen on the development of premplantation mouse embryos in vitro. J Exp Zool, 206, 73-80.

312. Quinn P, Kerin JF, Warnes GM (1985) Improved pregnancy rate in human in witro fertilization with the use of a medium based on the composition of human tubal fluid. Fertil Steril, 44, 493-498.

313. Quinn P. Wames GM, Kerin JF, Kirby C (1985) Culture factors affecting the success rate of th viltro fertilization and embryo transfer. Ann NY Acad Sci, 443, 195-204.

314. Ram PT, Schultz RM (1993) Reporter gene expression in G2 of the 1-cell mouse embryo. Dev Biol $156,552-556$ 
315. Rasmusson $R L$, Davis $D G$, Lieberman $M$ (1993) Amino acid loss during volume regulatory decrease in cultured chicik heart celis. Am J Physilo, 264, C136-C145.

316. Reed ML, fllera MU, Petters RiM (1992) in vitro culture of pig embryos. Theriogenology, 37, 95-109.

317. Reed ML, Jin DI, Petters RM (1992) Glucose and inorganic phosphate inhibits rat 8-cell embryo development in vitro. Theriogenology, 37, 282 (Aibstract).

318. Reitzer $L J$, Wice $B M$, Kennel D (1979) Evidence that glutamine, not sugar, is the major energy source for cultured HeLa cells. J Biol Chem, 254, 2669-2677.

319. Restall BJ; Wales RG (1966) The fallopian tube of the sheep. Ill: The chemical composition of the fluid from the fallopian tube. Aust $\mathrm{J}$ biol Sci, 19,687-698.

320. Restall BJ, Wales RG (1967) The fallopian tube of the sheep. W. Secretion from the ampulla and isthmus. Aust id Biol Sci, 21, 491-498.

321. Rieger $\mathrm{D}$, Loskutoff $\mathrm{NM}_{3}$ Betteridge KJ (1992) Developmentally related changes in the metabolism of glucose and glutamine by cattle embryos produced and co-cultured in vitro. J Reprod Fertil, 95, 585-595.

322. Robitaille $G$, St-Jacques $S$, Potier $M$, Bleau $G$ (1988) Characterization of an oviductal glycoprotein associated with the ovulated hamster oocyte. Biol Reprod, 38, 687-694.

323. Roblero $L_{i}$ Biggers $J D$, Lechene CP (1976) Electron probe analysis of the elemental microenvironment of oviducal mouse embryos. J Reprod Fert, 46, 431-434.

324. Roblero LS, Riffo MD (1986) High potassium concentration improves preimplantation development of mouse embryo in vitro. Fertil Steril, 45, 412-416.

325. Rogers P (1993) Uterine receptivity. In: Trounson A, Gardner DK (eds) Handbook of In Vitro Fertilization. CRC Press, Boca Raton, pg 263 285.

326. Roseboom TJ, Vermeiden JPW, Schoute $E_{\text {i }}$ Lens. JW, Schats R (1995) The probability of pregnancy after embryo transfer is affecled by the age of the patient, cause of infertility, number of embryos transferred and the average morphology score, as revealed by multiple logistic regression analysis. Hum Reprod, 10, 3035-3041.

327. Rozen $R_{\text {, Scriver }} C R$ (1982) Renal transport of taurine adapts to perturbed taurine homeostasis. Proc Natl Acad Sci USA, 79, 2101-2105.

328. Rufat $P$, Olivennes $F$, de Mouzon J, Dehan $M$, Fydman R (1994) Task force report on the outcome of pregnancies and children conceived by in vitro fertilization (France: 1987 to 1989). Fertil Steril, $61,324-330$.

329. Ryan JP', Spinks NR, O'Nell C , Ammit AJ, Wales RG (1989) Platelet activating fiactor (PAF) production by mouse embryos in vitro and its effect on embryonic metabolism. J Cell Biochem, 40, 387-395.

330. Sakkas D, Batt PA, Cameron AWN (1989) Development of preimplantation goat (Capra hiracus) embryos in vivo and in vitro. J Reprod Fert, 87, 356-359.

331. Sakkas D. Trounson AO (1991) Formulation of a complex serum-free medium (CSM) for use in the co-culture of mouse embryos with cells of the female reproductive tract. Reprod Fertil Dev, 3, 99-108.

332. Sánchez-Olea $\mathbb{R}$, Pasantes-Moralés $H$, Lazaro A, Cereijido M (1991) Osmolarity-sensitive release of tree amino acids from cultured kidney cell (MDCK). J Membr Biol, 121, 1-9.

333. Sauer MV "Bustillo M. Rodi IA, Gorrill MJ, Buster JE (1987) In-viwo blastocyst production and awum yield among fertile women. Hum Reprod, 2, 701-703.

334. Sawicki JA, Magnuson T. Epstein CJ (1981) Evidence for expression of the paternal genome in the two-cell mouse embryo. Nature, 294, 450-451.

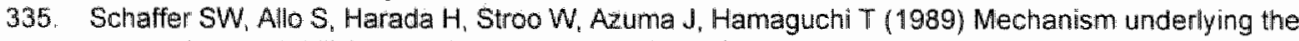
membrane-stabilizing activity of taurine. In: Iwata $H$, Lombardini JB, Segawa T (eds) Taurine and the heart Kluwer Acad Publ, Dordrecht, pp 43-50.

Schini SA, Bavister BD (1988) Development of golden hamster embryos through the two-cell block in chemically defined medium. J Exp Zool, 245, 111-115.

337. Schini SA, Bavister BD (1988) Two-cell block to development of cultured hamster embryos is caused by phosphate and glucose. Biol Reprod, 39, 1183-4192.

338. Schramm RD, Bavister BD (1996) Development of in-vitro-fertilized primate embryos into blastocysts in a chemically defined, protein-free culture medium. Hum Reprod, 11, 1690-1697.

339. Schulman JD (1986) Delayed expulsion of transfer fluid after IVFIET. Lancet, 1,44.

340. Schultz GA, Kaye PL, McKay DJ, Johnson MH (1981) Endogenous amino acid pool sizes in mouse eggs and preimplantation embryos. J Reprod Fert, 61, 387-393.

341. Schultz GA, Heyner S (1993) Cytokines in preimplantation mammalian embryos. Oxford Rev Reprod Biol, 15, 43-81. 
342. Scott DM (1987) Sodium cotransport systems: cellular, molecular and regulatory aspects. BioEssays, $7,71-78$

343. Seshagiri PB, Bavister BD (1989) Phosphate is required for inhibition by glucose of development of hamster 8-cell embryos in vitro. Biol Reprod, 40,607-614.

344. Seshagiri PB, Bavister BD (1989) Glucose inhibits development of hamster 8-cell einbryos in vitro. Biol Reprod; 40, 599-606.

345. Seshagiri $\mathrm{PB}$, Bavister $\mathrm{BD}$ (1991) Glucose and phosphate inhibit respiration and oxidative metabolism in cultured hamster eight-cell embryos: evidence for the 'Crabtree effect'. Mol Reprod Dev, 30, 105-111.

346. Seshagiri PB, McKenzie Dl; Bavister BD, Williamson J1. Aiken JM (1992) Golden hamster embryonic genome activation occurs at the two-cell stage: correlation with major dewelopmental changes. Mol Reprod Dev, 32, 229-235.

347. Shain W, Martin DL (1990) Uptake and release of taurine - an overview. In: Pasantes-Moralles H, Shain W. Martin DL, Martin del Rio M (eds) Taurine: Functional Neurochemistry, Physiology, and Cardiology. Wiley-Liss, Inc, New York, pg 243-252.

348. Smith RKW, Johnson MH (1986) Analysis of the third and fourth cell cycles of mouse early development. J Reprod Fert, 76, 393-399.

349. Society for Assisted Reproductive Technology, American Society for Reproductive Medicine (1995) Assisted reproductive technology in the United States and Canada: 1993 results generated from the American Society for Reproductive Medicine/Society for Assisted Technology Registry. Fertil Steril, 64, $13-21$

350. Sociely for Assisted Reproductive Technology. American Soclety for Reproductive Medicine (1996) Assisted reproductive technology in the United States and Canada: 1994 results generated from the American Society for Reproductive Medicine/Society for Assisted Technology Registry. Fertil Steril, 66, 697-705.

351. Sousa $M$, Barros A, Tesarik J (1996) Developmental changes in calcium dynamics, protein kinase $C$ distribution and endoplasmic reticulum organization in human preimplantation embryos. Mol Hum Reprod, 2, 967-977.

352. Sousa M, Barros A Silva J, Tesarik J (1997) Developmental changes in calcium content of ultrastructurally distinct subcellular compartments of preimplantation human embryos. Mol Hum Reprod, 3, 83-90.

353. Spindle A (1995) Beneficial effects of taurine on mouse zygotes developing in protein-free culture medium. Theriogenology, 44, 761-772.

354. Staessen $C$, Camus $M$, Khan I, Smitz J, Van Waesberghe L., Wisanto $A$, Devroey $P$, Van Steirteghem AC (1989) An 18-month survey of infertility treatment by in vitro fertilization, gamete and zygote intrafallopian transfer, and replacement of frozen-thawed embryos. J In Vitro Fert Embryo Transfer, $6,22-29$

355. Staessen C, Camus $M$, Bollen N, Devroey P, Van Steirteghem AC (1992) The relationship between embryo quality and the occurrence of multiple pregnancies. Fertil Sterill $\mathbf{5 7}, 626-630$

356. Staessen C, Van den Abbeel E, Janssenswillen C Devroey $P$, Van Steirteghem AC (1994) Controlled comparison of Earle's balanced salt solution with Menezo B2 medium for human in-vitro fertilization performance. Hum Reprod, 9, 1915-1919.

357. Steptoe PC, Edwards RG (1978) Birth after re implantation of a human embryo. Lancet, II, 366.

358. Stricker SA (1995) Time-lapse confocal imaging of calcium dynamics in starfish embryos. Dev Biol, $170,496-518$.

359. Sturman JA (1993) Taurine in development. Plhysiol Rev, 73, 119-147.

360. Sturman JA, Messing JM, Rossi SS, Hofmann AF, Neuringer M (1991) Tissue taurine content, activity of taurine synthesis enzymes and conjugated bile acid composition of taurine-deprived and taurinesupplemented Rhesus monkey infants at 6 and 12 mo of age. J Nutr. 121, 854-862.

361. Summers MC, Bhatnagar PR, Lawitts JA, Biggers JD (1995) Fertilization in vitro of mouse ova from inbred and outbred strains: complete preimplantation embryo development in glucose-supplemented KSOM. Biol Reprod ${ }^{53}, 431-437$.

362. Swann K, Ozil JP (1994) The dynamics of the calcium signal that triggers mammalian egg activation. Int Rev Cytol, $152,182-222$.

363. Swann $\mathrm{K}_{n}$ Lawrence $Y$ (1996) How and why spermatozoa cause calcium oscillations in mammalian oocytes. Moll Hum Reprod, 2, 388-390.

364. Sweadner KJ, Goldin SM (1980) Active transport of sodium and potassium ions. New Engl J Med. $302,777-783$.

365. Takahashi $Y$, First NL (1992) In vitro development of bowine one-cell embryos: influence of glucose, lactate, pyruvate, amino acids and vitamins. Theriogenology, 37, 963-978. 
360. Taflo CP, Vohr $\mathrm{B}_{\mathrm{r}}$ On W, Rubin LP, Seifer DB, Haning RV (1895) Maternal and neonatal morbidity associated with in wilro fertilization. J Pediatr, 127, 794-800.

367. Tan SL, Royston P. Campibell S, Jacobs $\mathrm{HS}$, Betts J, Mason B, Edwards RG (1992) Cumulatiwe conception and livebirth rates after in-vitro fertilisation. Lancet, 339, 1390-1394.

368. Telford NA, Watson As, Schultz GA (1990) Transition from maternal to embryonic control in early mammalian development: a comparison of several species. Mol Reprod Dev, 26, 90-100.

369 Templeton A, Morris . KK, Parslow W (1996) Factors that affect outcome of in-vitro fertilisation treatment. Lancel, 348, 1402-1406.

370. Tervit HR, Whittingham DG, Rowson LEA (1972) Successful culture in witro of sheep and cattle ova J Reprod Fert, 30, 493-497.

371. Tesarik ل, Kopecny $V$, Plachot M, Mandelbaum J (1988) Early morphological signs of embryonic. genome expression in human preimplantation development as revealed by quantitative electron microscopy. Dew Bial; 128, 15-20.

372. Tesarik ل, Kopecny $\vee(1989)$ Nucleic acid synthesis and development of human male pronucleus. J Reprod Fertil, 86, 549-558.

373. The American Fertility Society, Society for Assisted Reproductive Technology (1994) Assisted reproductive technology in the United States and Canada: 1992 results generated from The American Fertility Society/Society for Assisted Technology Registry. Fertil Steril, 62, 1121-1128.

374. Thomas EL, Grisham MB, Jefferson MM (1986) Preparation and characterization of chloramines. Methads Enzymol, 132, 569-585.

375. Thompson TGE, Simpson AC, Pugh PA, Donelly PE, Tervit HR (1990) Effect of oxygen concentration on in vitro development of preimplantation sheep and cattle embryos. J Reprod Fert, 89, 573-578.

376. Thompson JG, Simpson AC, Pugh PA, Tervit HR (1992) Requirement for glucose during in vitro culture of sheep preimplantation embryos. Mol Reprod Dev, 31, 253-257.

377. Thompson JG, Gardrier DK, Pugh PA, McMillan WH, Tervit HR (1995) Lamb birth weight is affected by culture system utilized during in vitro pre-elongation development of ovine embryos. Biol Reprod, $53,1385-1391$

378. Timbrell JA, Seabra V, Waterfield CJ (1995) The in vivo and in vitro protective properties of taurine. Gen Pharmac, 26, 453-462.

379. Toth $E$, Lajtha $A(1981)$ Elevation of cerebral levels of nonessential amino acids in viwo by administration of large doses. Neurochem Res, 6, 1309-1317.

380. Trenkner E (1990) Possible role of glutamate with taurine in neuron-glia interaction during cerebellar development In: Pasantes-Morales H, Shain W, Martin DL, del Rio RM (eds) Taurine: functional neurochemistry, physiology, and cardiology. Wiley-Liss, Inc, New York, pg 133-140.

381. Trenkner $E$, Sturman JA (1991) The role of taurine in the survival and function of cerebellar cells in cultures of early post-natal cat. Int J Dev Neurosci, 9,77-88.

382. Trounson A, Osbarm J (1993) In vitro fertilization and embryo development. In: Trounson A, Gardner DK (eds) Handbook of In Vitro Fertilization. CRC Press, Boca Raton; pg 57-84.

383. Tsai FCH, Gardner DK (1994) Nicotinamide, component of complex culture media, inhibits mouse embryo development in vitro and reduces subsequent developmental potential after transfer. Fertil Steril, 61, 376.382.

384. Uchida S, Kwon HM, Yamauchi A, Preston AS, Marumo F, Handler JS (1992) Molecular cloning of the CDNA for an MDCK cel Na*-and Cl-dependent taurine transporter that is regulated by hypertonicity. Proc Natl Acad Sci USA $89,8230-8234$.

385. Umaoka $Y$, Noda $Y$, Narimoto K, Mori T (1992) Effects of axygen toxicity on early development of mouse embryos. Mol Reprod Dev, 31, 28-33.

386. Van Blerkom J (1993) Development of human embryos to the hatched blastocyst stage in the presence or absence of a monolayer of Vero cells. Hum Reprod, 8, 1525-1539.

387. Vanderhyden BC. Armstrong DT (1988) Decreased embryonic survival of in-vitro fertilized oocytes in rats is due to relardation of preimplantation development. $J$ Reprod Fert $83,851-857$.

388. Van Winkle LJ (1992) Amino acid transport during embryogenesis. In: Mammalian Amino Acid Transport: Mechanisms and Control. Kilberg MS, Haussinger D (eds) Plenum Press, New York.

399. Van Winkle LJ, Campione AL, Kester SE (1985) A possible effect of the Na" concentration in oviductal fluid on amino acid uptake by cleavage-stage mouse embryos. J Exp Zool, 235, 141-145.

390. Van Winkle LJ, Haghighat N. Campione AL, Gorman JM (1988) Gilycine transport in mouse eggs and preimplantation conceptuses. Biochim Biophys Acta "941, 241-256. 
391. Van Winkle LJ, Campione AL, Gorman IM, Weimer BD (1990) Changes in the activities of amino acid transport systems $\mathrm{b}^{0.4}$ and $\mathrm{L}$ during development of preimplantation mouse conceptuses. Biochem Biophys Acta, 1025, 215-224.

392. Van Winkle LJ, Campione AL. Farrington BH (1990) Development of system bo.* and a broad-scope $\mathrm{Na}^{*}$-dependent transporter of zwitterionic amino acids in premplantation inouse conceptuses. Biochem Biophys Acta $1025,225-233$.

393. Van Winkle LJ, Haghighat N, Campione AL (1990) Glycine protects preimplantation mouse conceptuses from a detrimental effect on deve opment of the organic ions in oviductal fluid. J Exp Zool, 253, $215-219$

394. Van Winkle LJ, Mann DF, Weimer BD, Campione AL (1991) $\mathrm{Na}^{*}$-dependent transport of anionic amino acids by preimplantation mouse blastocysts. Biochem Biophys Acta, 1068, 231.236.

395. Van Winkle LJ, Campione AL (1991) Ouabain-sensitive Rb* uptake in mouse eggs and preimplantation conceptuses. Dev Bial, 146, 158-166.

396. Van Winkle LJ, Campione AL (1992) Novel bumetanice-sensitive $\mathrm{K}^{+}$transport in preimplantation mouse conceptuses. Am J Physiol, 263, C773-C779.

397. Van Winkle LJ, Mann DF, Wasserlauf HG, Patel M (1992) Mediated Na"-independent transport of L-glutamate and L-cystine in 1-and 2-cell mouse conceptuses. Biochem Biophys Acta, 1107, 299-304.

398. Van Winikle LJ, Patel M, Wasserlauf HG, Dickinson HR, Campione AL (1994) Osmotic regulation of taurine transport via system $\beta$ and novel processes in mouse preimplantation conceptuses. Biochim Biophys Acta, 1191, 244-255.

399. Van Winkle LJ, Dickinson HR (1995) Differences in amino acid content of preimplantation mouse embryos that develop in vitro versus in vivo: in vitro effects of five amino acids that are abundant in oviductal secretions. Biol Reprod, 52, 96-104.

400. Van Winkle LJ, Campione AL (1996) Amino acid transport regulation in preimplantation mouse embryos: effects on amino acid content and pre-and peri-implantation development. Theriogenology, 45, $69-80$.

401. Velazquez A, Delgado NM, Rosado A (4986) Taurine content and amino acid composition of human acrosome. Life Sci, 38, 991-995.

402. Viuff D, Avery B, Greve T, King WA, Hyttel $\mathrm{P}$ (1996) Transcriptional activily in in vitro produced bovine two- and four-cell embryos. Mal Reprod Dev, 43, 171-179.

403. Wales RG (1970) Effects of ions on the development of the pre-implantation mouse embryo in vitro. Aust $J$ biol Sci, 23, 421-429.

404. Wales RG, Edirisinghe WR (1989) Volume of fluid and concentration of cations and energy substrates in the uteri of mice during early pseudopregnancy. Reprod Fertil Dev, 1, 171-178.

405. Walker SK, Heard TM, Seamark RF (1992) In vitro culture of sheep embryos without co-culture: successes and perspectives. Theriogenology, 37, 111-126.

406. Walker SK, Hill JL, Kleemann DO, Nancarrow CD (1996) Development of ovine embryos in synthetic oviductal fluid containing amino acids at oviductal fluid concentrations. Biol Reprod, 55, 703-708.

407. Watson AJ, Kidder GM (1988) Immunofluorescence assessment of the timing of appearance and cellular distribution of Na/K-ATPase during mouse embryogenesis. Dev Biol, 126, 80-90.

408. Watson AJ, Pape C, Emanuel JR, Levenson R, Kidder GM (1990) Expression of Na,K-ATPase $\alpha$ and $\beta$ subunit genes during preimplantation development of the mouse. Dev Genet, 11, 41-48.

409. Welty JD, Welty MC (1981) Effects of taurine on subcellular calcium dynamics in the nomal and cardiomyopathic hamster heart. In: Schaffer SW Baskin SI, Kocsis $\downarrow J J$ (eds) The effects of taurine on excitable tissues. New York, Spectrum publications, pp 295-312.

410. Werdan K, Reithmann C, Krawiez W, Erdmann E (1984) Chronic exposure to toxic but not to "therapeutic" concentrations of ouabain increases cardiac glycoside receptors in cardiac muscle cells from chicken embryos. Biochem Pharmacol, 33, 2337-2340.

411. White HS, Chow SY, Yen-Chow YC, Woodbury DM (1992) Effect of elevated potassium on the ion content of mouse astrocytes and neurons. Can J Physiol Pharmacol, 70, 5263-5268.

412. Whittaker PG, Taylar $A$, Lind T (1983) Unsuspected pregnancy loss in thealthy women. Lancet, 1 , 1126-1127.

413. Whitten WK, Biggers JD (1968) Complete development in vitro of the preimplantation stages of the mouse in a simple chemically defined medium. I Reprod Fert, 17, 399-401.

414. Wilcox A.J, Weinburg CR, O'Connor J, Baird DD, Schatterer JP, Canfield RE, et al (1988) Incidence of early loss of pregnancy. $N$ Engl a Med, 319, 189-194.

415. Wiley LM (1984) Cavitation in the mouse preimplantation embryo: Na/K-ATPase and the origin of nascent blastocoele fluid. Dev Bioli, 105, 330-342. 
446. Wiley LM, Yanam S, Van Muyden $\mathrm{D}$ (1986) Effect of potassium concentration, type of protein supplement, and embryo density on mouse preimplantation development in vitro. Fertil Steril, 45, $111-119$.

417. Wiley LM, Kidder GM, Watson Ad (1990) Cell polarity and development of the first epithelium. BioEssays, $12,67-73$.

418. Willams $\mathrm{BJ}$, Ballenger $\mathrm{CA}_{\mathrm{i}}$ Malter $\mathrm{HE}$, Bishop $F$. Tucker $\mathrm{M}_{\mathrm{i}}$ Zwingman TA, Hassold TJ (1993) Non-disjunction in human sperm: results of fiuorescence in situ hybridization studies using two and three probes. Hum Mol Gen, 2, 1929-1936.

419. Wiliams JAC (1996) A comparison of IVF success rates using either standard formula Ham's F-10 or Ham's F-10 medium lacking glucose, hypoxanthine, fron, zinc and copper sulphate. Human Reprod, 11. Abstract book 1, abstract P131, pg 154 .

420. Wisanto $A$, Janssens $R$, Deschacht $J$, Camus $M$, Devroey $P$, Van Steirteghem $A C$ (1989) Performance of different embryo transfer catheters in a human in vitro fertilization program. Fertil Steril, 52, 79-84.

421. Wollenhaupt $K$, Alm $H$, Brussow K-P, Torner $H$ (1995) Untersuchungen zur Charakterisierunig der de novo Proteinsynthese von in vivo gewonnenen und in NCSU-23 Medium kultivierten Schweineembryonen wathrend der Zeit der frühen Embryonalenentwickling. Reprod Dom Anim, 24, 133-139.

422. Wood JW (1989) Fecundity and natural fertility in humans. In: Milligan SR (ed) Oxford Reviews of Reproductive Biology, Vol 11, Oxford University Press, Oxford, pg. 61.

423. World Collaborative Report 1989 , presented during the 7 th World Congress on In Vitro Fertilization and Assisted Procreations, Paris, 1991.

424. Wright CE, Tallan HH, Lin YY, Gaul GE (1986) Taurine: biological update. Ann Rev Biochem, 55, 427.453 .

425. Yancey PH, Clark ME, Hand SC, Bowlus RD, Somero GN (1982) Living with water stress: evolution of osmalyte system. Science, 217, 1214-1222.

426. Yancey $\mathrm{PH}_{i}$ Burg MB (1989) Distribution of major organic osmolytes in rabbit kidneys in diuresis and antidiuresis. Am J Physiol, 257, F602-F607.

427. Yochim JM, Mitchell JA (1968) Intrauterine oxygen tension in the rat during progestation: its possible relation to carbohycrate metabolism and the regulation of nidation. Endocrinology, 83, 706-713.

428. Yokoyama T, Lin L-R, Chakrapani B, Reddy VN (1993) Hypertonic stress increases NaKATPase, taurine, and myoinositol in human lens and retinal pigment epithelial cultures. Invest Ophthalm \& Vis Sci, 34, 2512-2517.

429. Zenzes MT. Casper RF (1992) Cytogenetics of human oocytes, zygotes, and embryos after in vitro fertilization. Human Genetics, 88, 367-375.

430. Zenzes MT. Wang P, Casper RF (1992) Chromosome status of untransferred (spare) embryos and probability of pregnancy after in-vitro fertilization. Lancet, 340, 391-394.

431. Zhang $X$. Armstrong DT (1990) Presence of amino acids and insulin in a chemically defined medium improved development of 8-cell rat embryos in vitro and subsequent implantation in vitro. Biol Reprod. $42,662-668$.

432. Zinaman $\mathrm{MJ}$, Clegg ED, Brown $\mathrm{CC}_{0}$ O'Connor J, Selevan SG (1996) Estimates of human fertility and preginancy loss. Fertil Steril, 65, 503-509. 


\section{Summary}

During In Vitro Fertilization (IVF) treatment, embryos will develop in vitro for several days in culture medium. The culture conditions are considered to be among the most important factors for the successrate after IVF. However, in view of the relatively low implantation rate of human embryos obtained after IVF, it can be argued that conventional culture conditions are suboptimal. Also in many other animal species, it has been demonstrated that in vitro culture will result in impaired embryo development as compared to development in vivo. Therefore "more studies are necessary in order to improve our understanding of preimplantation embryonic development and of the interactions between the developing embryo and its surrounding environment.

One would expect that culture systems will mimic the biochemical conditions of the female reproductive tract fluid. At present, however, most conventional culture media differ substantially in composition with the natural environment of embryos. The amino acid taurine was chosen as the subject of study. This amino acid is absent from most embryo culture media ${ }_{n}$ whereas it is present in high concentrations both in reproductive tract fluid of several species , as well as in embryos, suggesting a physiological function of taurine. Taurine has been shown to have many diverse effects on different cell types and tissues which can be summarized as being beneficial for cell viability.

We have determined the presence of taurine in mouse oviductal fluid. The results, described in chapter 2 , indicate that taurine comprises a much higher proportion of the total free amino acid present in oviductal fluid than in serum ( $59 \%$ versus $17 \%)$.

Our studies on the effect of taurine on preimplantation embryonic development in the mouse (chapters 2 and 3 ) indicate that at concentrations of 1, 5, 10 and $20 \mathrm{mM}$ taurine, significantly more two-cell embryos reach the blastocyst stage compared with medium without taurine ( $79-82 \%$ versus $64 \%$ ). Furthermore, culture in the presence of $5 \mathrm{mM}$ or $10 \mathrm{mM}$ taurine resulted in blastocysts with the highest mean number of cells (65-68 versus 55). The effect of taurine on blastocyst formation appears to be restricted mostly to the period $20-48 \mathrm{~h}$ after fertilization, during which time interval mouse embryos are at the two-cell stage. It was expected that a compound which exerts such a marked effect on mouse embryo development during the two-cell stage, might also influence the two-cell block in vitro of mouse embryos from random-bred strains. However, no effect of taurine on this developmental block was observed.

The next series of experiments were undertaken to examine the mechanisms by which taurine may be exerting its positive effect on mouse embryonic development in vitro. Because taurine has been reported to inhibit the enzyme $\mathrm{Na}^{+} \mathrm{K}^{+}$-adenosine triphosphatase ( $\mathrm{Na}{ }^{*} \mathrm{~K} \mathrm{~K}^{*}$ ATPase), we used two other conditions known to inhibit the $\mathrm{Na}^{+}-\mathrm{K}^{+}-$ATPase to sturdy their effect on mouse embryo development (chapters 4 and 5). Culturing embryos during a short period (the second day postinsemination) in low extracellular $\mathrm{K}^{+}$concentrations $(1.4 \mathrm{mM})$ or in medium supplemented with ouabain $(50 \mu \mathrm{M})$ showed positive effects similar to those of culturing in medium with taurine $(10 \mathrm{mM})$. When zygotes from randomly bred mice were used, inhibition of $\mathrm{Na}^{+}-\mathrm{K}^{+}$-ATPase with ouabain clearly promoted development through the 2-cell block in vitro. It is as yet unclear why the temporary inhibition of $\mathrm{Na}^{*}-\mathrm{K}^{*}$-ATPase by ouabain during the 2-cell stage leads to such a marked positive effect on subsequent embryonic development in vitro. 
In chapter 6 , we studied the osmoregulatory function of taurine, a function which could possibly be implicated in the effect of taurine on embryonic development in vitro. Mammalian cells maintain a constant cell volume by the release and uptake of solutes, followed by the release or uptake of water when confronted by either changing extracellular osmolality or changing concentrations of intracellular osmolytes. Taurine has been shown to be an important osmoregulator in many cell types. Our results indicate that also in mouse and human oocytes and embryos taurine functions as an osmolyte. Embryos loose much of their intracellular taurine when cultured in standard medium without taurine.

To conclude, taurinie has a positive effect on development in vitro of mouse embryos. The observed effect of taurine supplementation of the culture medium could be the result of the replenishment of intracellular taurine concentrations. When no taurine is addied to the medium, the resultant taurine depletion may be harmful to embryos, either because the embryo has to rely more on its inorganic osmolytes for its volume regulation, or because taurine can no longer provide its other protective functions, such as membrane stabilization. 


\section{Samenvatting}

Bij de In Vitro Fertilisatie (IVF) methode worden embryo's gedurende enkele dagen buiten het lichaam in een kweekvloeistof gehouden. Het kweekmilieu van embryo's is een belangrijke factor in het succes van de IVF behandeling. Gesteld kan worden dat de kweekomstandigheden nog niet optimaal zijin. De kansen voor embryo's, ontstaan na IVF, om zich tot een kind te ontwikkelen zijn geringer dan de kansen voor embryo's ontstaan na natuurlijke bevruchting. Ook bij verschillende andere diersoorten is gebleken dat in vitro kweek de ontwikkeling van embryo's nadelig beïnvloedt. Nader onderzoek naar de ontwikkeling van embryo's gedurende de eerste dagen van hun ontwikkeling (de preimplantatie fase) en de relatie tussen het embryo en zijn omringend milieu is dan ook zinvol.

Kweekomstandigheden van embryo's dienen het in vivo milieu zo veel mogelijk te benaderen. De meest gebruikte kweekvloeistoffen wijken echter op vele aspecten sterk af van de vloeistof in de eileider, waarin de embryo's zich bevinden in het lichaam van de moeder gedurende de pre-implantatie fase. In deze studie is het effect van het aminozuur taurine op de pre-implantatie embryo-ontwikkeling onderzocht. De keuze voor taurine berust enerzijds op het feit dat taurine voorkomt in relatief hoge concentraties in de vloeistof van baarmoeder en eileider bij verschillende diersoorten terwijl de stof afwezig is in de meeste kweekvloeistoffen en anderzijds op het feit dat taurine bekend staat als een stof met een algemeen "beschermend" effect tegen allerlei nadelige (milieu) omstandigheden bij zeer uiteenlopende celtypen. Het onderzoek werd uitgevoerd met muizenembryo's en, op zeer beperkte schaal, met menselijke rest-embryo's.

Als eerste werd de aanwezigheid van taurine in de eileider van de muis onderzocht. De resultaten, beschreven in hoofdstuk 2, geven aan dat taurine in de eileidervloeistof procentueel een veel groter aandeel heeft in de totale aminozuursamenstelling dan in serum $(59 \%$ versus $17 \%)$.

De invloed van taurine op de in vitro ontwikkeling van muizenembryo's wordt beschreven in de hoofdstukken 2 en 3 . Bij concentraties van 1, 5, 10 en $20 \mathrm{mM}$ taurine bleken significant meer embryo's het blastocyststadium te bereiken dan in medium zonder taurine (79-82\% versus $64 \%$ ). Ook bleken blastocysten, gekweekt in medium met 5 en $10 \mathrm{mM}$ taurine, uit significant meer cellen te bestaan dan blastocysten gekweekt in medium zonder taurine (65-68 versus 55). Het positieve effect van taurine bleek welhaast uitsluitend op te treden als embryo's tijdens de periode van 20-48 uur na de bevruchting gekweekt werden in de aanwezigheid van taurine. Tijdens deze periode bevinden muizenembryo's zich in het twee-cellig stadium, een stadium dat extra gevoelig is voor suboptimale kweekomstandigheden. Het lag derhalve voor de hand te veronderstellen dat taurine ook van invloed zou kunnen zijn op het zogenaamde '2-cell block', een ontwikkelingsblokkade die ontstaat als embryo's van bepaalde muizenstammen in vitro gekweekt worden. Taurine bleek echter geen effect te hebben op deze blokkade.

Nadat was vastgesteld dat taurine een duidelijk positief effect had op de embryoontwikkeling bij de muis, werd gepoogd dit effect van taurine te verklaren.

Omdat uit literatuurgegevens bekend is dat taurine de aktiviteit van het enzym $\mathrm{Na}^{+}-\mathrm{K}^{+}-$ adenosine trifosfatase ( $\mathrm{Na}^{+}-\mathrm{K}^{+}$-ATPase) remt, werd het effect van taurine op de embryoontwikkeling bij de muis vergeleken met twee andere condities waarvan bekend is dat ze de aktiviteit van het $\mathrm{Na}^{*}-\mathrm{K}^{\star}$-ATPase enzym remmen (ouabaine en een lage 
kaliumconcentratie). In de hoofdstukken 4 en 5 worden de resultaten beschreven. Inderdaad bleek het kweken van embryo's, gedurende de tweede dag van hun ontwikkeling, in medium met ouabaine $(50 \mu \mathrm{M})_{2}$ en in medium met een lage kaliumconcentratie $(1.4 \mathrm{mM})$, vergelijkbare effecten te hebben als de kweek in medium met taurine $(10 \mathrm{mM})$ op het percentage embryo's dat het blastocyststadium bereikt. Ook bleek ouabaine een duidelijk positief effect te hebben op het voorkomen van het '2-cell block' in vitro bij embryo's van 'random bred' muizenstammen. Waarom het remmen van het $\mathrm{Na}^{*}-\mathrm{K}^{*}-\mathrm{ATP}$ ase enzym leidt tot een betere embryo-ontwikkeling is nog onbekend.

In hoofdstuk 6 wordt een ander mechanisme onderzocht dat het effect van taurine op de embryo-ontwikkeling zou kunnen verklaren. Taurine blijkt bij zowel muizenembryo"s als bij menselijke embryo's te functioneren als een osmolyt, $d$.w.z. een stof die cellen snel kunnen opnemen of afstaan om veranderingen in de totale concentratie aan opgeloste stoffen in de cel te kunnen compenseren. In medium zonder taurine blijken embryo's hun intracellulaire taurine te verliezen als gevolg van osmolytische processen.

Concluderend kan gesteld worden dat taurine een positief effect heeft op de ontwikkeling in vitro van muizenembryo's. Dit effect is mogelijk het gevolg van de remming van het $\mathrm{Na}^{+}-\mathrm{K}^{+}-$ ATPase enzym door taurine. Meer waarschijnlijk is dat het effect een gevolg is van het feit dat embryo's in medium met taurine hun intracellulaire taurine op peil kunnen houden door opname uit het medium. Uit literatuur gegevens is bekend dat een constant hoge intracellulaire taurine-concentratie cellen beschermt tegen o.a. membraanschade. 


\section{Curriculum vitae}

1956

1976

1984

1985

1985-heden geboren te Maastricht, 28 september

eindexamen Atheneum- $B$, Henric van Veldeke College, Maastricht

doctoraal examen Biologie, Katholieke Universiteit Nijmegen

universitair docent, capaciteitsgroep Genetica en Celbiologie, Rijksuniversiteit Limburg, Maastricht

hoofd IVF-laboratorium. Afdeling Obstetrie en Gynaecologie, Academisch Ziekenhuis Maastricht 